\title{
A review of the current state of process-based and data-driven modelling: guidelines for Lake Erie managers and watershed modellers
}

\author{
Alex Neumann, Feifei Dong, Yuko Shimoda, Carlos Alberto Arnillas, Aisha Javed, Cindy Yang, \\ Sophia Zamaria, Sohom Mandal, Christopher Wellen, Diana Paredes, Natalie Feisthauer, \\ E. Agnes Blukacz-Richards, Ram Rao Yerubandi, and George B. Arhonditsis
}

\begin{abstract}
Elevated phosphorus (P) loading from the watersheds draining into Lake Erie, particularly from agricultural (53\%) and urban (43\%) sources, is identified as one of the main drivers of the severe eutrophication. In this study, we present a comprehensive evaluation of 11 process-based models to characterize the water cycle as well as nutrient fate and transport within a watershed context, and to find a robust and replicable way to optimize the modelling strategy for the Lake Erie watershed. Our primary objective is to review the conceptual/technical strengths and weaknesses of the individual models for reproducing surface runoff, groundwater, sediment transport, nutrient cycling, and channel routing, and to collectively guide the management of the Lake Erie Basin. Our analysis suggested that the available models either opted for simpler approximations of the multifaceted, nonlinear dynamics of nutrient fate and transport, and instead placed more emphasis on the advanced representation of the water cycle or, introduced a greater degree of biogeochemical complexity but simplified their strategies to recreate the roles of critical hydrological processes. Notwithstanding its overparameterization problem, the MIKE SHE model provides the most comprehensive 3D representation of the interplay between surface and subsurface hydrological processes with a fully dynamic description, whereby we can recreate the solute transport that infiltrates from the surface to the unsaturated soil layer and subsequently percolates into the saturated layer. Likewise, the physically based submodels designed to represent the sediment detachment and erosion/removal processes (DWSM, HBVINCA, HSPF, HYPE, and MIKE SHE), offer a distinct alternative to USLE-type empirical strategies. The ability to explicitly simulate the daily plant growth (SWAT and APEX) coupled with a dynamic representation of soil P processes can be critical when evaluating the long-term watershed responses to various agricultural management strategies. Drawing parallels with the (sub)surface and sediment erosion processes, a more complicated physically based approach, e.g., the dynamic wave model provided by MIKE SHE (coupled with MIKE URBAN or MIKE HYDRO) and SWMM may be more appropriate for realistically simulating the pressurized flow and backwater effects of water routing in both open channels and closed pipes. While our propositions seem to favor the consideration of complex models that may lack the commensurate knowledge to properly characterize the underlying processes, we contend this issue can be counterbalanced by the joint consideration of simpler empirical models under an ensemble framework, which can both constrain the plausible values of individual processes and validate macroscale patterns. Finally, our study discusses critical facets of the watershed modelling work in Lake Erie, such as the role of legacy $P$, the challenges in reproducing spring-freshet or event-flow conditions, and the dynamic characterization of water/nutrient cycles under the nonstationarity of a changing climate.
\end{abstract}

Key words: best management practices, model ensemble, uncertainty analysis, adaptive management implementation, Lake Erie.

Résumé : La charge élevée de phosphore (P) provenant des bassins versants qui se déversent dans le lac Érié, en particulier du bassin versant de la rivière Maumee à prédominance agricole, est identifiée comme l'un des principaux facteurs de gravité de l'eutrophisation. Dans cette étude, les auteurs présentent une évaluation complète de onze modèles fondés sur les processus pour caractériser le cycle de l'eau, le devenir et le transport des nutriments dans un contexte de bassin versant,

Received 5 July 2020. Accepted 26 February 2021.

A. Neumann, * Y. Shimoda, ${ }^{*}$ C.A. Arnillas, A. Javed, C. Yang, S. Zamaria, D. Paredes, and G.B. Arhonditsis. Department of Physical and Environmental Sciences, University of Toronto, Toronto, ON M1C 1A4, Canada.

F. Dong.* Department of Physical and Environmental Sciences, University of Toronto, Toronto, ON M1C 1A4, Canada; Institute of Groundwater and Earth Sciences, Jinan University, Guangzhou 510630, China.

S. Mandal and C. Wellen. Department of Geography and Environmental Studies, Ryerson University, Toronto, ON M5B 2K3, Canada.

N. Feisthauer. Science and Technology Branch, Agriculture and AgriFood Canada, Guelph, ON N1G 4S9, Canada.

E.A. Blukacz-Richards and R.R. Yerubandi. Watershed Hydrology and Ecology Research Division, Environment and Climate Change Canada, Burlington, ON L7S 1A1, Canada.

Corresponding author: George B. Arhonditsis (email: george.arhonditsis@utoronto.ca).

*These authors contributed equally to this work.

() 2021 Authors Arhonditsis, Arnillas, Dong, Mandal, Neumann, Shimoda, Wellen, Yang, and Her Majesty the Queen in Right of Canada as represented by the Minister of Agriculture and Agri-Food. This work is licensed under a Creative Commons Attribution 4.0 International License (CC BY 4.0), which permits unrestricted use, distribution, and reproduction in any medium, provided the original author(s) and source are credited. 
et pour trouver une façon robuste et reproductible d'optimiser la stratégie de modélisation pour le bassin versant du lac Érié. Leur objectif principal consiste à examiner les forces et les faiblesses conceptuelles ou techniques des différents modèles pour reproduire le ruissellement de surface, les eaux souterraines, le transport des sédiments, le cycle des nutriments, le tracé des canaux et pour guider collectivement la mise en œuvre de la gestion adaptative dans le lac Érié. Leur analyse suggère que les modèles disponibles ont soit opté pour des approximations plus simples de la dynamique complexe et non linéaire du devenir et du transport des nutriments et ont plutôt mis l'accent sur la représentation avancée du cycle de l'eau, soit introduit un plus grand degré de complexité biogéochimique, mais ont simplifié leurs stratégies pour recréer le rôle des processus hydrologiques critiques. En dépit de son problème de surparamétrage, MIKE SHE fournit la représentation 3D la plus complète de l'interaction entre les processus hydrologiques de surface et de sous-surface avec une description pleinement dynamique, par laquelle il est possible de recréer le transport d'un soluté qui s'infiltre de la surface à la couche de sol non saturée et percole ensuite dans la couche saturée. De même, les sous-modèles fondés sur la physique conçus pour représenter le détachement des sédiments et les processus d'érosion/ablation (DWSM, HBV-INCA, HSPF, HYPE et MIKE SHE) offrent une option distincte aux stratégies empiriques de type USLE. La capacité de simuler explicitement la croissance quotidienne des plantes (SWAT et APEX) couplée à une représentation dynamique des processus de P du sol peut être critique lors de l'évaluation des réponses à long terme des bassins versants à diverses stratégies de gestion agricole. En établissant un parallèle avec les processus d'érosion (sub)surface et sédimentaire, une approche physique plus complexe, par exemple le modèle dynamique de vagues fourni par MIKE SHE (couplé à MIKE URBAN ou MIKE HYDRO) et SWMM, peut être plus appropriée pour simuler de manière réaliste les effets de l'écoulement sous pression et du reflux de l'eau dans les canaux ouverts et les conduites fermées. Alors que leurs propositions semblent favoriser la prise en compte de modèles complexes qui peuvent manquer de connaissances adéquates pour caractériser correctement les processus sous-jacents, ils soutiennent que ce problème peut être contrebalancé par la prise en compte conjointe de modèles empiriques plus simples, dans un cadre d'ensemble, qui peuvent à la fois contraindre les valeurs plausibles des processus individuels et valider les modèles à grande échelle. Enfin, cette étude aborde des aspects critiques du travail de modélisation des bassins versants du lac Érié, tels que le rôle du phosphore résiduel, les difficultés à reproduire les conditions de crue printanière ou d'écoulement, et la caractérisation dynamique des cycles de l'eau et des nutriments dans le contexte de non-stationnarité d'un climat changeant. [Traduit par la Rédaction]

Mots-clés : meilleures pratiques de gestion, ensemble de modèles, analyse d'incertitude, mise en œuvre de la gestion adaptative, lac Érié.

\section{Introduction}

Lake Erie, the shallowest of the Great Lakes, has been the most severely impacted by eutrophication-related issues, including excessive harmful algal blooms (HABs) (Stumpf et al. 2012; Bertani et al. 2016), dissolved oxygen depletion (Zhou et al. 2013; Rucinski et al. 2014), and excessive growth of Cladophora in the eastern basin (Higgins et al. 2008; Depew et al. 2011; Watson et al. 2016). To ameliorate the severity of these eutrophication phenomena, the reduction of nutrient loading has been regarded as the primary and most effective mitigation strategy (Maccoux et al. 2016). Notwithstanding the multitude of factors (e.g., supply and chemical speciation of nitrogen, iron availability, enhanced water clarity in the nearshore zone mediated by dreissenid mussels, water column stability, and water temperature) involved in HAB formation (Chaffin et al. 2013), a popular concept is that cyanobacterial blooms are more strongly associated with the phosphorus loading in Lake Erie (Obenour et al. 2014; Bertani et al. 2016; Maccoux et al. 2016). Interestingly, the increased frequency in HABs has occurred without distinct trends in the total annual loading of phosphorus (TP), but may be related to the timing, sources, and increased bioavailability of TP inflows and (or) the increased frequency of extreme flow events (Obenour et al. 2014; Scavia et al. 2014). The proliferation of Cladophora along the northern shores of the eastern basin since the mid-1990s, has been primarily attributed to the increased water clarity, the suitable substrate following the colonization of the area by dreissenid mussels, and an interplay between external phosphorus loading and nearshoreoffshore exchanges (Higgins et al. 2005). That is, apart from the inflowing nutrient masses of the Grand River, the nutrient-rich hypolimnetic waters transported to the nearshore zone through upwelling events, excreted metabolic wastes, and (or) egesta of non-edible algae by dreissenids could also be suppliers of nutrients in the benthic environment (Wilson et al. 2006; Valipour et al. 2016).

Nonpoint sources are the dominant contributors $(>70 \%)$ of TP loading in Lake Erie, followed by point sources $(\approx 20 \%)$, and atmospheric deposition or discharges from ungauged areas $(\approx 10 \%)$ (Maccoux et al. 2016). The western part of Lake Erie basin, comprising both the western basin and the Huron-Erie corridor, is responsible for $>60 \%$ of the external TP loading on an annual basis (Fig. 1). Amongst all of the tributaries across the entire Lake Erie basin, the Maumee River watershed is the primary contributor of TP loading (28\%), followed by the Detroit-Windsor watershed (14\%), Sandusky River (7\%), Thames River (7\%), and Grand River (5\%) (Maccoux et al. 2016). According to a recent loadingsource apportionment exercise, the diffuse losses from agricultural areas account for more than $50 \%$ of all the external TP loading, followed by effluents from treatment plants (26\%), and urban stormwater runoff (17\%) (Robertson et al. 2019). It is also important to note that four watersheds (Maumee River, Sandusky River, Thames River, and Grand River) deliver $\sim 65 \%$ of the TP loading from agricultural land, while three watersheds are mainly responsible for the nutrient loading delivery from urban point and nonpoint sources, including the Detroit-Windsor (32\%), Maumee River (16\%), and Cleveland (16\%) watersheds (Robertson et al. 2019). TP export from agricultural areas represent a dominant source $(>48 \%$ of delivered TP loading) in 15 out of 22 major watersheds around the Lake Erie drainage basin, whereas nutrient losses from urban areas accounted for $>50 \%$ in only 6 watersheds (Robertson et al. 2019).

The Maumee River watershed lies in the Huron-Erie Lake Plains ecoregion and is characterized by a flat landscape (average slope $<2 \%$ ) and poorly drained soils (Gebremariam et al. 2014). Whereas this watershed historically comprised a mixture of forests and wetlands, urban (10\%) and forested (6\%) areas are currently patchily distributed, and agricultural land (73\%) is instead the dominant land use (Richards et al. 2010; Keitzer et al. 2016). More than $90 \%$ of the agricultural land is drained by ditches and subsurface drainage (Gebremariam et al. 2014; Culbertson et al. 2016), and $85 \%$ of phosphorus exports are reported to originate from agricultural (e.g., fertilizer and manure) inputs. Alongside the excessive agricultural inputs, the reduced flow velocity due to the relatively flat watershed topography promotes nutrient 
Fig. 1. Contribution of total phosphorous (TP) loading sources to Lake Erie from (a) the major basins and (b) the tributaries within the major basins. The spread of the box-plots and the error-bars represent the interannual variability of the various loading sources. Numbers on the top of the box-plots and error-bars correspond to the percentage contribution of each basin or loading source relative to the total exogenous TP load. TP loading estimates are based on supplementary data provided by Maccoux et al. (2016).

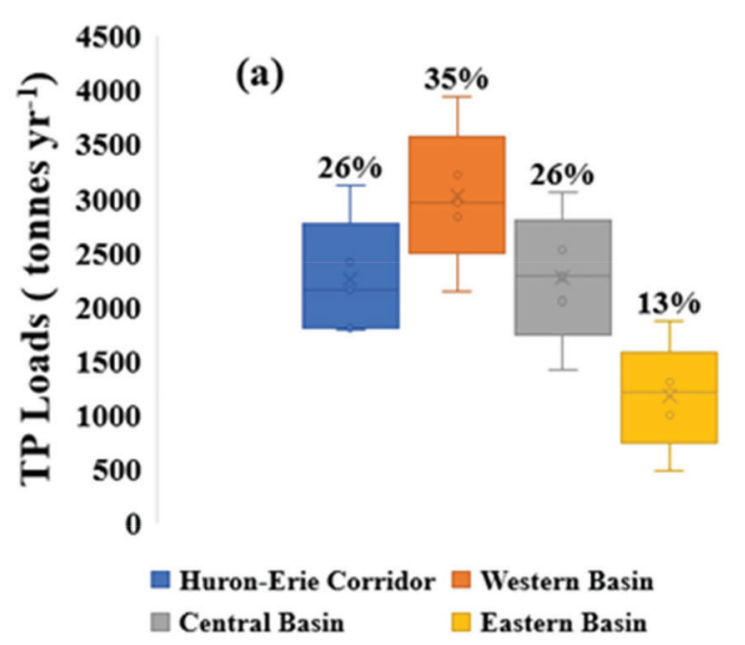

enrichment within the Maumee River (Muenich et al. 2016). To effectively control TP loading, agricultural management practices have been in place in the Maumee River watershed since the early 1990s (Myers et al. 2000). As of 2012, nearly 63\% of the agricultural land has adopted conservation tillage methods to mitigate TP loads due to erosion by reducing soil disturbances (USDA-NRCS 2016). In addition, concentrated-flow control practices during the storm events are implemented in $40 \%$ of the agricultural land, to control the impact of water erosion on gully formation, along with edge-of-field practices, such as vegetated buffers and filter strips (USDA-NRCS 2016).

Watershed process-based modelling has been considered an indispensable tool for analyzing the causal linkages among hydrological changes, agricultural management practices, and nutrient loads (Borah and Bera 2003). A variety of mathematical watershed models have been used in the Great Lakes area in this context, such as the agricultural nonpoint source pollution model (AGNPS; Kirnak 2002), distributed parameter large basin runoff model (DLBRM; He and DeMarchi 2010), dynamic watershed simulation model (DWSM; Borah et al. 1999, 2002), generalized watershed loading function (GWLF and GWLF-E; Haith et al. 1992, Evans and Corradini 2016), hydrologiska byråns vattenbalansavdelning - integrated catchment model (HBV-INCA; Crossman et al. 2013), hydrological simulation program - Fortran (HSPF; Canale et al. 2010), MIKE SHE (Refsgaard and Storm 1995), hydrological prediction for the environment watershed model (HYPE; Lindström et al. 2010), and storm water management model (SWMM; Rossman and Huber 2016a, $2016 b$ ). Given the immense diversity of watershed models, it is noteworthy that SWAT (soil and water assessment tool) alone represents more than $>70 \%$ of the published modelling studies in the Great Lakes literature, and even more so in Lake Erie (Arhonditsis et al. $2019 a, 2019 b$ ). The preference for SWAT over other watershed models may be attributed to its user-friendly interface and potential to facilitate continuous long-term simulations of hydrological changes and phosphorus loads in predominantly agricultural watersheds (Arnold et al. 1998; Neitsch et al. 2011). Interestingly, a recent meta-analysis of 257 peer-reviewed published studies showed that SWAT tends to display fairly higher performance relative to other commonly used processbased models, but the different calibration practices in regards to the number of stations used within a nested-basin context may be an important confounding factor for this registered trend among the spatially distributed models compared (Wellen et al. 2015).
Notwithstanding its conceptual or operational advantages, SWAT is sensitive to the spatial resolution selected, as any model with complex and spatially distributed nature, whereby the performance increases when finer granularity is introduced and remains relatively constant after an appropriate amount of spatial detail is found (Chaplot 2005). It is also sensitive to the density of rain gauges used to force it (Chaplot 2005), and the most sensitive parameters can vary with application site, or may not be the same at water quality stations upstream of the basin outlet (Cibin et al. 2010; van Griensven and Meixner 2006; Nossent and Bauwens 2012). It is also important to recognize that environmental management decisions relying upon a single model with a single parameter specification can introduce considerable bias and uncertainty (Arhonditsis et al. 2007; Ramin et al. 2012). Given that there is no "perfect" model of an open environmental system, but rather several adequate descriptions of different conceptual bases and structures, the development of model ensembles is a technique designed to explicitly account for the uncertainty inherent in the model selection process. Instead of picking the single "best-fit" model to predict future system responses, an ensemble synthesizes over multiple competing watershed-process characterizations, stemming from different model structures and (or) parameter specifications (Raftery et al. 2005). The latter issue is particularly important with complex overparameterized models that are typically characterized by the well-documented equifinality (poor identifiability) problem in which several distinct choices of model inputs lead to the same model outputs or many sets of parameters fit the model about equally well (Beven 2006; Cibin et al. 2010). This non-uniqueness of model solutions undermines the very basic premise of using mathematical models as inverse analysis tools, i.e., any information on the levels and the spatiotemporal variability of the dependent variables (flow, suspended solids, nutrient concentrations) is used through the model calibration exercise to infer the most likely values of independent variables (model parameters) typically describing fundamental processes/fluxes of the water budget and (or) nutrient cycles. The latter issue is critical when the model is intended for the evaluation of best management practices (BMPs), and thus for drawing predictions outside the domain used during its calibration or even validation (Arhonditsis et al. 2019a, 2019b). In hydrology, ensemble strategies have been applied to evaluate the uncertainty of multimodel predictions (Breuer et al. 2009; Seiller et al. 2012; Velázquez et al. 2013), but only few studies focused on watershed water quality (Schoumans et al. 2009; 
Boomer et al. 2013; Sharifi et al. 2017), and even less so to examine policy-relevant, land-use management scenarios (Kronvang et al. 2009; Beven and Lamb 2017).

In view of the documented uncertainties in selecting the optimal set of models when addressing important societal issues, the overarching goal of this study is to provide a comprehensive review of the capacity of 11 watershed process-based models regarding their strategies to capture surface runoff, groundwater, sediment transport, nutrient cycling, and channel routing. Our first objective is to examine the conceptual/technical strengths and weaknesses of the individual models, evaluate their capacity to simulate nutrient loading reduction, and guide management implementation in the Lake Erie Basin. Together with the process-based watershed modelling work, our study discusses the potential benefits of data-driven (statistical) modelling and advocates their use as a complementary tool for maximizing the learning opportunities within an adaptive watershed monitoring and modelling framework (Arnillas et al. 2021; Stow et al. 2020). Our thesis is that simple empirical models not only can provide predictive statements confined within the bounds of data-based parameter estimation, but may also constrain processes/fluxes parameterized by mechanistic models or even validate the corresponding nutrient loading reduction forecasts drawn with "post-audit" monitoring (García et al. 2016; Stow et al. 2020). In addition, our study identifies critical facets of the watershed functioning, such as the role of legacy $P$, the causes and consequences of the increasing long-term trends in dissolved reactive phosphorus loading, the challenges in reproducing springfreshet or event-flow conditions, and the dynamic characterization of water/nutrient cycles under the nonstationarity of a changing climate. We believe that the lessons learned from this critical review can be useful for the contemporary modelling practices to support environmental policy decisions and guide adaptive management implementation in Lake Erie and elsewhere.

\section{Process-based watershed modelling}

\section{Overview}

Eleven process-based models designed to reproduce the variability in water quantity and quality within a watershed context were reviewed in this study (Table 1). Their selection was based on their popularity as depicted by the number of case studies published in the peer-reviewed literature (Wellen et al. 2015; Arhonditsis et al. 2019a, 2019b). All of these models are dynamic and have distinct differences in terms of their temporal resolution, spatial granularity, watershed delineation, and complexity to represent the hydrological and biogeochemical processes considered. All 11 models are capable of recreating the spatial heterogeneity by disaggregating the watersheds into multiple discrete units, composed of homogeneous soils, land uses, and other landscape features or management practices (Table 1). These discrete units can be homogeneous squares on a grid pattern, subsections of a sub-basin in the watershed that lack a specific location in it, such as Hydrological Response Units (HRUs), or idealized representations of the sub-basin catchment patterns, such as cells in AnnAGNPS (annualized AGNPS model) (Fig. 2). Hydrological and biogeochemical mechanisms are mathematically represented within each of the spatial units, which are then connected to a final draining outlet via other spatial units, pipes, channels, or rivers. Each spatial unit without specific location (HRUs) is implicitly treated as being connected to a channel, in that the water in it is not routed through adjacent spatial units but is discharged directly to the channel. The latter simplification can limit the capacity for spatial analysis of optimal BMP placements, and nutrient-source tracking at the edge-of-field (EOF) and edge-ofstream (EOS) levels (Arnillas et al. 2021). There is also a wide range of vertical segmentations that have been used to accommodate the functional properties of the different soil layers (Fig. 3). Most models also include some type of fully mixed water body (pond, reservoir, wetland), other models represent the rivers as the main channel along with a flood plain, and few models also allow the flow of water from channels back to the land (flooding). The shape of the channels and the way the water is routed throughout the system is another source of variability among the models and is largely related to the original purpose of the models (Table 1).

The basic premise of the examined models is to characterize the processes associated with the water budget and biogeochemical cycles that collectively modulate the fate of nutrients until they reach the watershed outlet. Surface-, subsurface-, and groundwater-transport processes determine the vertical distribution of nutrients within the soils and ultimately shape the predominant mode of their delivery into the receiving waterbodies. Water or soil chemistry, and vegetation at any location are represented as state variables, which are then expressed as functions of a suite of processes transporting or transforming water or nutrients. In the following section, we briefly introduce each of the 11 watershed process-based models by providing the purpose and (or) rationale behind their original inception and subsequent development.

\section{Annualized agricultural nonpoint source pollution model (AnnAGNPS)}

AnnAGNPS is a watershed-scale modelling tool that aims to evaluate the effect of different management practices on runoff and water quality. AnnAGNPS is a continuous model that can simulate runoff, sediment and nutrient transport, and chemical oxygen demand (COD) for individual rainfall events (Young et al. 1989). AnnAGNPS was developed by the United States Deportment of Agriculture (USDA) - Agricultural Research Service (ARS) in collaboration with the Minnesota Pollution Control Agency and the Soil Conservation Service. In AnnAGNPS, spatial watershed properties are represented with an irregular homogeneous cell system, with characterization of land and soil properties that bears resemblance to the HRUs of the SWAT model (see the section below on Soil and water assessment tool). Land processes are modelled in each cell, and surface runoff from each cell is calculated separately. The runoff is then routed from one cell to the next based on flow directions prior to reaching the receiving waterbody. AnnAGNPS has evolved from its predecessor, AGNPS, to enable the modelling of watershed dynamics over several months to years and to allow for a nonsquare representation of the spatial units. Aside from these differences, both models use the curve number $(\mathrm{CN})$ method to quantify the surface flow, and the revised Universal Soil Loss Equation (RUSLE) method to predict soil and sediment loads (Bingner et al. 2018). AnnAGNPS can also use RUSLE2, which has been endorsed by the Ontario Ministry of Agriculture, Food and Rural Affairs (OMAFRA), to estimate soil erosion. RUSLE2 is considered a superior tool over the USLE and MUSLE (modified universal soil loss equation) models for sheet and rill erosion (see the section below on Sediment transport), which are typically mitigated through a complex combination of conservation practices. AnnAGNPS was the only reviewed model with explicit ephemeral and classic gully erosion subroutines, and its application in the Lake Erie basin suggested that gully erosion could account for $85 \%$ of the total erosion in the watershed compared with $15 \%$ for sheet and rill erosion (LimnoTech 2010, available from https://www.nrcs.usda.gov/Internet/FSE_DOCUMENTS/ nrcs144p2_028976.pdf). Even with AnnAGNPS though, the user should specify the gully erosion locations after preliminary landscape analysis; none of the reviewed models is capable of predicting gully density (Bingner et al. 2010; Douglas-Mankin et al. 2020). Thus, the parameterization of gully processes might require additional validation from regional empirical studies to ensure correct delineation of landscape pathways of soil erosion and defensible selection of conservation practices. Additionally, both 
Table 1. General description of the 11 watershed models reviewed in the present study.

\begin{tabular}{|c|c|c|c|c|c|c|c|c|c|c|c|}
\hline Feature & AnnAGNPS & APEX & DLBRM & DWSM & GWLF-E & HSPF & HYPE & INCA & MIKE SHE & SWAT & SWMM \\
\hline \multicolumn{12}{|l|}{ General } \\
\hline Model focus & Agriculture & Agriculture & Hydrology & Hydrology & $\begin{array}{r}\text { Hydrology/ } \\
\text { Nutrient }\end{array}$ & $\begin{array}{r}\text { Hydrology/ } \\
\text { Nutrient }\end{array}$ & $\begin{array}{r}\text { Hydrology/ } \\
\text { Nutrient }\end{array}$ & Nutrient & Hydrology & $\begin{array}{r}\text { Hydrology/ } \\
\text { Nutrient }\end{array}$ & Hydrology \\
\hline Spatial representation & $\begin{array}{l}\text { Irregular, } \\
\text { homogeneous }\end{array}$ & $\begin{array}{l}\text { Irregular, } \\
\text { homogeneous }\end{array}$ & Square grid & $\begin{array}{l}\text { Rectangular, } \\
\text { homogeneous }\end{array}$ & $\begin{array}{l}\text { Irregular, } \\
\text { heterogeneous }\end{array}$ & $\begin{array}{l}\text { Irregular, } \\
\text { homogeneous }\end{array}$ & $\begin{array}{l}\text { Irregular, } \\
\text { heterogeneous }\end{array}$ & $\begin{array}{l}\text { Irregular, } \\
\text { heterogeneous }\end{array}$ & $\begin{array}{l}\text { Grid/irregular, } \\
\text { homogeneous }\end{array}$ & $\begin{array}{l}\text { Irregular, } \\
\text { heterogeneous }\end{array}$ & $\begin{array}{l}\text { Rectangular, } \\
\text { heterogeneous }\end{array}$ \\
\hline Temporal scale $^{a}$ & Daily $^{a}$ & Daily & Daily & Sub-daily & Daily/monthly & Sub-daily/daily & Daily & Daily & Sub-daily/daily & Daily & Sub-daily \\
\hline Event/continuous ${ }^{b}$ & $\mathrm{C}$ & $\mathrm{C}$ & C & $\mathrm{E}$ & $\mathrm{C}$ & $\mathrm{E}, \mathrm{C}$ & $\mathrm{C}$ & C & $\mathrm{E}, \mathrm{C}$ & $\mathrm{C}$ & $\mathrm{E}, \mathrm{C}$ \\
\hline GIS interface & & 0 & & & 0 & 0 & & 0 & 0 & 0 & 0 \\
\hline \multicolumn{12}{|l|}{ Climate } \\
\hline Solar radiation & 0 & 0 & 0 & & 0 & 0 & 0 & 0 & 0 & 0 & 0 \\
\hline $\mathrm{PET}^{\mathrm{c}}$ & 1 & $1,2,3,4,5$ & 7 & & 6 & 7 & $2,3,7$ & & 2 & $2,3,4$ & 4,8 \\
\hline Precipitation input & ○ & $\bigcirc$ & ○ & $\circ$ & 0 & $\circ$ & $\circ$ & & $\circ$ & $\circ$ & $\circ$ \\
\hline \multicolumn{12}{|l|}{ Hydrology } \\
\hline Surface runoff & O & 0 & O & 0 & 0 & 0 & 0 & $g$ & 0 & 0 & 0 \\
\hline Lateral/interflow & 0 & 0 & 0 & 0 & & 0 & 0 & $g$ & 0 & 0 & \\
\hline Water table dynamics & 0 & 0 & & & & $f$ & 0 & & 0 & 0 & 0 \\
\hline Tile drainage & 0 & 0 & & $\mathrm{~g}$ & 0 & $\mathrm{~g}$ & 0 & $\mathrm{~g}$ & 0 & 0 & 0 \\
\hline Snowmelt & 0 & 0 & 0 & & 0 & 0 & 0 & 0 & 0 & 0 & 0 \\
\hline Stream routing & 0 & 0 & & 0 & & 0 & 0 & 0 & 0 & 0 & 0 \\
\hline Reservoir/Lake & & ○ & & 운 & & $\circ$ & $\circ$ & & 0 & $\circ$ & 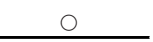 \\
\hline \multicolumn{12}{|l|}{ Fate and transport ${ }^{d}$} \\
\hline FEMA approved & & & & & & 0 & & & $h^{h}$ & & 0 \\
\hline Sediment & $\mathrm{P}, \mathrm{T}$ & $\mathrm{P}, \mathrm{T}$ & $\mathrm{T}$ & $\mathrm{P}, \mathrm{T}$ & $\mathrm{P}, \mathrm{T}$ & $\mathrm{P}, \mathrm{T}$ & $\mathrm{P}, \mathrm{T}$ & $\mathrm{P}, \mathrm{T}$ & $\mathrm{P}, \mathrm{T}$ & $\mathrm{P}, \mathrm{T}$ & $\mathrm{T}$ \\
\hline Nutrient & $\mathrm{P}, \mathrm{T}$ & $\mathrm{P}, \mathrm{T}$ & $\mathrm{T}$ & $\mathrm{T}$ & $\mathrm{T}$ & $\mathrm{P}, \mathrm{T}$ & $\mathrm{P}, \mathrm{T}$ & $\mathrm{P}, \mathrm{T}$ & $\mathrm{P}, \mathrm{T}^{h}$ & $\mathrm{P}, \mathrm{T}$ & $\mathrm{T}$ \\
\hline Toxin/Pesticides & $\mathrm{T}$ & $\mathrm{P}, \mathrm{T}$ & $\mathrm{T}$ & $\mathrm{T}$ & & $\mathrm{P}, \mathrm{T}$ & & & & $\mathrm{P}, \mathrm{T}$ & $\mathrm{T}$ \\
\hline \multicolumn{12}{|l|}{ Management $^{e}$} \\
\hline Crop & $\mathrm{PB}$ & $\mathrm{PB}$ & $\mathrm{EF}$ & $\mathrm{EF}$ & $\overline{\mathrm{DR}}$ & DR & DR & DR & $\mathrm{EF}^{h}$ & $\mathrm{~PB}$ & $\overline{E F}$ \\
\hline Tillage effects & $\mathrm{S}, \mathrm{N}$ & $S, N$ & & & s & & $\mathrm{N}$ & & $\mathrm{N}^{h}$ & $S, N$ & \\
\hline Manure erosion & & ○ & & & & & & & & & \\
\hline Urban loading & & & & & 0 & 0 & & & $\mathrm{O}^{h}$ & O & O \\
\hline
\end{tabular}

0

0

Note: AGNPS, agricultural non-point source pollution model; AnnAGNPS, annualized AGNPS model; APEX, agricultural policy environmental extender model; DLBRM, distributed-parameter large basin runoff model

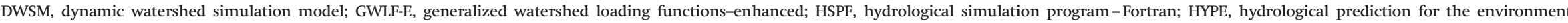

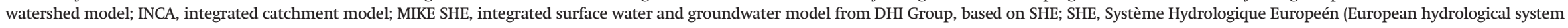
model); SWAT, soil and water assessment tool; SWMM, storm water management model.

${ }^{a}$ Simulation time steps may differ within a model based on the modelled component (i.e., hydrology, nutrient), e.g., AnnAGNPS uses sub-daily computation of soil moisture.

${ }^{b}$ E, event-based model; C, continuous simulation model.

${ }^{c}$ Estimation method of potential evapotranspiration are listed as: (1) Penman, (2) Penman-Monteith, (3) Priestly-Taylor, (4) Hargreaves, (5) Baier-Robertson, (6) Hamon, (7) other estimation methods, (8) user defined time-series of evapotranspiration measurements.

${ }^{d}$ P: when model represents processes, i.e., sediment erosion process, soil nutrient cycle, and metal/toxin/pesticide transformation (volatilization, wash-off, built-up) processes. T: when model represents transport of the material. ${ }^{e} \mathrm{DR}$, dynamic representation of crop seasonality; EF, externally forced plant/crop effects; PB, dynamic plant biomass simulation; S, effects of tillage on sediments (e.g., soil erodibility); N, effects of tillage on nutrient redistribution; $\bigcirc$, indicates the presence of process-based representation (i.e., manure erosion, fertilizer loss by urban build-up and wash-off).

${ }^{f}$ Water table dynamics will be available in next HSPF v.12, which is currently under internal review by the Environmental Protection Agency (https://github.com/respec/FORTRAN/tree/master/f90apps).

${ }^{g}$ Hydrological dynamics in INCA requires externally simulated time-series for Hydrologically Effective Rainfall (HER) and soil moisture deficit data. INCA also simulates conceptual a quick flow (primarily overland flow and tile drainage), subsurface soil water and groundwater flows. Tile drainage in DWSM and HSPF was simulated by adopting effective parameters in subsurface flow.

${ }^{h}$ Represents information from an add-on module DAISY (model for simulation of water and nitrogen dynamics and crop growth in agroecosystems) for MIKE SHE. MIKE 11 (which can be coupled with MIKE SHE) has been approved by FEMA. Urban loading in storm water pipe network can be simulated by coupling MIKE SHE with MIKE-URBAN. 
Fig. 2. Spatial (horizontal) disaggregation strategies of watershed process-based models. Black arrows indicate water routing. Cluster 1 is a fully distributed discretization with homogeneous square spatial units and water flow between adjacent cells. Cluster 2 represents each sub-basin as a rectangle with homogeneous slope and land cover, which allows recreating flow velocities that are on par with those realized during storm events. Cluster 3 is a semi-distributed approach with conceptual landscape units, such as agricultural fields, vegetative buffer strips, or grassed waterways. Cluster 4 is a semi-distributed approach with homogeneous subwatersheds of irregular size or shape, with one or several property-based subclasses of land with common land cover, soil types, slopes, and other landscape features; ${ }^{\dagger}$, indicates models that can have more than one subclass of land; *, indicates models that can represent reservoirs, sedimentation basins, and other structures with the potential to modify water flow properties.

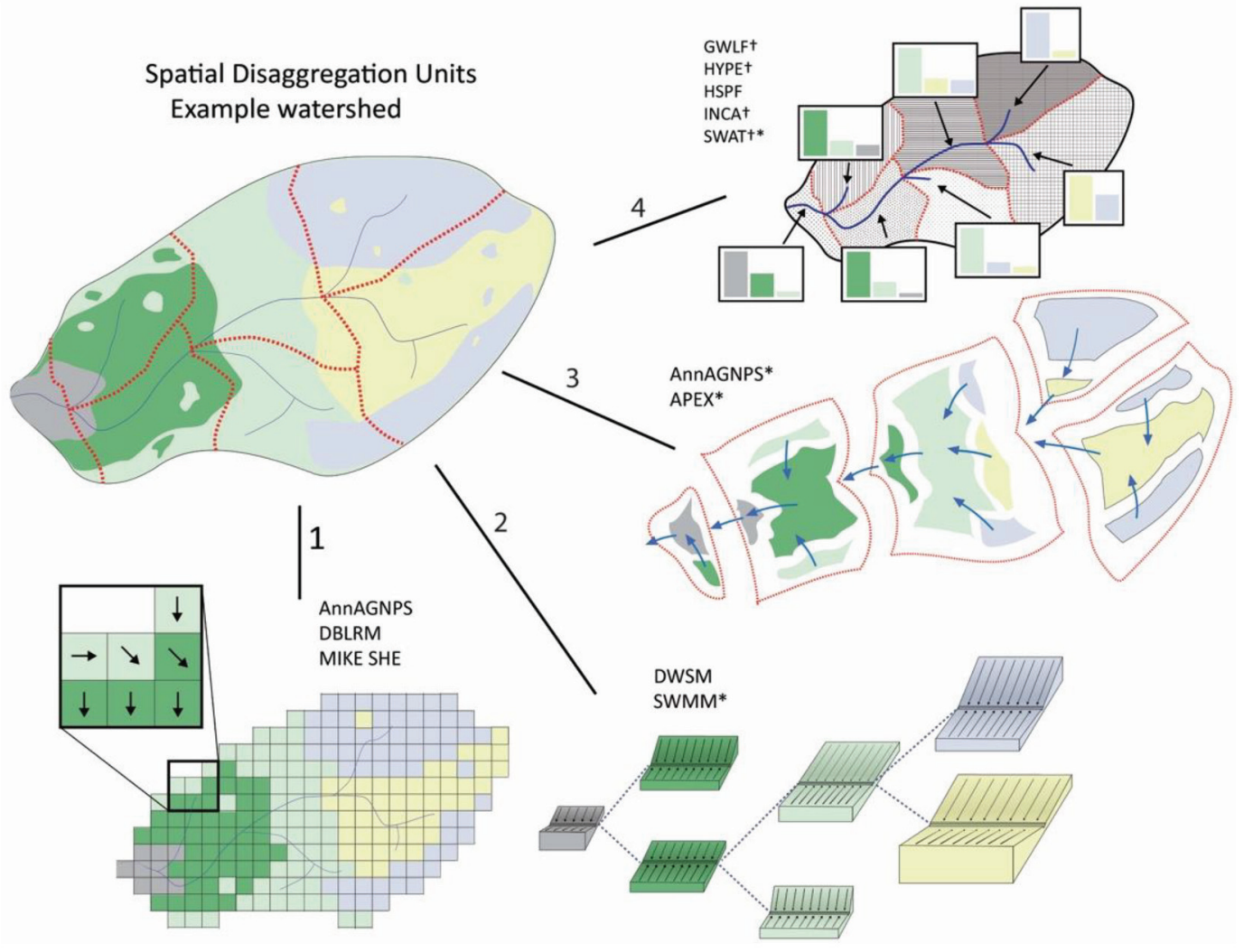

AnnAGNPS and AGNPS integrate other models to represent processes such as stream flow evolution (CCHE1D; a 1D model for simulations of unsteady flows, sediment transport, pollutant transport, water quality, ecosystem, and ecotoxicology in dendritic channel networks), pollutant transport (CONCEPTS; CONservational Channel Evolution and Pollutant Transport System computer model to simulate the evolution of incised streams and to evaluate the longterm impact of rehabilitation measures to stabilize stream systems and reduce sediment yield), plant growth (FAO; Food and Agriculture Organization of the United Nations), and stream temperature (SNTEMP; a mechanistic, 1D heat transport model that predicts the daily mean and maximum water temperatures as a function of stream distance and environmental heat flux) (Bingner et al. 2018).

\section{Agricultural policy environmental extender model (APEX)}

The APEX model, developed by Texas A\&M University as a tool for managing whole farms or small watersheds, can represent processes related to nutrient load generation, as well as crop productivity (among others), and can use that information to estimate economic benefits at the watershed level (Williams et al. 2015). APEX, initially released in the mid-nineties, is essentially a multifield version of the EPIC model (environmental policy integrated climate model; erosion productivity impact calculator) (Sharpley and Williams 1990). APEX incorporates GLEAMS (groundwater loading effects of agricultural management systems) (Leonard et al. 1987) to model pesticide fate, and HYMO (problem-oriented computer language for HYdrologic MOdeling) to represent the routing between individual fields (Williams and Hann 1972). Operating with a daily time-step, APEX provides longterm simulations (1-4000 years) for a multitude of water-, plant-, nutrient-, and land-related processes, and can recreate the routing of runoff water through farms or small watersheds, which in turn are divided into several fields or subareas $(<100)$. To assess nutrient loading at the regional and national scales, APEX farm-scale estimates from cultivated cropland can be integrated with modelling outputs from SWAT for uncultivated land uses (Wang et al. 2011). The model has been selected by the USDA to evaluate benefits from conservation practices at the plot, field, and EOF scale (Williams et al. 2015; Moriasi et al. 2020). APEX cropland assessment in CEAP has also been coupled with SWAT to route the flows and nutrient loads to the outlet of large river basins (Kannan et al. 2011; Santhi et al. 2014).

\section{Distributed-parameter large basin runoff model (DLBRM)}

The DLBRM model has evolved from the large basin runoff model (LBRM) from the National Oceanic and Atmospheric Administration - Great Lakes Environmental Research Laboratory (NOAA-GLERL) (Croley and He 2005). LBRM was developed to study the overall water balance of the watersheds draining towards the Great Lakes during the mid-eighties, based on a rather coarse grid with spatial resolution of $1 \mathrm{~km} \times 1 \mathrm{~km}$. LBRM treats a watershed as a single unit with four land-water compartments (snow, upper soil, lower soil, underground), one surface storage compartment, and a basin outflow. DLBRM extends the logic of LBRM by dividing 
Fig. 3. Representation of vertical soil profiles among the 11 reviewed watershed models. The soil layers are colour-coded to represent the unsaturated and saturated soil zones with brown and blue colours, respectively. The different shades of each colour represent model segmentation with multiple layers within each zone. The different layers within the saturated soil zone/groundwater suggest that the model can simulate the water table dynamics. Models with a plant at the soil surface have the capacity to recreate the vegetation effects on water interception.

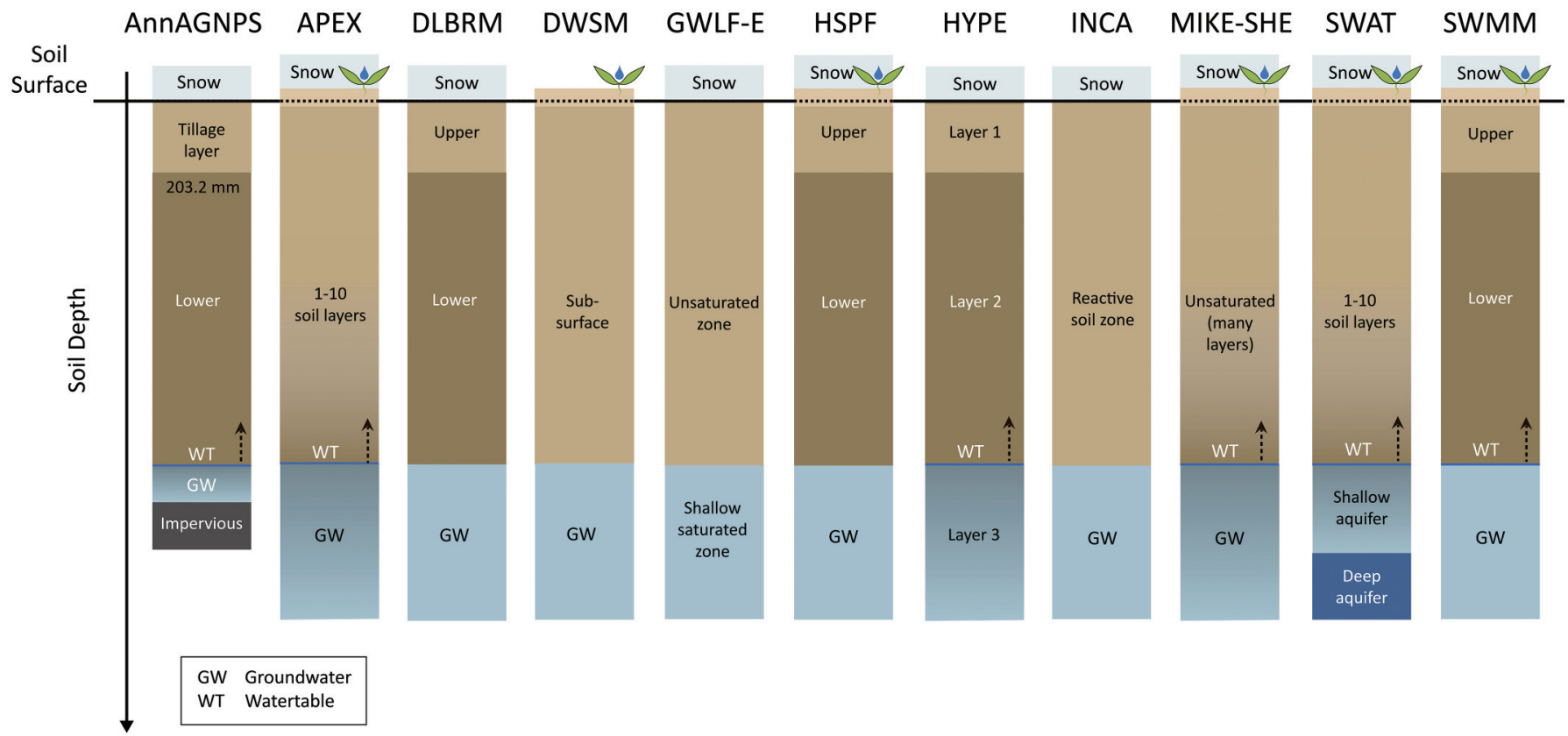

the watershed into gridded cells, applying a modified version of LBRM model to each cell of the watershed, and allowing lateral flow from one cell to the next one. Croley et al. (2005) extended DLBRM to represent the runoff of pollutants using solute dilution and then tracking the mass balance of the solutes throughout the watershed.

\section{Dynamic watershed simulation model (DWSM)}

DWSM was developed by the Illinois State Water Survey in cooperation with USDA-ARS and the University of Illinois during the late seventies, and was originally assigned the name SEDLAB (SEDimentation LABoratory watershed simulation model; Borah et al. 2002). DWSM is a storm-event model with physical description of surface and subsurface storm flow, soil erosion, and sediment and chemical transport within a watershed context. To simplify the mathematical representation, DWSM divides a watershed into subwatersheds and then conceptualizes each subwatershed as two symmetric, one-dimensional, overland planes from each side of a linear-channel segment, with area and parameters equivalent to the original subwatershed (Fig. 2). This spatial simplification allows the model to implement approximate analytical solutions of the dynamic behavior of water. DWSM comprises three major components: (i) DWSMHydro for watershed hydrology simulation, (ii) DWSM-Sed for soil erosion and sediment transport, and (iii) DWSM-Agchem for nutrient and pesticide simulations.

\section{Generalized watershed loading functions-enhanced (GWLF-E)}

The GWLF model was developed to reproduce long-term responses of water, sediment, and total and dissolved nitrogen and phosphorus at the watershed scale, with monthly resolution (Haith et al. 1992; Evans and Corradini 2016). ArcView GIS interface for GWLF (AVGWLF) and MapShed (a GIS-based watershed modelling tool, which replaced AVGWLF) were updated iterations of the original GWLF model with user-friendly graphical user interface (GUI), and
GWLF-E is the most recent version. GWLF was designed as an optimal balance between empirically estimated export coefficients and complex physically based models (Haith and Shoemaker 1987). The most recent version, GWLF-E, disaggregates the watershed surface into several homogeneous areas but lumps the underground processes into a single unit. Urban pollution is described with a buildup-runoff model, whereby GWLF-E first considers the pollutant accumulation since the last rain (or cleaning) event for each combination of pollutant and land use, while the amount of pollutants released during a rainfall event increases with the amount of water precipitating into the studied area. River channels, ponds, and other water bodies are not modelled explicitly in the GWLF-E. The public domain model code has been further adopted by Greenland Consulting Engineers as the proprietary CanWET software. More recently, GWLF-E has been extended to operate with daily time-steps and simulate streambank erosion (Wu and Lin 2015; Evans and Corradini 2016).

\section{Hydrologic simulation program - Fortran (HSPF)}

HSPF was developed by the United States Environmental Protection Agency (USEPA) to simulate short- and long-term hydrology and water quality in watersheds of various sizes and complexities (Bicknell et al. 1996). Through integration of multiple models in tandem, HSPF can simulate water peaks as well as a wide range of water quality descriptors, such as nutrients, biochemical oxygen demand (BOD), dissolved oxygen (DO), phytoplankton, zooplankton, and benthic algae. HSPF was developed from the Stanford Watershed Model and comprises three major components: (i) pervious land; (ii) impervious land (where infiltration is neglected); and (iii) water routing and biogeochemical processes within waterbodies. It also provides great flexibility to the users by allowing them to represent the watershed as a set of interconnected modules, which are organized in a noncyclical manner, thereby disallowing the consideration of feedback loops. Modules that can generate feedback 
loops have to be grouped together and act collectively as a singleprocessing unit (e.g., pervious units may allow soil nutrients to increase plant biomass, and plant biomass to decrease soil nutrients). Different modules and different variables within each module are connected by simple or complex processes, depending on application requirements and data availability. HSPF is one of the reviewed models endorsed by the Federal Emergency Management Agency (FEMA) for hydrological risk analysis, and by the Ontario Ministry of Transportation for runoff simulation.

\section{Hydrological predictions for the environment (HYPE)}

The HYPE model is a daily resolution water quality model developed by the Swedish Meteorological and Hydrological Institute (SMHI 2019) based on the HBV hydrological model, an elaborate conceptual reservoir-based model (Bergström 1976; Lindström et al. 1997), and the HBV-NP water quality model (water quality model based on HBV that simulates nitrogen $(\mathrm{N})$ and phosphorus $(\mathrm{P})$; Andersson et al. 2005; Arheimer et al. 2005; Lindström et al. 2005). HYPE uses a multibasin approach whereby river discharge and nutrient transport can be simulated simultaneously within each subbasin. Each sub-basin is composed of one or more classes, and each class represents a noncontiguous region with similar hydrological responses characterized by a combination of soil types, land uses, and elevations (Lindström et al. 2010; Strömqvist et al. 2012). Water from snow melt and precipitation is sequentially allocated to the constituent processes of the water cycle. The soil water content is the first layer to be filled, followed by the water distribution between surface runoff and percolation towards the deeper soil layers. Once the deeper soil layers are filled, water can fill the top layers, allowing for saturated overland flow to occur. Evapotranspiration involves the fraction of water content within the top two soil layers, which then defines the plant-rooting depth. Thus, HYPE can simulate stream flow and nutrient concentrations in rivers and lakes, based on commonly available climate data (precipitation and temperature), and some agricultural practices that can be incorporated with its parameters.

\section{Integrated catchment model (INCA)}

The INCA model was developed by the University of Reading, UK, to identify the potential sources of nitrogen loading at the watershed level (Wade et al. 2002a, 2002b). Access to the source code can be requested from the authors of the model. INCA has been continuously updated with the support of the European Union. Extensions of INCA include INCA-Carbon (INCA-C), focusing on the dynamics of dissolved organic carbon; and INCA-P, which simulates overland organic and inorganic phosphorus, and in-stream TP-concentrations. INCA requires hydrologically effective rainfall (HER, rainfall minus actual evapotranspiration) and soil moisture deficit data from external meteorological models [e.g., MORECS (Meteorological Office Rainfall and Evaporation Calculation System), Hough and Jones 1997; HBV, Tisseuil et al. 2008] or any other modelling frameworks to estimate these inputs [e.g., PERSiST (rainfall-runoff conceptual, bucket-type model), Futter et al. 2014]. Similar to DBRLM, land grid discretization is based on a coarse resolution of $1 \mathrm{~km}^{2}$ cells, and the parsimonious model structure considers up to six land-use classes.

\section{MIKE SHE}

MIKE SHE is a proprietary model developed from SHE, a fully distributed three-dimensional hydrological and water quality modelling tool that can represent waterflow processes within a watershed context (Refsgaard and Storm 1995; DHI 2017a, 2017b). SHE was collaboratively created during the early eighties by the Danish Hydraulic Institute (DHI), the British Institute of Hydrology, and the Société Grenobloise d'Etudes et d'Applications Hydrauliques (SOGREAH, currently Artelia). After that, DHI released MIKE
SHE and has continuously updated the modelling software. Simulations can either be based on cell grids, providing a full 3D description of the area, or on lumped areas with conceptual representation of the processes occurring in them. A unique feature of MIKE SHE is the ability to simulate both event-based and continuous (long-term) hydrologic responses. To do so, MIKE SHE provides alternative hydrological representations of a given watershed, which can be as complex as different approximations of the Saint-Venant equations that provide high resolution and detailed mathematical solutions on high resolution 2D surfaces, or use simple approximations to water routing in lumped subwatersheds, based on an empirical relationship between flow depth and surface detention according to the Stanford Watershed Model (DHI 2017a). MIKE SHE facilitates simulation of overland and channel flow with complex interactions and hydrological feedbacks, such as floodplain inundation. MIKE SHE allows different submodels to be represented with various temporal resolution in that overland flow can be modelled in minutes or hours, while groundwater processes can be simulated with longer time-steps. MIKE SHE can be linked sequentially with DAISY (model for simulation of water and nitrogen dynamics and crop growth in agroecosystems) (Abrahamsen and Hansen 2000; Refsgaard and Hansen 2010), a dynamic water-soil-crop model, and use as input estimates for the soil moisture, soil nutrients, plant roots, and leaf area index; EUROSEM can be used to simulate the spatial distribution of soil erosion/sedimentation. Owing to its physically based 3D configuration, MIKE SHE can track the solute transport that infiltrates from the surface to the unsaturated soil layer and subsequently percolates into the saturated layer. MIKE SHE can simulate solute transport through the unsaturated zone both in the soil matrix with a one dimensional (1D) advectivedispersion equation, as well as in the macropores with a mechanistic description of solute exchange between matrix and macropores. The solute transport in the saturated zone is also governed by an advection-dispersion equation with a third-order numerical solution based on the quadratic upstream interpolation for convective kinematics with estimated streaming terms (QUICKEST; Quadratic Upstream Interpolation for Convective Kinematics with Estimated Streaming Terms) scheme proposed by Leonard (1979) and updated by Vested et al. (1992).

\section{Soil and water assessment tool (SWAT)}

SWAT is a continuous watershed model developed by the USDA-ARS (Neitsch et al. 2011). SWAT incorporates models developed during the 1970s and 1980s, particularly CREAMS (Chemicals, Runoff, and Erosion from Agricultural Management Systems model; a field-scale model aimed to represent different edge-offield management practices); GLEAMS (which represents groundwater loading of pesticides and nutrients); EPIC (a model that simulates erosion at the field level); and the universal soil loss equation (USLE; used to represent soil transport at the field level). Using a daily time-step, SWAT employs a digital elevation model (DEM), soils, land cover, and climate data (specifically, precipitation, temperature, wind speed, solar radiation, and relative humidity) to define HRUs that are nonspatially located in a sub-basin (Fig. 2). In each HRU, SWAT reproduces water, plant, nutrient, and other land processes; the water and eroded sediments are transferred to the sub-basin outlet and routed from there throughout the basin using variations of the kinematic wave flood method. Water flow is then used to model the fate of sediments, nutrients, and other water quality properties. As previously mentioned, SWAT may be the most popular watershed model, likely due to its public domain license (cc-zero), detailed documentation, computational efficiency, parsimonious model structure for many subroutines, and user-friendly GUI. Several improvements are regularly incorporated in the model by the development team based on suggestions from an actively involved user community. 
Table 2. Effects of vegetation specified in the models (when relevant, the specific model used to describe the processes or the mechanisms modelled is indicated).

\begin{tabular}{|c|c|c|c|c|c|c|c|c|c|c|c|}
\hline Model & AnnAGNPS & APEX & DLBRM & DWSM & GWLF-E & HSPF & HYPE & INCA & MIKE SHE & SWAT & SWMM \\
\hline \multicolumn{12}{|l|}{ Water dynamics } \\
\hline $\operatorname{Runoff}^{a}$ & $\mathrm{CN}(\mathrm{CS})$ & $\mathrm{CN} / \mathrm{GA}$ & & $\mathrm{CN} / \mathrm{II}$ & $\mathrm{CN}(\mathrm{S} / \mathrm{PP})$ & $\mathrm{Y}(\mathrm{RD})$ & $\mathrm{Y}$ & $\mathrm{Y}$ & $\mathrm{Y}(\mathrm{RD})$ & CN/GA & $\mathrm{H} / \mathrm{CN} / \mathrm{GA}$ \\
\hline Water routing $^{b}$ & $\mathrm{Y}$ & & $\mathrm{Y}$ & $\mathrm{Y}$ & & $\mathrm{Y}$ & & & $\mathrm{Y}$ & $\mathrm{Y}$ & \\
\hline Potential ET & & Y & & & & & $\mathrm{Y}$ & & & & \\
\hline Actual ET ${ }^{d}$ & $\mathrm{~B}(\mathrm{bl})$ & $\mathrm{A}-\mathrm{B}(\mathrm{bl})$ & & & $\mathrm{Y}$ & $\mathrm{B}(\mathrm{bl})$ & $\mathrm{Y}$ & E1 & $\mathrm{Y}$ & $\mathrm{A}-\mathrm{B}(\mathrm{bl})$ & $\mathrm{Y}$ \\
\hline Snow dynamics & & & & & & & $\mathrm{Y}$ & & $\mathrm{Y}$ & & \\
\hline Litter accumulation & $\mathrm{Y}$ & $\mathrm{Y}$ & & & & $\mathrm{Y}$ & $\mathrm{Y}$ & & & $\mathrm{Y}$ & \\
\hline Nitrogen uptake ${ }^{f}$ & $\mathrm{Y}$ & $\mathrm{Y}$ & & & & $\mathrm{F} / \mathrm{M} / \mathrm{N}$ & $\mathrm{Y}$ & $\mathrm{Y}$ & $(0)^{g}$ & $\mathrm{Y}$ & \\
\hline Nitrogen fixation & & $\mathrm{Y}$ & & & & $\mathrm{Y}$ & & & & $\mathrm{Y}$ & \\
\hline Phosphorous uptake $\mathrm{e}^{f}$ & $\mathrm{Y}$ & $\mathrm{Y}$ & & & & $\mathrm{F} / \mathrm{N}$ & $\mathrm{Y}$ & $\mathrm{Y}$ & $(\mathrm{O})^{g}$ & $\mathrm{Y}$ & \\
\hline Soil temperature & & & & & & & & & & $\mathrm{Y}$ & \\
\hline
\end{tabular}

Note: See Table 1 for details of the abbreviations. Y, direct effect of vegetation in the process is described using a model-specific parameterization; Y(ND),

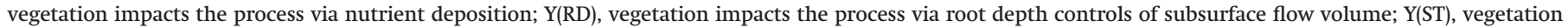
impacts the process via soil temperature.

${ }^{a}$ Main runoff approaches (mechanisms indicated are detailed if they were mentioned in the documentation), CN/GA/H/II = alternative methods to estimate runoff:

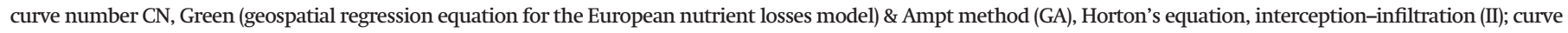
number $\mathrm{CN}(\mathrm{S}, \mathrm{PP}, \mathrm{CS})$, curve number affected by seasonality, $\mathrm{S}$; recent precipitation, PP; changes in plant stage, $\mathrm{CS}$.

${ }^{b}$ Description for water routing via Manning's roughness.

'Description related to interception: *, only when using GA method; **, canopy interception can be represented as a "depression storage".

${ }^{d}$ Direct impact of transpiration on soil moisture. (A and B) Effects of above-ground (cover) and below-ground (root depth or biomass). (B) Below-ground layer only effects (bl): model accounts for different layers of the soil; E1, external dataset that included the effects of vegetation, originally estimated using MORECS.

${ }^{e}$ Main approaches to model erosion, U(C, P): USLE model or one of its variations (RUSLE or MUSLE). It can affect the cover (C) or the practice (P) components of the USLE equation.

${ }^{f}$ Main approaches to model nutrient dynamics, F/M/N: Alternative methods to estimate solute uptake with first-order kinetics (F), Michaelis-Menten kinetics (M), and NLEAP (N) (Shaffer et al. 1991); O, the process can be modelled using an extension of the core model.

${ }^{g}$ Represents information from an add-on module, DAISY (model for simulation of water and nitrogen dynamics and crop growth in agroecosystems), for MIKE SHE.

\section{Storm water management model (SWMM)}

SWMM was first developed to represent short-term urban water flow for the USEPA, with participation of the University of Florida and other institutions in the USA (Rossman and Huber 2016a, 2016b; Rossman 2017). The USEPA started to lead the project during the early 2000s, and obtained approval by FEMA in 2005 to use the model to draw flood-risk predictions for insurance purposes. The Ontario Ministry of Transportation endorsed the use of SWMM for estimating catchment runoff and stream flows. SWMM is widely applied for nonpoint source pollutant loading analysis in urban settings (Lee et al. 2017), but has also been applied to non-urban areas (Talbot et al. 2016). SWMM was the only reviewed model to simulate urban storm water hydraulics in closed conduits as influenced by pumps, culverts, weirs, and other drainage network features. The application of dynamic wave routing method allows SWWM to simulate pressurized flow, ponded overflows/flooding, backwater effects, reverse flows, and tidal effects. The sediment and nutrient pollutants (i.e., sediment, nutrient, pesticides, metals, organics) are described with event-mean concentration or empirical nonlinear buildup-wash-off algorithms, similar to urban area routines in GWLF, HSPF, and SWAT. The SWWM model is typically applied in urban environments, but Talbot et al. (2016) showcased its applicability for simplified BMP analysis in agricultural catchments, without a detailed simulation of plantsoil nutrient interactions, even though the authors underscored the need for further validation of SWWM applicability in agricultural catchments. Importantly, Talbot et al. (2016) selected SWWM for its hydraulic capabilities to simulate backwater and reverse overland flows in flat landscapes in the Great Lakes basin, as well as the flow in pipes of municipal drain networks in Ontario, Canada. SWWM has been approved by FEMA for hydrological risk analysis.

\section{Watershed processes ${ }^{1}$}

\section{Plant growth-seasonality and succession}

Land cover and associated vegetation play a predominant role in shaping the water budget and nutrient cycles within a watershed context (Lohse et al. 2009). Specifically, leaf cover reduces the impact of precipitation on the ground (Pearce 1976), reduces soil water evaporation, and (or) increases transpiration (Ritchie 1972); roots maintain the soil cohesion (Gyssels et al. 2005) and pump subsurface water to the atmosphere, capturing nutrients in the process (Chapin et al. 2011); carbon fixed by plants provides energy to microbial organisms that modify nutrient availability (Gougoulias et al. 2014); leguminous plants can fix nitrogen; plant growth produces litter (fallen branches and leaves), which ultimately integrates into the soil as soil organic matter, and subsequently shapes the water retention capacity, cationic exchange capacity, and other soil chemistry properties (Chapin et al. 2011).

The strength of the causal linkages between land cover and watershed dynamics are influenced by the proportion of the area covered by plants, the weather seasonality in the covered area, the succession patterns of the plant community, the nutrient inputs through fertilizers/manure implementation and litterfall within a given area, and organic matter cycling. For instance,

\footnotetext{
${ }^{1}$ One of the critical issues during our review was the inconsistency in the terminology used for certain conceptual mechanisms in the documentation of the selected 11 models. For a systematic comparison of the modelled processes, we used common definitions in the field of hydrology and soil sciences as provided in the Supplementary data ${ }^{2}$, instead of the terms used in the model manuals and (or) by the authors.

${ }^{2}$ Supplementary data are available with the article at https://doi.org/10.1139/er-2020-0070.
} 
plant cover tends to be high in forest and meadows throughout the year, decreasing during fall and winter when the plants drop their leaves. Croplands are often more dynamic, with changes driven by sawing and harvesting activities, rotation of crops among years, the use of cover crops, fertilizers, and other management decisions. In contrast, urban areas tend to have a larger proportion of impervious areas than other land-cover classes, but the lawn cover tends to be more stable within and among years (Hedblom et al. 2017). Furthermore, the vegetation itself can be composed of different layers (e.g., trees, shrubs, grasses, epiphytes), each with different species composition and seasonal succession patterns. These species can either compete, or facilitate their coexistence, leading to multiyear successional trends in natural conditions (McIntire and Fajardo 2014), weed-management practices (Kiniry et al. 1992), or intercropping (Duchene et al. 2017) in man-made environments.

Despite the critical role of vegetation dynamics in multiple hydrological and biogeochemical processes, not all watershed models are capable of capturing all of these aspects (Table 2). There are three general strategies to accommodate the abovementioned vegetation effects: externally forced (either static or dynamic); dynamic representations of the vegetation effects; and explicit consideration of the plant biomass and community dynamics, which are essential to design watershed modelling studies suitable for assessing the impact of agricultural conservation practices (Arnillas et al. 2021):

(1) The externally forced strategy is designed to capture the wide range of vegetation effects through multiple parameters assigned to different land-cover classes. For instance, land-cover classes capture the spatial variability in nutrient loads in DWSM, similar to the event-specific, mean nutrient concentrations in SWMM. In these cases, the land-use layer and its associated properties capture the spatial variation of the vegetation effects on the modelled processes. This approach is defensible when the temporal variability is deemed irrelevant because the focus is on short-term flooding events (DWSM) or is due to limitations of the studied setting that make it unlikely for the vegetation to change, such as in urban environment (SWMM). The temporal variability in the vegetation effects is sometimes recreated by modelling vegetation traits or effects outside of the watershed model. For instance, leaf cover (represented as the leaf area index) and root depth are inputted into MIKE SHE (e.g., DAISY can generate the data needed), while AnnAGNPS considers external values of plant height (Supplementary data, Table $\mathrm{S1}^{2}$ ). INCA uses an external rainfallrunoff model (i.e., HBV, MORECS) to estimate effective rain, in which evapotranspiration changes with the day of the year for different vegetation types. Besides these specific changes in parameters, some of the models (i.e., AnnAGNPS, APEX, HSPF) offer the option to change landcover characteristics (Supplementary data, Table S2 ${ }^{2}$ ), like crop rotation or urbanization, thereby allowing the user to represent changes in the vegetation effects across the same area over time.

(2) The dynamic representation of the vegetation effects accommodates the seasonality within a given vegetation type through the watershed model itself. For instance, HYPE represents changes in evapotranspiration within each land cover type, as a sinusoidal function of the day of the year, modified by temperature, soil thickness, and other physical soil properties (Lindström et al. 2010). HYPE also considers the seasonal variability in nutrient uptake as a combination of two functions: one for spring, and one for autumn. HYPE can simulate different plant stages using heat units or simply the day of the year. Similarly, HSPF and INCA consider nutrient uptake as a function of the day of the year. GWLF-E also incorporates smooth changes on evapotranspiration during the season, but the associated mathematical formula is not described in the user's manual (Evans and Corradini 2016).

(3) Three models (AnnAGNPS, APEX, and SWAT) explicitly reproduce the plant biomass and community dynamics (Supplementary data, Table $S 1^{2}$ ), which can be an essential feature for reproducing the accumulation of legacy nutrients in soils and assessing the impact from conservation practices, such as phosphorus drawdown (Zhang et al. 2020). AnnAGNPS incorporates a simple model consisting of the FAO crop model to simulate aboveground biomass (Allen et al.1998) and the TETrans (Trace Element Transport layer-equilibrium model of one-dimensional solute transport through the vadose zone under transient-state conditions) model to account for the one-dimensional, vertical movement of chemicals through the vadose zone under transient conditions (Corwin 1995). Feedback loops between vegetation, soil, and water availability are limited in AnnAGNPS as well as in most of the models reviewed here. This limitation occurs because most models are sequential and have no way to represent, for instance, the amount of nutrients in soil and vegetation simultaneously, or how plant nutrient uptake changes for different environmental conditions. SWAT and APEX can represent feedback loops by a detailed description of the plant growth and soil conditions, thereby allowing the integration of the positive effect of nutrients on crop yield, as well as the effect of yield on nutrient depletion. Feedback loops are also important to obtain continuous nutrient simulations, as seasonal plant succession simultaneously affects soil chemistry and the plant community (Lovett et al. 2018). Although HSPF does not model plant growth, it considers the plant organic nitrogen pool as part of the nitrogen cycle and accounts for the return of nitrogen into the soil layer (Bicknell et al.1996).

SWAT and APEX can represent plant growth and its feedback loops, and integrate them in a dynamic way to represent water and nutrient fate, which is a critical requirement for assessing the impact of field conservation practices, such as conservation tillage and cover crops (Arnillas et al. 2021). Both models are modifications of the erosion-productivity impact calculator (EPIC) (Sharpley and Williams 1990) and use heat units and other atmospheric drivers (Supplementary data, Table $S 2^{2}$ ) to predict plant growth and trait changes (Supplementary data, Table $\mathrm{S1}^{2}$ ), which in turn can be modulated by extreme temperatures, nutrient availability, and soil moisture. Both models describe the above- and below-ground vertical profile of plants, and their local effect on the environment. APEX and SWAT, since 2009, incorporate the model ALMANAC (model to simulate crop growth, competition, light interception by leaves, biomass accumulation, partitioning of biomass into grain, water use, nutrient uptake, and growth constraints such as water, temperature, and nutrient stress) (Kiniry et al.1992, 2008; MacDonald et al. 2008) to allow for the incorporation of up to 10 competing species that interact within the same area that interact within the same area. For interacting species, light interception is the main driver of their competition. Species might also compete with each other for the available nutrients and water. In APEX, aluminum can negatively affect root growth, and therefore reduce plant biomass. Facilitative interactions are not included in SWAT and APEX, limiting the capacity to model intercropping and other situations, where more than one crop or plant species coexist. In either case, a common practice for natural systems with several coexisting species is to lump the entire plant assemblage into a single "idealized" species, and therefore the plant-growth effect on the soil environment is not representative of a diverse community. Modelling multiple species concurrently, or in other words, modelling biodiversity, could be particularly important to examine the implications of watershed management for important ecosystem services (van der Plas 2019). Plant modelling is an important component for predicting litter accumulation (e.g., dead leaves, stems) and decomposition, which in turn is critical for accurately assessing the likelihood of long-term accumulation and establishment of a nutrient legacy pool. Many models do not explicitly consider litter or humus variability in the soils (e.g., SWMM, INCA), or use fixed parameters to represent the role of litter in nutrient availability 
(Table 2). HSPF and HYPE represent some of the changes in the humic component of soil, but only APEX and SWAT have the potential to simulate litter variability as a function of biomass production. However, litter mass is not necessarily well predicted by productivity (O'Halloran et al. 2013) and may require explicit representation of the local diversity (Arnillas 2019), which in turn casts doubt on the potential applicability of these models.

To recap, despite the wide range of processes in which vegetation has a critical role at the watershed scale (Table 2), such as linking water and nutrient cycles or acting as a bridge between rural and urban development through food provisioning, most models have a minimal (or completely lack) description of plant community dynamics (Supplementary data, Table $S 1^{2}$ ). Only APEX and SWAT include plant-growth models that can recreate crop production dynamics. The current configuration only allows for the representation of a few competing species, and therefore can be inherently inadequate for reproducing natural succession patterns outside of fields (e.g., shift from meadow to forest, Arnillas et al. 2021). Notwithstanding the ability of SWAT and APEX to model actual changes in soil nutrient content due to plant growth, natural vegetation dynamics are based on alternative routines that are often simpler than the default ones. For instance, even though VFSMOD (vegetative filter strip modelling system) was used to develop the effect of vegetative filter strips in SWAT (Neitsch et al. 2011), it is an event-based model that does not account for changes in biomass nutrient content (Muñoz-Carpena et al.1999).

\section{Hydrological processes on land surface}

In theory, the application of watershed models should allow natural-resource managers to simulate various hydrological pathways of nutrient losses, to target structural BMPs for optimal placement and timing of nutrient reduction (Rittenburg et al. 2015). In agricultural land without tile drainage, surface runoff in the form of sheet and concentrated flow over the land surface represents a major hydrological pathway of phosphorus losses from agricultural fields into waterways (Reid et al. 2018). The hillslope hydrology distinguishes between two principal runoff generation mechanisms: namely, the infiltration-excess and the saturation-excess overland flow (Buda 2013). The reviewed watershed models mostly considered infiltration-excess (Hortonian flow), when precipitationdriven runoff is initiated after the rainfall intensity exceeded the infiltration rates of soils. Nonetheless, in humid continental climates, such as the Great Lakes drainage basin (Bailey 2014), the saturation-excess surface runoff (or Dunne runoff) has been identified as an equally important mechanism (Beven and Kirkby 1979). In the latter case, the saturation overland flow is generated even when soil infiltration rates are greater than rainfall intensity due to increase in groundwater table, when subsurface water can exfiltrate as surface runoff, while rain can fall on completely saturated soils (Beven and Kirkby 1979). By definition, the saturation-excess runoff is not an event-driven process, but rather a continuous process of complex interactions of multiple environmental factors, such as precipitation, evaporation, snow melt, infiltration, soil moisture storage, and lateral shallow subsurface flow. Thus, the spatial extent of completely saturated soils is a dynamic process that evolves in time and space ("variable-source" area concept), which contrasts the "constant-area" assumption in the majority of reviewed models, postulating that the entire watershed contributes to runoff generation. The simulation of hydrologically sensitive and active areas can be essential for guiding management decisions on targeted BMP placement in critical source areas of soil erosion and nutrient losses (Arnillas et al. 2021).

The surface runoff modelling strategies could be additionally categorized into three types: (i) empirical; (ii) conceptual; and (iii) physically based methods (Devia et al. 2015). Empirical models include various statistical (e.g., regression) methods and data-driven hydroinformatics, such as artificial neural networks, genetic programming, support-vector machines, wavelets and fractal analysis, and chaos theory (Sivakumar and Berndtsson 2010). The empirical precipitation-runoff relationships downplay complex surface-subsurface hydrological interconnections and can serve as a complimentary approach preceding the application of more complex models. The empirical methods allow for explanatory data analysis of hydrological time series records, such as baseflow separation in stream hydrographs (Granato 2012; Lott and Stewart 2016), hypothesis-driven improvement of the representation of hydrological processes in more complex models (Gupta et al. 2014; Beven 2019), data assimilation to account for observational uncertainties (Coustau et al. 2013), imputation of missing data (Gao et al. 2018), upscaling/downscaling for boundary conditions and regionalization of model parameters in more complex models for cross-catchment transferability (Blöschl 2005; Smith et al. 2016), hydrological forecasting (Babovic and Savic 2009), and approximation methods prior to the application of more complex routines (Rossman and Huber 2016b). The main disadvantages of empirical methods are their limited extrapolation capacity to simulate hydrological processes outside of the domain of collected data used for calibration, which can be critical for analysis of future and previously unobserved scenarios, e.g., extreme flooding events, climate-change conditions.

The Soil Conservation Service curve number (SCS-CN) is the most commonly used empirical method, which facilitates specification of the amount of precipitation that is allocated to infiltrationexcess, and then calculates surface runoff in the reviewed models (AnnAGNPS, APEX, DWSM, GWLF-E, SWAT, and SWMM) as a function of the antecedent moisture conditions and hydrological characterizations of the soil group (Table 3). The default method assumes that $20 \%$ of the potential retention or total maximum storage occurs as an initial abstraction $\left(I_{\mathrm{a}}\right)$. The SCS-CN method lumps together all types of abstraction into $I_{\mathrm{a}}$, including rainfall interception, depression storage, and infiltration into the soil. After $I_{a}$ is subtracted from the total rainfall volume, the remaining precipitation is inputted into an equation that estimates runoff as a nonlinear regression function of an empirical curve number $(\mathrm{CN})$. Total precipitation volume must therefore exceed $I_{\mathrm{a}}$ before any surface runoff can be generated, which allowed Steenhuis et al. $(1995,2019)$ to extend the SCS-CN empirical method in a saturation-excess context. Curve numbers for a given day are updated to take the antecedent soil moisture into account (Mishra and Singh 2003). Notwithstanding its wide range of application and satisfactory overall agreement between observed and predicted daily runoff, the SCS-CN approach has a limited capacity to predict overland flow depths and stream peak flows (Borah et al. 2007; Gassman et al. 2007). Several empirical studies advocated to revisit the $20 \%$ cutoff threshold for $I_{\mathrm{a}}$ in favor of a 5\% level (Lim et al. 2006; Baltas et al. 2007), which should allow for better simulations of frequently occurring lower rainstorm depths, and climatic conditions with modest return period rainfall (Woodward et al. 2003). Under the SCS-CN method, the precipitated water is typically diverted to runoff before assigned to evapotranspiration, infiltration, and other processes, in contrast to alternative approaches whereby infiltration precedes the overland flow generation (APEX, DWSM, HSPF, MIKE SHE, SWAT, SWWM).

Conceptual methods, as a combination of empirical and physically based runoff subroutines, tend to provide general descriptions of watersheds based on prior knowledge and understanding of the relationships among catchment features (e.g., size, slope, land use/cover, soils, and geology). These conceptual methods employ semi-empirical equations, and the values of the relevant effective model parameters are subject to calibration against observations (Devia et al. 2015). Models such as DLBRM, HSPF, INCA, and HYPE implement conceptual reservoir strategies to simulate the processes pertaining to water cycle at the watershed scale (Table 3). Minimally, two conceptual reservoirs are incorporated into the models, in which the upper and lower reservoirs represent surface 
Table 3. Methods used to simulate surface, subsurface runoff, and sediment erosion in the 11 reviewed watershed models.

\begin{tabular}{lll}
\hline Model & Infiltration/surface runoff & \\
\hline AnnAGNPS & SCS-CN & Subsurface flow $^{b}$ \\
APEX & GA/SCS-CN & Darcy's equation (saturation zone) \\
& & $\begin{array}{c}\text { Nonlinear storage routing and pipe flow } \\
\text { equations for vertical flow }\end{array}$
\end{tabular}

$\begin{array}{ll}\text { DLBRM } & \begin{array}{c}\text { Partial-area infiltration concept for the } \\ \text { supply and linear reservoir model for } \\ \text { the movement of surface runoff } \\ \text { Interception-infiltration method/GA to } \\ \text { describe rainfall excess and Kinematic } \\ \text { wave equations for surface flow routing/ } \\ \text { SCS-CN }\end{array} \\ & \text { SCS-CN }\end{array}$

INCA Linear reservoir model with two reservoirs in the reactive soil zone and groundwater. The model simulates conceptual quick flow, soil water flow, and groundwater flow

HSPF Philip's equation (Philip 1957) for infiltration; Chezy-Manning equation and an empirical expression that connects outflow depth to detention storage for surface runoff simulation
HYPE Linear reservoir model with surface runoff from infiltration-excess and as saturated overland flow
MIKE SHE Richards' equation/2-layer water balance method/gravity flow method for surface infiltration; 2-D diffusive wave/ Manning's equation/ponded drainage for the simulation and conceptual reservoir model for the routing of overland flow
SWAT GA/SCS-CN

SWMM Horton equations/modified Horton/GA/ SCS-CN for infiltration; nonlinear reservoir model with Manning's equation for overland volumetric flow; optional approximation methods include runoff coefficient method; SCS$\mathrm{CN}$; unit hydrograph; externally generated runoff data
Linear reservoir model Kinematic storage model for lateral
subsurface flow

Linear reservoir model

INCA-sed, which includes splash detachment, flow erosion, and sediment transport capacity via quick flow

Linear reservoir model (Stanford watershed model IV) for saturated zone outflow, interflow outflow, groundwater outflow

Regional groundwater flow model/aquifer mass-balance model

3-D finite difference method/linear reservoir method for groundwater flow (saturated flow)

Kinematic storage model for lateral subsurface flow; perched water table; exponential decay function for shallow recharge; deep aquifer as a loss term

Two-zone variable volume model for unsaturated and saturated zones
Sediment erosion model ${ }^{c}$

Ephemeral gully erosion, sheet and rill erosion with RUSLE, HUSLE

USLE, USLE Onstad-Foster modification, RUSLE, MUSLE, MUST, MUSS, MUSI; ephemeral gully erosion is assessed by subtracting MUSS from the MUSLE soil erosion estimates

Not included

Raindrop erosion and sediment routing based on sediment transport capacity and continuity equations

USLE for pervious (rural) areas/ Exponential wash-off for urban areas

Sediment erosion on pervious land considers rainfall splash detachment and scouring of the soil matrix to represent gully erosion, while impervious surfaces consider the rate of accumulation of solid materials (buildup and wash-off); equations for simulation and transport of sediments follow ARM and NPS models

Default erosion transport model based on raindrop erosion and surface runoff; an optional model based on catchment erosion index

Soil erosion (SE) add-on (adapted EUROSEM) simulates splash erosion and flow detachment in inter-rills, depressions, and rills

MUSLE for pervious areas/USGS linear regression or exponential wash-off for impervious (urban areas)

Empirical equations for urban areas (three options): (i) exponential wash-off; (ii) rating curve wash-off (proportional to flow); (iii) EMC wash-off

\footnotetext{
Note: See Table 1 for details of the abbreviations.

${ }^{a}$ SCS-CN (USDA-SCS 1985); GA (Green and Ampt 1911); interception-infiltration procedure (Simons et al. 1975); Manning's equation (Manning 1891); Philip's

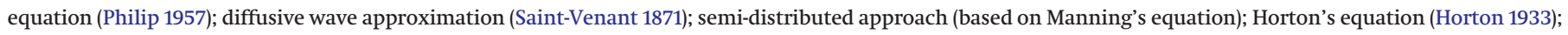
modified Horton equation (Akan and Houghtalen 2003).

${ }^{b}$ Darcy's equation (Darcy 1856); Richards' equation (Richards 1931); 3D Bousinesq equation (Yang et al. 2018); Kinematic storage model (Sloan et al. 1983).

'USLE (Wischmeier and Smith 1978); USLE Onstad-Foster modification (Onstad and Foster 1975); RUSLE (Renard et al. 1997); MUSLE (Williams 1975a); MUST, MUSS, and MUSI (Williams et al. 2015); MIKE SHE (DHI 2017a, 2017b).
} 
water and groundwater storage, respectively. These reservoirs are interconnected by vertical groundwater flow through soil matrix and macropores from unsaturated to saturated zone reservoirs. The reservoir models assume that the outflow from each reservoir is proportional to the reservoir storage. The reservoir concept can allow for saturation-excess overland flow generation when the soil water input (precipitation) is greater than what the soil can store (HYPE), in contrast to infiltration-excess (HSPF) when inputs occur at a rate greater than what the soil can absorb and (or) move vertically. In this context, Chapi et al. (2015) showed that surface runoff in Lake Erie catchment in Southern Ontario was generated by the infiltration-excess mechanism during summer and fall (soil moisture deficit), and the saturation-excess during the spring period. Considering that a major fraction of nutrient loading in the Great Lakes occurs during the spring freshet (OMECC 2017), the capability of models to recreate the processes associated with saturationexcess overland flow could be a primary criterion for model selection. The ability of models to simulate saturation-excess is intrinsically connected to spatiotemporal allocation of soil moisture content and runoff generating areas (Giri et al. 2016), which highlights the necessity to apply fully distributed models for robust management analysis of the Great Lakes watersheds (Johnson et al. 2003). There are variations for SWAT and GWLF with adequate gridded spatial discretization that warrants broader consideration (Schneiderman et al. 2007; Rathjens and Oppelt 2012). The semi-distributed models HSPF and SWWM can potentially replicate peak runoffs via the infiltration-excess runoff mechanism, while HYPE and the DHI model of MIKE SHE can additionally use the saturation-excess runoff generation.

Physically based models apply conservation laws for mass, energy, momentum, and kinematics (Sitterson et al. 2017), such as Saint-Venant shallow water mass conservation equations for overland and channel flows, which has a robust theoretically foundation (Rossman 2017). MIKE SHE considers the Saint-Venant equations for overland water flow, whereas SWWM, MIKE HYDRO RIVER (MIKE SHE coupled with MIKE HYDRO River), SWWRP-NPS (based on incorporated nutrient and erosion subroutines into FEMA-endorsed Gridded Surface/Subsurface Hydrologic Analysis model GSSHA), and HEC-RAS (US Army Corps of Engineers Hydrologic Engineering Center's river analysis system) for 1-D flood routing in pipes, open channels, and streams. Application of the Saint-Venant equation within the context of fully distributed spatial representation serves to simulate the dynamics of runoff water depth in neighboring cells, which ultimately allows representation of the backwater conditions in overland flow and streams (MIKE SHE coupled with MIKE HYDRO RIVER, SWWRP-NSM). Application of the Saint-Venant equation for overland flow requires a numeral solution for spatially distributed (2D) nonlinear partial differential equations, which is achieved in MIKE SHE with a finite-difference method with implicit and explicit solvers. 2D representation (in $\mathrm{X}-\mathrm{Y}$ Cartesian coordinates) of overland flow is a typical practice in watershed modelling, whereas 3D strategies were previously deemed redundant, or even infeasible due to computational challenges in desktop computers (Kampf and Burges 2007). The advent of high performance computing (HPC) allows the shift from 2D (grid-based) to 3D (volume-based) overland flow simulations, which can improve the characterization of complex infiltration and overland flow generating mechanisms (Yusoff et al. 2009). Another prospect could be the increase in complexity for solving the Saint-Venant differential equations with HPC. Specifically, MIKE SHE applies a diffusive wave approximation of 2D SaintVenant equations, which has demonstrated limited capacity for timely prediction of backwater effects (Kampf and Burges 2007). The latter feature could be critical for simulating nutrient fate and transport in the Great Lakes floodplains during peak hydrological events.

Rate of infiltration is a critical parameter in infiltration-excess surface-runoff models, and depends upon the soil properties, such as the unsaturated hydraulic conductivity, diffusivity, and water holding capacity. In SWMM, infiltration can be estimated using Horton's and Modified Horton's empirical infiltration decay curves. Simplifications of the physically based Richards' equation for infiltration, such as the Green-Ampt (GA) method (APEX, DWSM, SWAT, SWWM) and Philip's equation (HSPF, MIKE SHE) have been incorporated in several models. The boundary and initial conditions in these models are simplified with assumptions of movement of water from the surface down through the deep soil with a sharp wetting front, which separates upper saturated and lower unsaturated zones. These assumptions reduce the data requirements of soil properties for calculating numerical solutions, but their applicability is inevitably limited under changing initial and boundary conditions (Parlange et al. 1987). Most importantly, the simplification affects the capacity to simulate realistic water table dynamics, which is a critical requirement for saturationexcess overland flow generation and estimation of temporarily and spatially variable source areas. HSPF uses Philip's equation to quantify the relationship between the infiltration rate and soil moisture (Philip 1957). Specifically, the equation models runoff as the amount of water that cannot be stored within a soil layer nor can move towards a deeper layer, while evapotranspiration is a function of storage. Additionally, HSPF incorporates linear probability density to capture areal variations within a land segment, which may be fixed (e.g., soil permeability and land slopes) or variable (e.g., soil moisture content and surface roughness).

The unsaturated vertical flow in MIKE SHE follows the physically based Richards' equation, which is computationally intensive and the most accurate when describing vertical movement of water through unsaturated soils (vadose zone), based on the Darcy's Law (Richards 1931; DHI 2017b), whereby the vertical flow rate through porous media is proportional to the hydraulic gradient and unsaturated hydraulic conductivity (Whitaker 1986). Hydraulic conductivity in the unsaturated zone in MIKE SHE is a dynamic term dependent on volumetric soil moisture and soil water capacity (DHI 2017b). To achieve a realistic dynamic simulation of vertical water percolation, MIKE SHE requires detailed information on the vertical heterogeneity of soil properties. Another limitation of Richards' equation is its inability to account for macropores, although existing evidence underscores their importance in causing infiltration through preferential flow pathways, thereby allowing for the vertical movement of nutrients through burrow and crack flow, and subsequent delivery to the tributaries of the Great Lakes with lateral flow and tile drainage (Christiansen et al. 2004; Allaire et al. 2011; Beven and Germann 2013). Compared with empirical and conceptual models, the physically based models can, in principle, improve the representation of storm events and simulate the impacts of rainfall intensity and duration. Physically based methods are recommended when sub-daily precipitation data are available. In the same context, although the majority of the models explicitly (GA and Philip's methods) or implicitly (SCS-CN) presume that the dominant mechanism of surface runoff is infiltration-excess, a key point to add is that runoff is produced by saturation-excess processes in most watersheds (Tilahun et al. 2013), which has been shown to produce more accurate overland flow estimates (Croley and He 2005).

Another critical facet of the water cycle in snowmelt-dominated watersheds, such as the Great Lakes drainage basins, is characterization of the snowpack and snowmelt processes (Fig. 4). In general, the methods for modelling snowmelt are grouped into the "energybalance" and "degree-days" methods. The energy-balance approach relates a change in snowpack heat content to the sum of all heat fluxes, i.e., solar radiation, thermal radiation, sensible heat transfer from air, latent heat of vaporization from condensation, or evaporation/sublimation, conducted heat from underlying ground, and advected heat from precipitation (USDA-NRCS 2004). The energy-balance methods require multiple hydrometeorological inputs (air temperature, wind, precipitation, humidity, cloudiness) 
Fig. 4. Surface, subsurface, and groundwater processes of the water cycle typically characterized by the spatially distributed watershed models.

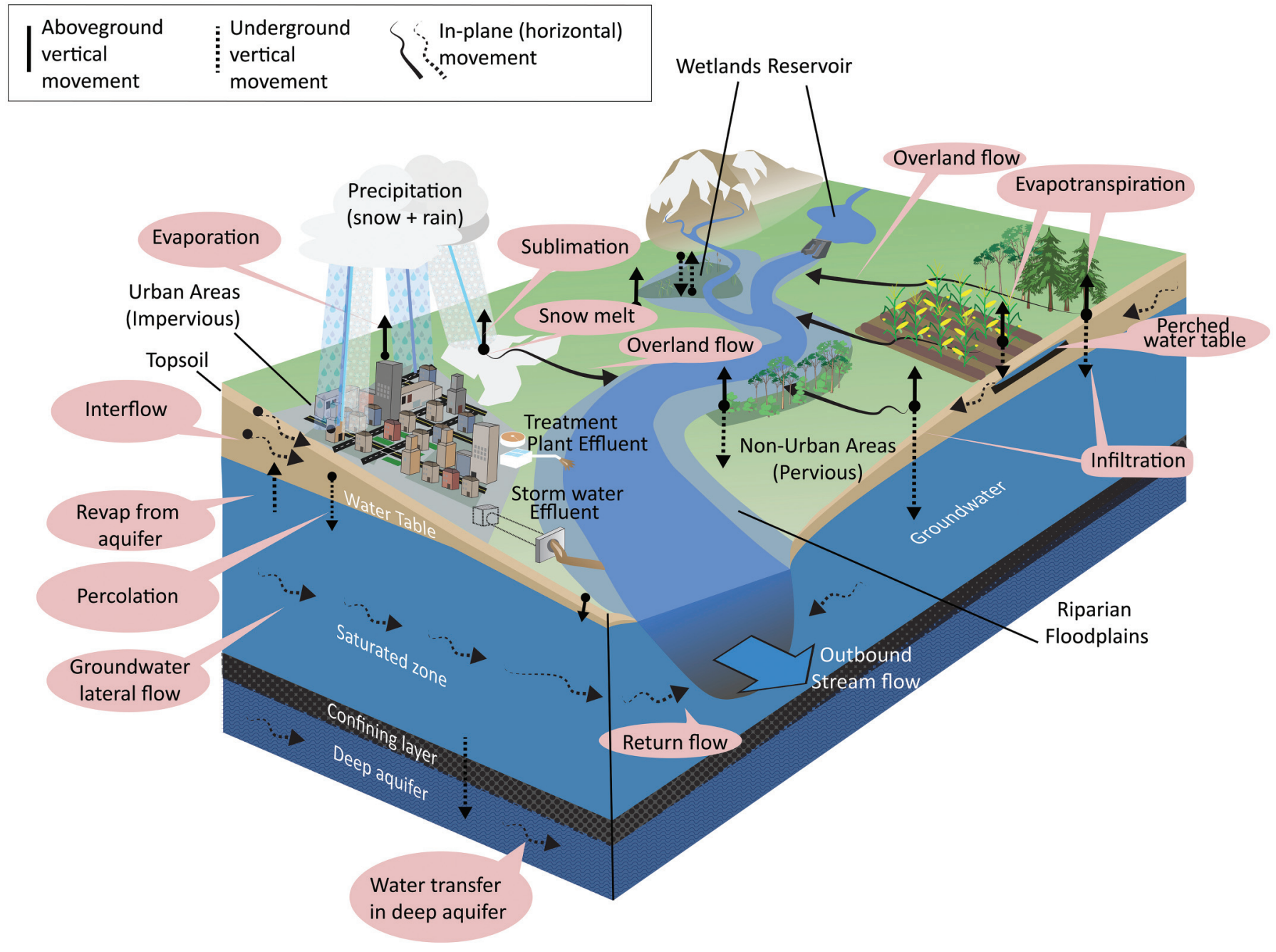

and spatial descriptors (elevation, aspect, slope), as well as information on vegetation, soil, land use/land cover. Recent advances in the mathematical description of snow melt can also account for snow drift, layered snow pack metamorphism, subsurface melt, and dynamic changes in groundwater percolation. The HSPF snowmelt subroutine considers long- and short-wave net radiation heat, convection of sensible heat from air, latent heat transfer by condensation of moist air on the snow pack, heat from rain, latent heat from rain freezing on the snowpack, and conduction of heat from the ground. AnnAGNPS includes an option for calculating the energy balance for each of the snowpack thermal layers. The consideration of multiple snowmelt factors with energy-balance models allows for the prediction of different snow-melt regimes under similar air temperature conditions (e.g., rain-on-snow events) or for different (shaded versus nonshaded, forested versus open-space) locations. An interesting study by Qi et al. (2017) showed that a SWAT modification with an energy-balance module could achieve reliable estimates of rain-on-snow events and snow depths, which in turn can be essential for recreating the spring freshet dynamics in the Great Lakes and elsewhere

Other watershed models (APEX, DLBRM, GWLF-E, HYPE, INCA, MIKE SHE, and SWAT) follow a simplified conceptual degree-days approach, which postulates that the amount of snowmelt is proportional to the temperature difference between the air and snowmelt threshold, with elaborate snowmelt factors to convert degree-days into millimetres of water $\left(\mathrm{mm} \mathrm{H}_{2} \mathrm{O}\right)$. As a result, the threshold temperatures represent effective parameters that include effects from (not explicitly defined) controlling factors. By default, these models specify snowmelt parameters at the basin scale, and several models (AnnAGNPS, HYPE, SWAT) allow adjustments for sub-basin elevation. Moreover, SWAT simulates snowmelt dynamics with seasonally variable snowmelt conversion factors and empirically defined snow-cover fractions based on lumped basin-wide parameters. The existing evidence suggests that the latter approach can be a challenge for multisite calibration in mixed catchments with both agricultural and urban areas (Dong et al. 2019). Besides snowpack and air temperature, there are also degree-day models that additionally consider soilsurface temperature to specify hydrological conditions for frozen soils. In particular, SWAT considers the soil as frozen only if the temperature of the top soil layer drops below $0^{\circ} \mathrm{C}$, when runoff is increased by adjusting the retention parameter $S$ in the SCS-CN runoff subroutine with an empirical exponential equation, while prohibiting percolation, lateral flow, and tile drainage. To address elevated runoff in SWAT due to precipitation on frozen soil, Fu et al. (2014) assigned curve number (CN) values for impervious areas to generate infiltration-excess and overland flow for topsoil temperatures below zero. In the same context, Qi et al. (2016) modified the SWAT module for soil temperature and improved the simulation of freeze-thaw cycles in soils, which has been 
recognized as a seasonal mobilization factor for elevated rates of soil erosion and nutrient leaching in the Great Lakes (Wang 2015).

Several degree-day models estimate snow depth in water equivalents (HYPE, INCA-P), which could provide an additional modelendpoint for validation. The accuracy of snowmelt simulations also depends on the spatial granularity of the models, and MIKE SHE, with fully distributed discretization, has displayed improved performance over SWAT with respect to the spatial characterization of snowpack distribution (Liu et al. 2016). Generally, the reviewed models mostly simulate the temporal evolution of snow storage within isolated spatial units without accounting for lateral snow redistribution processes between these units, while the simulation of wind-induced lateral transport of snow is treated as being beyond the scope of the typical catchment-scale watershed modelling exercises.

\section{Subsurface processes}

Subsurface vertical flow pathways include: the infiltration of water into the soil porous matrix, where it can be stored as moisture in an unsaturated zone; downward movement through preferential pathways in macropores (non-Darcy flow), where the infiltrated water bypasses large portions of soil through burrows, cracks, and fingers in soil without interacting with the soil matrix (Allaire et al. 2011); percolation through an unsaturated (vadose) zone downward to the water table, which separates unsaturated from saturated zones; percolation to confined aquifers (deep groundwater recharge); groundwater evaporation from water table; uptake by plant roots, followed by reentry to the atmosphere through plant transpiration. The subsurface horizontal flow pathways in the reviewed models typically include: lateral flow in an unsaturated zone; horizontal flow of groundwater along a horizontal hydraulic gradient in unconfined and confined aquifers (Darcy's Law regarding laminar flow in porous media with negligible inertial forces); and artificial drainage through tile drains (Fig. 4).

By comparison with surface runoff, subsurface flow in a porous soil matrix is slower, thereby allowing for consistent baseflow supply (return flow) to streams during dry periods (Henshaw et al. 2000). Generally, the subsurface component in all of the reviewed models distinguishes between unsaturated (upper) and saturated (lower) zones (Fig. 4). The dynamic representation of the boundary between the two layers, defined as the (ground) water table, is a critical model requirement for tile drainage simulation in agricultural lands in the Great Lakes (Table 1). The conceptual representation of groundwater varied from simulation of local (perched) water tables (AnnAGNPS), to conceptual simulation of groundwater within spatial subwatershed boundaries (SWAT), to representation of regional-scale dynamics of groundwater with conceptual reservoir schemes, and to 3D flow dynamics with partial differential equations in MIKE SHE (Table 3).

The unsaturated zone is typically subject to (subsurface) lateral flow (APEX, AnnAGNPS, SWAT) in slope parallel macropores or soil pipes (Weiler et al. 2006), which is also known as interflow (HSPF, HYPE), or subsurface stormflow (Hu and Li 2018). AnnAGNPS simulates subsurface lateral flow in saturated conditions with Darcy's equation, with the requirement that an impervious layer is present within the soil profile. Horizontal groundwater flow in Darcy's equation is assumed to be the product of saturated hydraulic conductivity and horizontal hydraulic gradient. The current limitation of AnnAGNPS is the lack of dynamic simulation of groundwater-fed baseflow, which requires model users to perform preliminary hydrograph separation to estimate the surface-runoff contribution for model calibration purposes. Other models distinguish between subsurface lateral flow in the vadose zone and groundwater table with lateral flow simulation in the saturated zone. Specifically, SWAT incorporates a kinematic storage model developed by Sloan et al. (1983) and Sloan and Moore (1984) to simulate lateral flow in the vadose zone. The Sloan kinematic storage model is a water mass-balance equation in which the subsurface flow path is conceptually represented as a steep hillslope flow in a 2D cross-section parallel to the direction of the flow. For the groundwater system, SWAT simulates two aquifers: the shallow aquifer (unconfined aquifer), and the conceptual deep (confined) aquifer. It is assumed that only the shallow aquifer contributes to channel (stream) flow, whereas the deep aquifer allows for water to flow outside of the watershed as an ultimate loss in the catchment water balance (Neitsch et al. 2011). SWMM similarly adopts the two-zone representation with the upper (unsaturated) and lower (saturated) zones, but (unlike SWAT and HSPF; see next section), the saturated zone is not further divided. Conceptual reservoir models of different complexity are implemented in DLBRM, GWLF-E, HSPF, HYPE, and INCA. In HSPF, both lateral and groundwater flows depend on the volume of stored water and user-specified recession rates. The saturated layer in HSPF is divided into two storage reservoirs: active and inactive groundwater, which are conceptually similar to the distinction between shallow and deep (confined) aquifers in SWAT. Similar to SWAT, HSPF assumes that only the active groundwater discharges contribute to the return channel (stream) flow, which in turn are calculated with a simple proportional method based on active groundwater storage, without taking into account the hydraulic conductivity. In HYPE, subsurface flow only occurs when the soil moisture content is greater than the field capacity, while the amount reaching the stream is controlled by a recession coefficient. HYPE also accounts for groundwater flow: the water in the aquifers is typically treated in a linear manner, whereby outflows are proportional to storage. INCA offers a parsimonious approach that distinguishes between: (i) quick flow, comprising surface runoff (saturation and infiltration-excess), tile drainage through soil cracks and macropores, and ditch flow; (ii) soil water represented as an intermediate reservoir for soil water drainage/retention; and (iii) conceptual groundwater flow (Jackson-Blake et al. 2016).

Overall, MIKE SHE provides the most comprehensive representation of the interplay between surface and subsurface hydrological processes (Table 3). MIKE SHE incorporates a physically based $3 \mathrm{D}$ saturated zone model, and therefore groundwater quality in the overland, unsaturated, and saturated components can be explicitly modelled. The MIKE SHE 3D finite difference method numerical engine is similar to MODFLOW (MODular 3D FiniteDifference Ground-Water FLOW Model), an advanced 3D model for recreating groundwater conditions and groundwater - surface water interactions. The main difference between these two models is that MIKE SHE includes an unsaturated zone, whereas MODFLOW only deals with a saturated zone. In MIKE SHE, the saturated zone is influenced by all of the other water fluxes: overland flow, unsaturated flow, channel flow, and evapotranspiration. Flow in the unsaturated zone is calculated by the 1D Richards' equation. The governing equation for 3D flow in saturated porous media for both MIKE SHE and MODFLOW is the 3D Boussinesq equation, solved with finite difference methods. Simulation of the subsurface process with MIKE SHE incorporates saturated hydraulic conductivity, wells, pumping, and drainage routing. MIKE SHE can simulate rapidly changing groundwater levels, flow, and two-way aquifer-channel seepage. It should be noted that several watershed models have been coupled with dedicated groundwater models to further improve the representation of groundwater dynamics at regional scale, e.g., APEX, HSPF, SWAT, and SWWMMODFLOW, and MIKE SHE with the subsurface model FEFLOW.

\section{Sediment transport}

Sediment transport is a complex process comprising the detachment, transportation, and deposition of soil particles at some downslope location, as mediated by the action of raindrops and flowing 
Fig. 5. Sediment erosion processes reproduced by the spatially distributed watershed models. Definitions of sheet, rill, and gully erosion are provided in the Supplementary data ${ }^{2}$ (glossary).
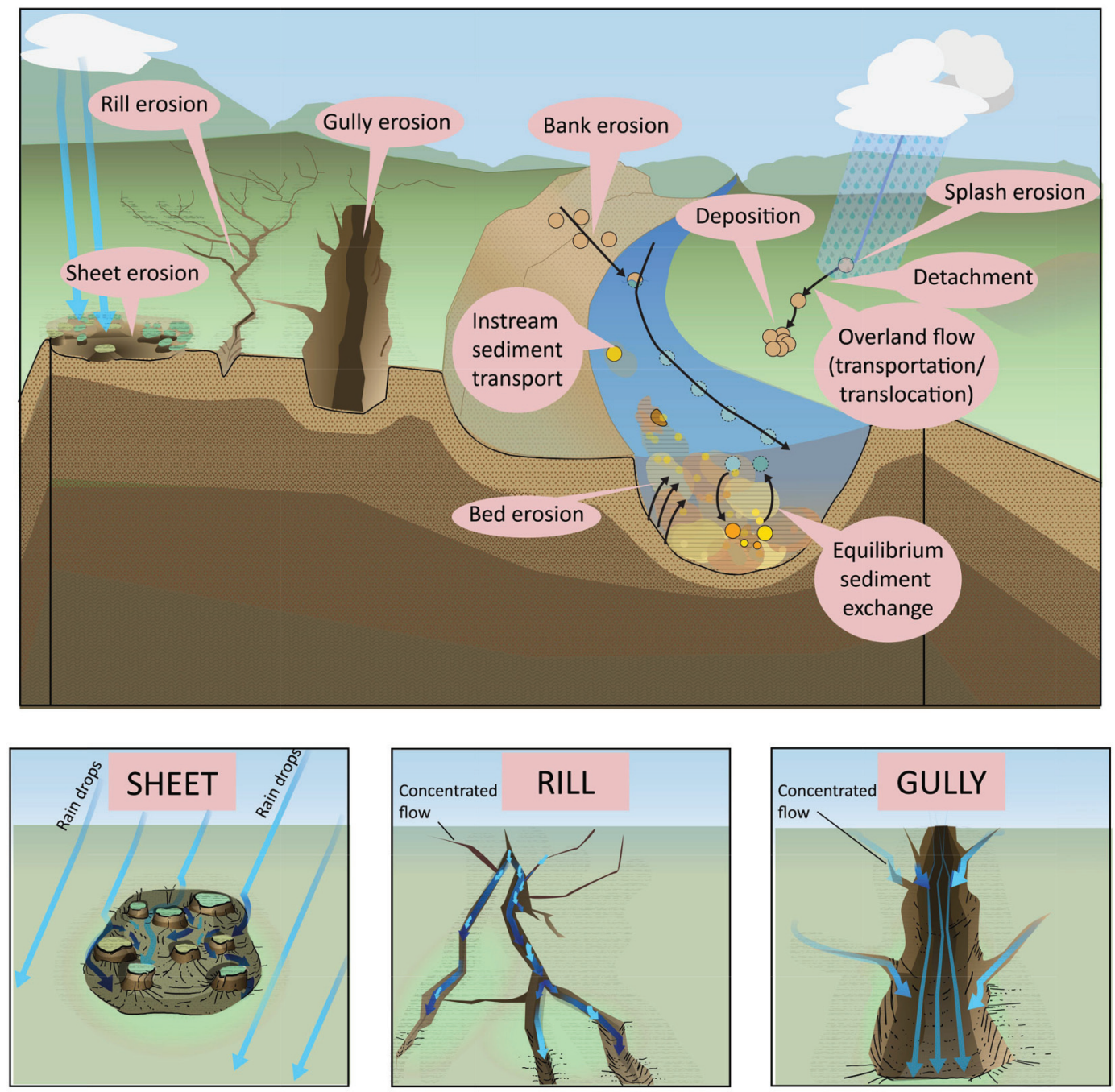

water (Fig. 5). Erosion begins when raindrops strike the land surface, creating loose and noncohesive sediments. Overland flow (sheet, rill, gully, and in-stream erosion) provides a mechanism for further detachment and transportation of the loosened soil particles to downslope locations (Li et al. 2019; Lu 2019). Soil detachment through overland flow is the dominant process of soil erosion (Zhang and Wang 2017; Li et al. 2019), which in turn is regulated by rainfall intensity (i.e., the more intense the rainfall event is, the greater the detachment of soil particles and sediment transportation by overland flow). Within a watershed context, erosion occurs at stream banks and stream beds, and therefore overland erosion may be profoundly underestimated when models fail to account for bed and bank erosion (Gellis and Gorman-Sanisaca 2018). We discuss the importance of bed and bank sediment sources in the section below on Water/sediment routing and instream processes, while this section focuses exclusively on overland sediment sources. The models used to simulate soil erosion can be divided into empirical and physically based models, depending on the degree of sophistication used for recreating detachment and transport processes (Table 3). There is also significant diversity with respect to sediment particle-size class or soil types considered in conjunction with the simulated watershed processes (Supplementary data, Table $\mathrm{S3}^{2}$ ). Additionally, the fidelity of the spatial characterization of soil erosion can vary depending on the granularity of landscape discretization considered, such as drainage density and related hydrological connectivity (Hession et al. 1996; Gonzalez et al. 2016). Models that can reproduce BMPs as spatial objects, instead of spatially disconnected HRUs, could be expected to provide better spatial characterizations of soil erosion processes, if properly supported by refined site-specific spatial information (Jetten et al. 2003).

SWMM encompasses a data-oriented approach based merely on surface runoff and fixed or event-mean concentrations. The model provides three simple options for wash-off estimation; namely, the exponential relationship, the rating-curve approach, and event-mean concentration wash-off, which reflect different assumptions of the relationship between wash-off and overland flow rate. In doing so, SWMM is mainly used to represent sediment transport patterns in urban catchments, as the spatiotemporal variability of erosive sediment concentrations is relatively high in agricultural watersheds. AnnAGNPS, APEX, GWLF-E, and SWAT are based on the empirical Universal Soil Loss Equation (USLE) approach, which was developed by the USDA in the 1970s to predict long-term sheet and rill erosion under different rainfall conditions, soil types, management practices, and topography (Benavidez et al. 2018). GWLF-E uses the original USLE model, 
where the annual average soil loss in USLE $(A)$ displays a linear relationship with the rainfall erosivity $(R)$, soil erodibility $(K)$, topography factor determined by field slope length and steepness (LS), cover management $(C)$, and supporting practice $(P)$ (Wischmeier and Smith 1978). The annual soil erosion estimates obtained with the original USLE formula do not account for the broader influence of rainfall duration and intensity over the magnitude of soil erosion. USLE was therefore updated to the computerized RUSLE1 model in which the original USLE mathematical operations were maintained, but the estimates of many factors involved were improved based on additional research, experiments, and data collection (Renard et al. 1997; Stone 2015). For instance, the $K$ factor is expressed as a timevarying parameter to address the seasonality of soil erodibility due to freeze-thaw and soil moisture; the LS factor reflects the ratio of rill to inter-rill erosion and also captures the variations in slope shapes; the P factor considers the amount and location of deposition in conservation planning (Renard 1991). Further enhancement of the RUSLE1 model led to the development of RUSLE2, which is a computer program that incorporates different mathematical integrations from USLE and RUSLE1. Whereas USLE and RUSLE1 are based on the product of average annual values for all of the aforementioned factors, RUSLE2 initially computes the products of daily factor values and then sums up the estimated daily erosion values to yield the annual erosion prediction (Foster et al. 2003). According to Foster et al. (2003), this simple difference in the underlying calculations may result in up to $20 \%$ variation in the average annual erosion estimates between RUSLE2 and the USLE or RUSLE1 methods. Another drawback of USLE and RUSLE1 is the inability to directly estimate runoff, because rainfall and runoff factors are estimated based on an erosion index. Consequently, the USLE and RUSLE1 models cannot be used to simulate event-based, soil-loss responses. AnnAGNPS adopts the refined RUSLE 1 and 2 approaches, along with the additional hydrogeomorphic USLE (HUSLE) model (Theurer and Clarke 1991). HUSLE is required to determine the delivery ratio of sheet and rill erosion of each cell to the receiving reach, because RUSLE only provides erosion estimates and not field deposition estimates (Bingner et al. 2018). MUSLE is a modified form of USLE used in APEX and SWAT to predict sediment yield by replacing the rainfall factor R in USLE with a runoff factor (Sadeghi et al. 2014), thereby allowing for the consideration of antecedent soil water content and predictions of sediment losses driven by storm events. Despite its ability to estimate individual storm erosions and work at large spatial scales, some studies have noted that MUSLE still tends to underestimate sediment yields for large events (Kale and Vadsola 2012; Sadeghi et al. 2014). By comparison with USLE, RUSLE and MUSLE are more reliable at explicitly accounting for the temporal variability in sediment erosion with higher resolution. However, RUSLE2 is currently the most recommended soil-loss equation, and can provide robust estimates of average annual sheet and rill erosion across different land uses/covers, as well as soil and climate conditions (Foster et al. 2003; Dabney et al. 2011).

In addition to sediment erosion, SWAT considers sediment loading from lateral and groundwater flows to the main stream channel; however, similar to SWMM, SWAT requires measured data of inflowing sediment concentrations, and so does DLBRM, which lacks any mechanistic foundation. DWSM, HBV-INCA, HSPF, HYPE, and MIKE SHE explicitly consider the sediment detachment and erosion/removal processes. The foundational concept of these five physically based models is that the transport of detached particles is largely driven by overland flow. MIKE SHE and DWSM use a mass-balance equation for dynamic simulation of soil erosion, whereby sediment mass at a specific point and time is computed using the runoff rate and sediment concentration in the flowing water. MIKE SHE also accommodates explicit inter-rill and rillflow simulations (Morgan et al. 1999). The dynamic mass-balance equation of DWSM and MIKE SHE is calculated with a numerical solution. In contrast to the complex 2D dynamic simulations with DWSM and MIKE SHE, sediment transport in HSPF, HYPE, and INCA is calculated by a much simpler nonlinear equation. HYPE deals separately with the effects of rainfall energy and surface runoff on soil detachment, and the delivery into streams involves a transport factor.

Generally speaking, the application of more complex and physically based sediment-erosion models should be accompanied by more detailed spatial information to calibrate and validate different contributing processes and to control uncertainty in model parameters (Jetten et al. 2003). The practice of training watershed models through a "judicious fiddling" of multiple sediment sources and sinks against sediment loads at a single gauging station has been criticized (Arnold et al. 2015). This practice could, in principle, lead to satisfactory model performance by overpredicting upland erosion and underpredicting channel erosion, which would ultimately compromise our ability to evaluate the efficiency of soil conservation measures. In the same context, Arnold et al. (2015) recommended multicriteria calibration and validation of sediment budgets with additional soft data, such as core dating, extrapolation of data from neighboring locations, consideration of LIDAR mapping to estimate soil erosion rates, analysis of aerial photographs for active erosion, and sediment transport processes.

\section{Nutrient cycles}

Changes in land uses and intensity of agricultural practices can induce significant changes to the fate and transport of nutrients and pollutants (e.g., pesticides) within a watershed context (Fig. 6). Carbon $(C)$ is the main elemental constituent of living matter generated by autotrophic photosynthesis and consumed by heterotrophic organisms. Carbon can be found in the soil as both organic (living or dead) or inorganic (carbon dioxide and bicarbonates attached to clay-size particles) forms. Nitrogen $(\mathrm{N})$ and phosphorus (P) are two important macronutrients for the growth of primary producers. Both nutrients exist in the soil as organic and inorganic forms either associated with humus, held by soil colloids or dissolved in pore water. These nutrients can be introduced by fertilizers, manure, or plant residues, and may be subject to a multitude of biogeochemical processes. They are lost from soil surface to streams and subsurface waters through runoff and leaching, respectively. Soluble inorganic forms of nutrients $\left(\mathrm{NO}_{3}^{-}, \mathrm{NH}_{4}^{+}\right.$, and $\mathrm{PO}_{4}^{-3}$ ) may be removed from the soil through plant uptake. Plant residues in turn may decompose and contribute to the organic pool of soil nutrients (Chapin et al. 2011). Microbial activity could convert the organic nutrient pools to bioavailable inorganic forms through mineralization, or transform inorganic nutrients back to organic forms through immobilization. The rates of these microbial activities are regulated by several environmental factors, such as soil moisture, temperature, $\mathrm{pH}$, cation-exchange capacity of soils, available nutrient levels, and stoichiometry (C:N and C:P ratios). Phosphorus and nitrogen compounds can also be deposited onto the land/water surface through adsorption to inorganic minerals in the rainfall and through direct adsorption of the nutrient compounds to plants, soil particles, rocks, and water molecules on the land surface.

The following three subsections provide the modelling strategies used to simulate $\mathrm{C}, \mathrm{N}$, and $\mathrm{P}$ cycles in the reviewed watershed models. Generally, the models can be categorized into two types in regards to the representation of nutrient fate and transport: (i) process-based models with explicit nutrient biogeochemical cycles, and (ii) runoff - mass-transport models. The former type includes AnnAGNPS, APEX, HSPF, HYPE, and SWAT, which follow the soil organic matter (SOM) concept to simulate the cycling of nutrients (e.g., Neitsch et al. 2011; Bingner et al. 2018). The SOM approach subdivides the soil organic matter into multiple pools (or distinctive compartments) at different decomposition stages. These pools include: $(i)$ the fresh organic matter newly added to the soil that contains plant tissue residues and animal excreta (labile or active); (ii) organic residues that can be partially 
Fig. 6. Major processes on the carbon, nitrogen, and phosphorus cycles (decomposition, humification, mineralization, immobilization, soil respiration, adsorption, plant uptake, volatilization, leaching, runoff) typically characterized by the semi-distributed watershed models in clusters 2, 3, and 4 (see Fig. 2).

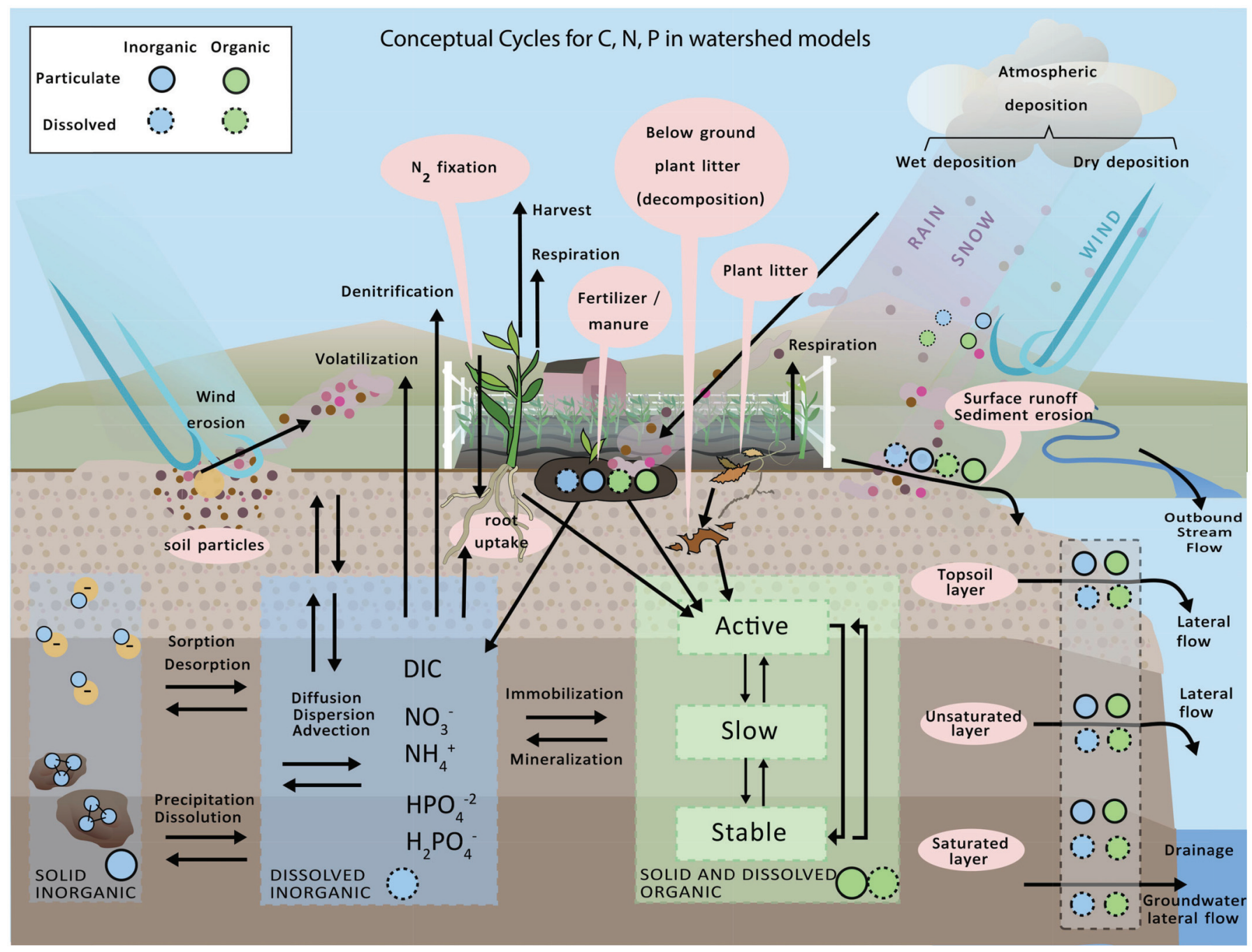

decomposed (slow); and (iii) humus, the most stable soil organic matter (passive), which is subject to extremely slow decomposition rates (Osman 2013). Nutrient transformations involve exchange among the nutrient pools contained within the individual SOM compartments. Thus, the turnover rate of organic soil nutrients is closely linked to the characteristics of individual SOM types, which in turn is a critical, and often overlooked, factor in our efforts to recreate soil nutrient dynamics and subsequently determine the best strategies to alleviate the environmental impact of agricultural practices (Abrahamsen and Hansen 2000; Neitsch et al. 2011; Williams et al. 2015; Bingner et al. 2018). Strictly speaking, HSPF does not follow the SOM conceptualization but rather assigns differential kinetics to prespecified nutrient pools (Bicknell et al. 1996; Lindström et al. 2010), and was thus categorized as a SOM-based model for the purpose of this review. The latter type, categorized as runoff - mass-transport models, includes DLBRM, DWSM, GWLF-E, MIKE SHE, and SWMM, which simulate the generation of nutrient loads primarily as a function of transport with surface and subsurface runoff, and also consider adsorption/desorption to soil particles (Borah et al. 1999; Croley and He 2005; Croley et al. 2005). INCA generally follows the latter type by partitioning the nutrient pools into solid and dissolved phases. Unlike the other runoff mass-transport model, independently developed INCAs for individual nutrient element (i.e., INCA-C, INCA-N, and INCA-P) simulate both organic and inorganic forms and associated biological/chemical transformations (i.e., mineralization). INCA-P further partitions the organic $\mathrm{P}$ into two pools (labile and inactive $\mathrm{P}$ ) with different turnover rates (Jackson-Blake et al. 2016). Although MIKE SHE is a physically based runoff model originally developed to characterize transport of nonreactive constituents (DHI 2017a), it can be coupled with an add-on module (DAISY) that simulates $\mathrm{C}$ and $\mathrm{N}$ cycling within the crop-root zone sequentially to the hydrological component (Thirup et al. 2014), and therefore the following description will be based on that module.

\section{Carbon cycle}

Soil is the most stable reservoir for carbon, and changes in land use and agricultural production intensity can significantly influence the degree of carbon sequestration, which in turn can contribute to the variability of atmospheric carbon levels $\left(\mathrm{CO}_{2}\right)$. The presence of organic $C$ in soil may also affect nutrient availability (Haynes 2005). The nutrient stoichiometry (C:N and C:P) of microbial biomass is also known to determine the demand for mineralization (Sinsabaugh et al. 2008), thereby regulating the production rate of transformed material. The organic $\mathrm{C}$ fraction also affects the physical properties of soils (e.g., soil aggregation) and thus their 
Table 4. Representation of the soil C cycle with the current generation of watershed models.

\begin{tabular}{|c|c|c|c|c|}
\hline Model & Phases & Processes & Sources to soil & Loss pathways \\
\hline AnnAGNPS & $\begin{array}{l}\text { Organic pool: } \\
\text { - } \text { Plant residue } \\
\text { - Soil }\end{array}$ & $\begin{array}{l}\text { Decomposition, humification, } \\
\text { sediment sorption, decay } \\
\text { through soil layer by transport }\end{array}$ & $\begin{array}{l}\text { Plant residues, fertilizer/ } \\
\text { manure }\end{array}$ & $\begin{array}{l}\text { Humification, sediment } \\
\text { erosion, soil respiration }{ }^{a} \text {, } \\
\text { transport decay }\end{array}$ \\
\hline APEX & $\begin{array}{l}\text { Organic pool: } \\
\text { - } \text { Metabolic and } \\
\text { structural residue } \\
\text { - } \text { Active } \\
\text { - Slow } \\
\text { - } \text { Passive }\end{array}$ & $\begin{array}{l}\text { Decomposition, humification, } \\
\text { mineralization/immobilization }{ }^{b} \text {, } \\
\text { sediment sorption, leaching }\end{array}$ & $\begin{array}{l}\text { Plant and roots residues (above } \\
\text { and below ground), manure }\end{array}$ & $\begin{array}{l}\text { Soil respiration }{ }^{c} \text {, manure } \\
\text { erosion, leaching }\end{array}$ \\
\hline HYPE & $\begin{array}{l}\text { Organic pool: } \\
\text { - Fast } \\
\text { - Slow (humus) } \\
\text { - Dissolved }\end{array}$ & $\begin{array}{l}\text { Decomposition, mineralization } \\
\text { (degradation)/immobilization, } \\
\text { humification, leaching }\end{array}$ & Plant residues & $\begin{array}{l}\text { Surface runoff, interflow/ } \\
\text { return flow }\end{array}$ \\
\hline INCA-C & $\begin{array}{l}\text { Organic pool: } \\
\text { - Soil } \\
\text { - Dissolved } \\
\text { Inorganic pool: } \\
\text { - Dissolved }\end{array}$ & $\begin{array}{l}\text { Decomposition, mineralization, } \\
\text { soil respiration (volatilization), } \\
\text { leaching }\end{array}$ & $\begin{array}{l}\text { Litter fall (aboveground), roots } \\
\text { (belowground) as adsorbed } \\
\text { organic C only }\end{array}$ & $\begin{array}{l}\text { Surface runoff, soil respiration, } \\
\text { interflow (diffuse runoff) }\end{array}$ \\
\hline MIKE SHE ${ }^{d}$ & $\begin{array}{l}\text { Organic pool: } \\
\text { - Crop } \\
\text { - Plant residue } \\
\text { - Microbial } \\
\text { - Humus }\end{array}$ & $\begin{array}{l}\text { Decomposition, humification, } \\
\text { plant and soil respiration, } \\
\text { immobilization }\end{array}$ & $\begin{array}{l}\text { Photosynthesis (crop C), } \\
\text { fertilizer/manure }\end{array}$ & $\begin{array}{l}\text { Crop } C \text { harvest, plant and soil } \\
\text { respiration }\end{array}$ \\
\hline SWAT & $\begin{array}{l}\text { Organic pool: } \\
\text { - Plant residue } \\
\text { - Manure } \\
\text { - Soil }\end{array}$ & $\begin{array}{l}\text { Decomposition, humification, } \\
\text { mineralization }\end{array}$ & $\begin{array}{l}\text { Plant residues, fertilizer/ } \\
\text { manure }\end{array}$ & Mineralization \\
\hline
\end{tabular}

\footnotetext{
Note: See Table 1 for details of the abbreviations

${ }^{a}$ Soil respiration is assumed to be responsible for $50 \%$ of the losses of decomposed C.

${ }^{b}$ Conceptual mineralization/immobilization rate calculated based on $\mathrm{N}$ demand, as derived from the $\mathrm{N}$ content in the organic pool for a given soil mineral $\mathrm{N}$ availability.

${ }^{c}$ Constant soil respiration allocation to $\mathrm{CO}_{2}$ is assigned to various soil organic pools.

${ }^{d} \mathrm{C}$ cycle for MIKE SHE is based on the description of the add-on module DAISY (model for simulation of water and nitrogen dynamics and crop growth in agroecosystems). MIKE SHE-DAISY follows the SOM model with two soil organic matter pools (structural and metabolic) with different turnover rates.
}

bulk density and water retention (Ramesh et al. 2019). Consequently, understanding the mechanisms of $\mathrm{C}$ cycling has broader implications for the accurate representation of water balance, $\mathrm{N}$ and $\mathrm{P}$ cycling, and ultimately for the assessment of different management strategies.

Despite the significant role of organic $C$ in soil, there are only five SOM-based watershed models that can simulate the $C$ cycle: AnnAGNPS, APEX, HYPE, SWAT, and an add-on module (DAISY) available for MIKE SHE and INCA-C (Table 4), whereas HSPF uses the SOM-based compartmentalization for organic $\mathrm{N}$ and $\mathrm{P}$ pools (e.g., labile and refractory) but does not explicitly simulate the soil $\mathrm{C}$ cycle. Generally, the aforementioned watershed models have three pools for organic C: (i) active (plant residue/manure); (ii) slow; and (iii) passive/stable fractions associated with humus (e.g., Williams et al. 2015). APEX further splits plant residues/ manure into two types depending on the structure of organic biomass: metabolic (or easily decomposable) and structural litter in which the lignin fraction determines the transformation rate of organic C (Abrahamsen and Hansen 2000; Williams et al. 2015). By contrast, AnnAGNPS and SWAT aggregate the slow and passive pools of organic $C$, and explicitly treat the newly added plant residue/manure C (Neitsch et al. 2011; Bingner et al. 2018). There is also significant variation in the representation of transformation and transport processes among these models, depending on how organic $C$ pools are considered (Table 4). For example, although both AnnAGNPS and SWAT consider a three-pool compartmentalization, distinguishing among plant residues, fertilizers/ manure, and organic soil $\mathrm{C}$, the definition of the latter pool is slightly different between the two models. AnnAGNPS represents the soil organic C as "active humus", which is subject to losses through humification as well as through runoff of organic C attached to clay particles in the top-soil layer (Bingner et al. 2018). By contrast, SWAT treats the soil organic C pool as "passive" humus, which receives an amount of decomposed plant residues (or fertilizers/manure) through humification, and a userspecified $C$ fraction is permanently lost by immobilization (Neitsch et al. 2011). HYPE is one of the two models (along with INCA-C) that simulate both solid (fast or slow) and soluble organic $C$ phases along with the associated transformation processes (Lindström et al. 2010). C transformations are represented by decomposition, mineralization/immobilization, and humification (SMHI 2019). This approach simulates the loss of organic $C$ by both surface runoff and percolation through the soil layers and allows the estimation of the contribution of organic C to groundwater flow (SMHI 2019).

Mechanistic descriptions of microbial transformations of organic C, such as decomposition, mineralization, and humification, are typically represented as first-order kinetics with environmental correction factors due to the prevailing soil temperature and moisture conditions as a combined, multiplicative effect (e.g., Abrahamsen and Hansen 2000; Neitsch et al. 2011). Some models 
Table 5. Representation of the soil $\mathrm{N}$ cycle with the current generation of watershed models.

\begin{tabular}{|c|c|c|c|c|}
\hline Model & Phases & Processes & Sources to soil & Loss pathways \\
\hline AnnAGNPS & $\begin{array}{l}\text { Organic pool: } \\
\text { Plant residue } \\
\text { - Soil } \\
\text { Inorganic pool: } \\
\text { - Nitrate }\end{array}$ & $\begin{array}{l}\text { Decomposition, humification, sediment } \\
\text { adsorption }\left(N_{\text {org }}\right) \text {, denitrification, plant uptake, } \\
\text { leaching }\end{array}$ & Plant residue, fertilizer/manure & $\begin{array}{l}\text { Plant uptake, humification, soil } \\
\text { erosion, surface runoff, } \\
\text { interflow, tile drainage flow }\end{array}$ \\
\hline APEX & $\begin{array}{l}\text { Organic pool: } \\
\text { - Metabolic and structural plant } \\
\text { residue } \\
\text { - Active } \\
\text { - Slow } \\
\text { - Passive } \\
\text { Inorganic pool: } \\
\text { - } \text { Nitrate, ammonium }\end{array}$ & $\begin{array}{l}\text { Feedback of plant } \mathrm{N} \text { to soil } \mathrm{N}_{\text {org }} \text {, mineral sorption } \\
\text { to plant residue } \mathrm{N}_{\text {org, }} \text {, decomposition, } \\
\text { humification, mineralization/immobilization } \\
\text { nitrification, denitrification, volatilization, } \\
\text { sediment adsorption }\left(\mathrm{N}_{\text {org }}\right) \text {, plant uptake, } \mathrm{N}_{2^{-}} \\
\text {fixation, upward movement by soil moisture } \\
\text { evaporation }\left(\mathrm{NO}_{3}^{-}\right) \text {, leaching }\end{array}$ & $\begin{array}{l}\text { Plant residues, roots (above- and below- } \\
\text { ground), } \mathrm{N}_{2} \text {-fixation, fertilizer/manure, } \\
\text { wet atmospheric deposition }\end{array}$ & $\begin{array}{l}\text { Crop harvest, denitrification, } \\
\text { volatilization, soil erosion, } \\
\text { surface runoff, interflow, return } \\
\text { flow, deep groundwater recharge, } \\
\text { manure erosion, tile drainage }\end{array}$ \\
\hline HSPF & $\begin{array}{l}\text { Organic pool: } \\
\text { - Plant (above and below ground) } \\
\text { - Litter } \\
\text { - Labile and refractory (adsorbed/ } \\
\quad \text { dissolved) } \\
\text { Inorganic pool: } \\
\text { - Nitrate, ammonium }\end{array}$ & $\begin{array}{l}\text { Feedback of plant } \mathrm{N} \text { to soil } \mathrm{N}_{\text {org }} \text {, decomposition, } \\
\text { mineralization, sorption/desorption (labile and } \\
\text { refractory } \mathrm{N}_{\text {org }}, \mathrm{NH}_{4}^{+} \text {), immobilization, } \\
\text { nitrification, denitrification, volatilization, } \\
\text { plant uptake, } \mathrm{N}_{2} \text {-fixation, leaching }\end{array}$ & $\begin{array}{l}\text { Two options: } \\
\text { 1. User defined input to the storage } \\
\text { variables in surface and upper soil } \\
\text { layers } \\
\text { 2. Dry and wet atmospheric deposition, } \\
\text { fertilizer/manure }\end{array}$ & $\begin{array}{l}\text { Plant harvest, denitrification, } \\
\text { volatilization, soil erosion, } \\
\text { surface runoff, interflow, return } \\
\text { flow, deep groundwater } \\
\text { recharge }\end{array}$ \\
\hline HYPE & $\begin{array}{l}\text { Organic pool: } \\
\text { - Fast } \\
\text { - Slow (humus) } \\
\text { - Dissolved } \\
\text { Inorganic pool: } \\
\text { - Dissolved }\end{array}$ & $\begin{array}{l}\text { Decomposition (dissolution), mineralization, } \\
\text { plant uptake, denitrification, decay through soil } \\
\text { layers }\left(N_{\text {org }}\right) \text {, leaching }\end{array}$ & $\begin{array}{l}\text { Plant residues, dry and wet atmospheric } \\
\text { deposition, fertilizer/manure, rural } \\
\text { household load }\end{array}$ & $\begin{array}{l}\text { Plant uptake, denitrification, } \\
\text { surface runoff, interflow, tile } \\
\text { drainage flow }\end{array}$ \\
\hline INCA-N & $\frac{\text { Inorganic pool: }}{\text { - Nitrate, ammonium }}$ & $\begin{array}{l}\text { Mineralization (forcing), immobilization, plant } \\
\text { uptake, nitrification, denitrification, } \mathrm{N}_{2} \text {-fixation } \\
\text { (forcing), leaching }\end{array}$ & $\begin{array}{l}\text { Organic } \mathrm{N} \text { (unlimited), } \mathrm{N}_{2} \text {-fixation, } \\
\text { fertilizer/manure, dry and wet } \\
\text { atmospheric deposition }\end{array}$ & $\begin{array}{l}\text { Plant uptake, denitrification, } \\
\text { surface runoff, return flow, deep } \\
\text { groundwater recharge }\end{array}$ \\
\hline MIKE SHE ${ }^{b}$ & $\begin{array}{l}\text { Organic pool: } \\
\text { - Crop } \\
\text { - Plant residue } \\
\text { - Microbial } \\
\text { - Humus } \\
\text { Inorganic pool: } \\
\text { - Nitrate, ammonium }\end{array}$ & $\begin{array}{l}\text { Feedback of crop } \mathrm{N} \text { to soil } \mathrm{N}_{\text {org }} \text { Decomposition, } \\
\text { mineralization (ammonification), immobilization, } \\
\text { plant uptake, nitrification, denitrification, } \\
\text { sorption/desorption }\left(\mathrm{NH}_{4}^{+}\right) \text {, leaching }\end{array}$ & $\begin{array}{l}\text { Plant residues, fertilizer, dry and wet } \\
\text { atmospheric deposition }\end{array}$ & $\begin{array}{l}\text { Crop harvest, denitrification, } \\
\text { leaching }\end{array}$ \\
\hline
\end{tabular}




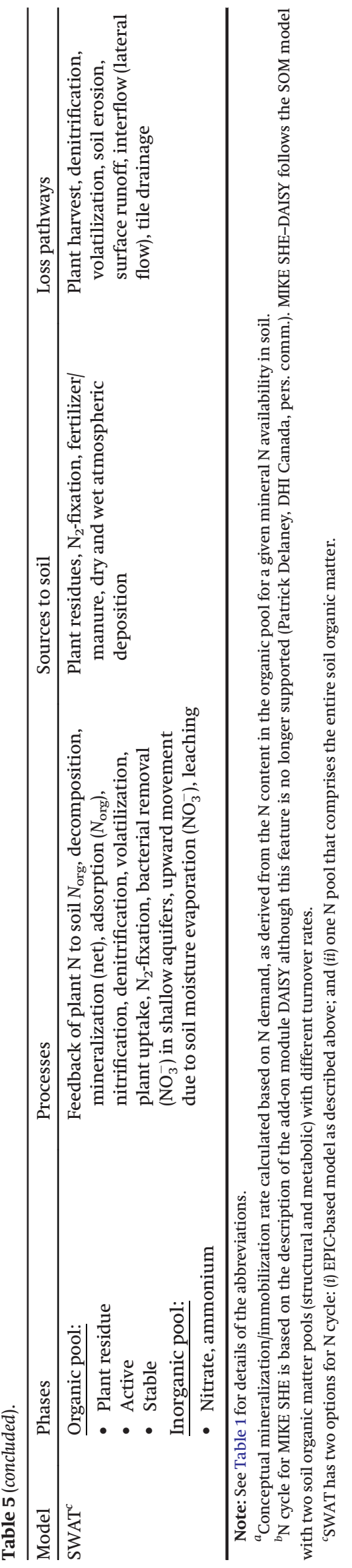

include additional factors to accommodate the impact of agricultural operations and land-use types. For example, lower soil temperatures and moisture levels may reduce the degree of decomposition, whereas an increased oxygen level due to cultivation and tillage could instead increase the microbial transformation rates. APEX and SWAT consider the combined effect of aeration, soil temperature, and moisture to assess the effects of agricultural practices on nutrient cycles (Neitsch et al. 2011; Williams et al. 2015). Decomposition rates of plant residues in AnnAGNPS are separately specified for "crop land" and "non-crop land" (Bingner et al. 2018). While plant residues in non-crop land are assumed to be decomposed all year round, except when soil temperature falls below $0{ }^{\circ} \mathrm{C}$, the decomposition of crop residues in the top-soil layer may not be considered if they are removed from crop harvest (Bingner et al. 2018). In AnnAGNPS, it is also assumed that $50 \%$ of $\mathrm{C}$ is lost as gas $\left(\mathrm{CO}_{2}\right)$ to the atmosphere during the decomposition process (Bingner et al. 2018).

One of the critical differences among the SOM-based watershed models is the characterization of nitrogen and phosphorus demand during the biological transformations. That is, the rate of microbial mineralization is regulated by the stoichiometry $(\mathrm{C}$ : $\mathrm{N}$ and C:P ratios) of crop residues or decomposing organic matter. If the organic matter contains enough $\mathrm{N}$ (i.e., low $\mathrm{C}: \mathrm{N}$ ratio), then the decomposition to simpler C compounds, such as glucose, will be solely regulated by $\mathrm{N}$ contained in the plant residues to meet the bacterial growth demand. On the other hand, if the $\mathrm{N}$ content in the organic material does not meet the bacterial demands (i.e., high C: $\mathrm{N}$ ratio), then bacteria can use the available $\mathrm{N}$ in the soil layer. MIKE SHE-DAISY is based on this simple concept, stipulating a constant $\mathrm{C}: \mathrm{N}$ ratio for the fresh organic matter pool, i.e., plant residues or manure (Abrahamsen and Hansen 2000). AnnAGNPS and SWAT use daily updated C:N ratios based on the predicted C- and $\mathrm{N}$-concentrations within each soil layer. Whereas AnnAGNPS postulates that the mineralization rate of $C$ is proportional to that of $\mathrm{N}$ (see the section on Nitrogen cycle) according to the computed soil C:N ratio (Bingner et al. 2018), SWAT introduces a limitation formula, assessing the relative deviation from a threshold $\mathrm{C}: \mathrm{N}$ ratio (Neitsch et al. 2011). APEX estimates the "potential" $\mathrm{N}$ demand for the $\mathrm{C}$ transformation processes among the organic matter pools considered, as the product of the corresponding "potential" reaction rate with the organic $C$ content, the lignin fraction, and $\mathrm{N}: \mathrm{C}$ ratio of the transformed substrate (Williams et al. 2015). The latter ratio is expressed as a linear function of the nitrogen content in the general decomposing material. The "potential" transformation rates are further regulated by soil temperature, moisture, oxygen, tillage effects, and are only realized when the $\mathrm{N}$ supply of the source pool exceeds the demand in the receiving compartment material (Williams et al. 2015). The biological transformation rates in HYPE are expressed as a function of the nutrient concentration in the individual pool and the effects of soil temperature and moisture, whereas the stoichiometry is not a limiting factor. A major challenge of the SOM-based strategy is that the typical fractionation measurements do not match the physicochemical characteristics used for the compartmentalization of organic matter in models (Campbell and Paustian 2015). Thus, notwithstanding the conceptual advantages of linking the various organic matter fractions with specific mechanisms affecting soil nutrient dynamics, there are tradeoffs between the degree of simplification (to avoid overparameterization) and the actual attributes of organic matter (Campbell and Paustian 2015). Selection of the suitable model may be largely influenced by the type and available data.

Generally, the reviewed models consider C losses from each soil layer through organic $C$ export as suspended sediments, and (or) dissolved organic/inorganic $C$ with flowing water (Futter et al. 2007; Williams et al. 2015; Bingner et al. 2018). AnnAGNPS estimates the total organic $C$ loss from a given soil layer as the product of the fraction of $C$ attached to clay size sediments and the mass of eroded sediments from that layer within a given point in time. 
Then, the attached organic $\mathrm{C}$ lost to the reaches is determined by the amount of eroded clay in the modelled unit, travel time, and half-life due to the collective effect of decay processes (Bingner et al. 2018). Counter to the majority of the runoff - mass-transport models (DLBRM, DWSM, GWLF-E, and SWMM) that do not simulate soil C cycle (Table 4), INCA-C simulates the fate and transport of surface and within-soil $C$ to examine the impact of different land-cover types and hydrological flows (Futter et al. 2007). Similar to HYPE, INCA-C considers both solid- and dissolved-phase $C$ contained in three pools: solid-organic C (SOC); dissolved-organic C (DOC); and dissolved-inorganic $\mathrm{C}$ (DIC). Owing to the consideration of dissolved-phase $C$, INCA-C can also recreate the vertical soil $C$ distribution. Organic $C$ is added as SOC through the litterfall to the upper-soil layer, as well as through the death of microorganisms or the decomposition of below-ground (e.g., roots, plant tissues) organic C (Futter et al. 2007). In the lower soil, the main supply mechanism is the SOC decomposition to DOC. DIC can be lost from the upper-soil layer through soil respiration (i.e., DIC transformation to $\mathrm{CO}_{2}$ ). One of the features of INCA-C is the capacity to characterize the sources and sinks of organic $C$ in peat, forest soils, and streams (Futter et al. 2007). Although the nutrient processes specific to wetlands and (or) riparian zone are available in some of the SOM-based models such as AnnAGNPS, HYPE, and SWAT, the parsimonious INCA-C makes it easier to constrain model parameters with the typically available data (Futter et al. 2007).

\section{Nitrogen cycle}

Nitrogen is a critical element for plant growth and has the most complex transport and transformation processes of all the mineral elements in agricultural soils (Follett and Hatfield 2001). Generally, watershed models that explicitly describe the nitrogen cycle (AnnAGNPS, APEX, HSPF, HYPE, MIKE SHE-DAISY, and SWAT) consider both organic and inorganic $\mathrm{N}$ pools in soils (and in some cases) subsurface and in-stream waters (Table 5). Similar to the soil $\mathrm{C}$ cycle, each $\mathrm{N}$ pool is compartmentalized according to the SOM conceptualization. Various $\mathrm{N}$ pools are identified depending on the source (soil, plant residues, manure/fertilizer), $\mathrm{N}$ form $\left(\mathrm{NH}_{4}^{+}\right.$and $\left.\mathrm{NO}_{3}^{-}\right)$, solubility (dissolved and particulate), turnover rates (slow and fast), solubility, transportability (uptake) from the plants, and chemical (active, labile, and refractory) characteristics (Lindström et al. 2010). The most complex $\mathrm{N}$ models generally consider two inorganic nitrogen forms $\left(\mathrm{NH}_{4}^{+}\right.$and $\left.\mathrm{NO}_{3}^{-}\right)$in each soil layer, and three pools of organic matter: fresh organic $\mathrm{N}$ associated with crop residue/manure (active organic $\mathrm{N}$ ), and two additional organic $\mathrm{N}$ pools that differ with respect to their turnover rates (slow and passive/stable organic N) (Neitsch et al. 2011; Bingner et al. 2018). AnnAGNPS and HYPE only consider one aggregated inorganic $\mathrm{N}$ pool. Similar to the $\mathrm{C}$ cycle, there is some variability in the compartmentalization of the organic $\mathrm{N}$ pools among the models. While AnnAGNPS uses a general approach that simulates a lumped soil organic matter $\mathrm{N}$ pool within each soil layer along with plant residue and manure/fertilizers (fresh organic $\mathrm{N}$ ) in the topsoil (Bingner et al. 2018), SWAT has two options to simulate soil N: one organic $\mathrm{N}$ pool like AnnAGNPS, and a multipool that splits humic soil $\mathrm{N}$ into active and stable fractions (Neitsch et al. 2011). APEX includes two additional compartments for the plantresidue $\mathrm{N}$ based on their lignin contents (i.e., metabolic and structural). HSPF does not consider the soil C cycle, but does simulate the $\mathrm{N}$ cycle using the one of the most complex compartmentalizations, which separates the plant-residue $\mathrm{N}$ into three pools; above-ground, litter, and below-ground plant residues (Bicknell et al. 1996). HSPF also considers both particulate and dissolved forms of labile and refractory organic $\mathrm{N}$ in the soil particles and pore-waters, respectively. HYPE considers fast-turnover and humic organic $\mathrm{N}$ with different turnover rates (Lindström et al. 2010), and plant residues are treated as external inputs to the soil surface (SMHI 2019). INCA-N explicitly simulates inorganic $\mathrm{N}\left(\mathrm{NH}_{4}^{+}\right.$and $\left.\mathrm{NO}_{3}^{-}\right)$, while the organic $\mathrm{N}$ pool is assumed to be an unlimited source subject to mineralization (Wade et al. 2002a; Rankinen et al. 2013). Both fertilizer and manure applications can supply the organic and inorganic $\mathrm{N}$ pools, while atmospheric dry and wet deposition are sources of inorganic N (Bicknell et al. 1996; Abrahamsen and Hansen 2000; Lindström et al. 2010; Neitsch et al. 2011). HYPE also considers the potential diffuse source from rural households, whereby a fraction of inorganic $\mathrm{N}$ contributes directly to nearby surface waters and to bottom-soil layers in the catchment (SMHI 2019).

Transformations of organic $\mathrm{N}$ within soil layers described in SOM-based models (AnnAGNPS, APEX, HSPF, HYPE, MIKE SHEDAISY, and SWAT) include processes associated with the decomposition of plant-residue $\mathrm{N}$, mineralization of organic $\mathrm{N}$, and immobilization of inorganic to organic N (Table 5). Similar to what is described in the section on Carbon cycle, the biogeochemical processes with $\mathrm{N}$ pools are characterized by different turnover rates, as modulated by soil temperature and moisture. These models may thus be more sensitive to changes in environmental conditions and could provide more defensible predictions under future climate change scenarios. Decomposition/mineralization algorithms are often referred to as "net mineralization", in that they also account for the microbial immobilization of plantavailable inorganic soil $\mathrm{N}$ to plant-unavailable organic $\mathrm{N}$. SWAT further differentiates between mineralization modulated by the amount of $\mathrm{N}$ in plant residues and microbial activity, and mineralization in humic soils (humus mineralization), which convert organic $\mathrm{N}$ unavailable for plant uptake into plant-available inorganic N (e.g., Neitsch et al. 2011; Bingner et al. 2018). The mineralization of $\mathrm{N}$ from plant residue, described in SWAT, is similar to the approach used for organic $C$ (Neitsch et al. 2011) and is regulated by the $\mathrm{N}$ demand for microbial activity relative to the $\mathrm{N}$ supply of the receiving pool in the soil (see contrasting C:N ratios in the section on Carbon cycle). APEX also uses a similar approach to $\mathrm{C}$ cycle, in that the $\mathrm{N}$ fluxes among the different $\mathrm{N}$ pools are determined by the $\mathrm{C}: \mathrm{N}$ ratios as well as the soil temperature and moisture (Williams et al. 2015). APEX and HSPF offer two of the most complex compartmentalizations for organic N; APEX postulates a more conventional characterization distinguishing among structural and metabolic litter, active, slow, and passive N pools, whereas HSPF considers both particulate- and dissolved-organic $\mathrm{N}$ which is partitioned by adsorption-desorption reactions described by equilibrium isotherms (Bicknell et al. 1996). Particulate labile organic $\mathrm{N}$ is subject to mineralization to $\mathrm{NH}_{4}^{+}$, and conversion to particulate refractory $\mathrm{N}$. Along with the transport of particulate organic $\mathrm{N}$ forms, HSPF simulates the loss of the two desorbed (soluble) organic $\mathrm{N}$ forms via surface-runoff transport (Bicknell et al. 1996). Other organic $N$ transformations in HSPF are simulated by first-order kinetics corrected by soil temperature (Bicknell et al. 1996). HYPE also considers the organic $\mathrm{N}$ in soil solution, which is determined by the difference between the available fast $\mathrm{N}$ pools and an equilibrium concentration (Lindström et al. 2010). Only the two aforementioned models consider organic $\mathrm{N}$ in soil-pore water.

Nutrients can be lost from surface soil as dissolved forms through runoff and leaching water, and as particulate forms attached to eroded sediments through surface runoff. Particulate organic $\mathrm{N}$ is primarily attached to clay particles (colloids), and thus the sediment loads typically contain a significant portion of organic N (Neitsch et al. 2011). Based on this assumption, AnnAGNPS estimates the mass of organic $\mathrm{N}$ attached to sediment particles as a function of the soil organic $\mathrm{N}$ concentration, fraction of clay in the total composite soil, and the mass of sediment at the modelled unit (Bingner et al. 2018). AnnAGNPS also accounts for the sediment particle size, which can also be modified by the irrigation practices in the location studied. APEX and SWAT, however, introduce the "enrichment ratio" to determine the fraction of organic $\mathrm{N}$ transported by the suspended sediments (Neitsch et al. 2011; Williams et al. 2015). The enrichment ratio (ER) is defined as the 
concentration of a given nutrient in the eroded sediment relative to that in the soil. While both models base the ER estimates on empirical logarithmic relationships with sediment concentration as described by Menzel (1980), their enrichment - sediment concentration relationships for individual storm events are slightly different. SWAT calculates the ER for each storm event using only the sediment concentration (SED) in surface runoff $\left(\mathrm{ER}=0.78 \cdot \mathrm{SED}^{-0.2468}\right)$, and estimates the loss of organic $\mathrm{N}$ as a function of the ER, the organic $\mathrm{N}$ concentration in the soilsurface layer, and the sediment yield on a given day (Neitsch et al. 2011). APEX considers the upper and lower ER bounds to ensure that the loss of attached organic $\mathrm{N}$ does not exceed the realistic range of sediment loss at given peak runoff event (Williams et al. 2015). HSPF combines two types of organic $\mathrm{N}$ loss associated with wash-off (fine sediment) and scoured material (coarse sediment) using a user-specified potency factor parameter, reflecting how strongly a particular constituent is attached to the eroding sediment and thus the ease that is removed from the surface (Bicknell et al.1996).

Sources of inorganic $\mathrm{N}$ pools are the $\mathrm{N}$ fertilizer/manure and mineralization of organic $\mathrm{N}$, whereas sinks (losses) from the surface soil are the volatilization of $\mathrm{NH}_{4}^{+}$, denitrification of $\mathrm{NO}_{3}^{-}$, and plant uptake of $\mathrm{NO}_{3}^{-}$(Table 5). All of the SOM-based models, except AnnAGNPS, consider atmospheric depositions of inorganic $\mathrm{N}$ pools $\left(\mathrm{NH}_{4}^{+}\right.$and $\left.\mathrm{NO}_{3}{ }^{-}\right)$through rainfall and dry deposition at the soil surface. $\mathrm{NO}_{3}^{-}$on the soil surface is dissolved in the water, and subsequently is either transported by runoff or infiltrates through the soil profile. Ammonia volatilization is the gaseous loss of $\mathrm{NH}_{3}$ that occurs when ammonia fertilizer or urea, $\left(\mathrm{NH}_{2}\right)_{2} \mathrm{CO}$, is applied to calcareous soils. Soil $\mathrm{NH}_{4}^{+}$is also transformed to $\mathrm{NO}_{3}^{-}$ via bacterially mediated oxidation (i.e., nitrification). APEX, HSPF, and SWAT explicitly simulate both transformations of $\mathrm{NH}_{4}^{+}$in the soils, which are also dependent on soil temperature and moisture content. INCA-N calculates the change in N-concentration in the soil pool as a function of drainage and volume of retention water (Wade et al. 2002a). That is, any process that contributes to the change in the mass of both $\mathrm{NO}_{3}^{-}$and $\mathrm{NH}_{4}^{+}$is calculated as the amount of $\mathrm{N}$ relative to the retention water volume and soil at any given time (Wade et al. 2002a). Volatilization is further regulated by the depth and cation-exchange capacity, which can be assigned a constant value in SWAT (Neitsch et al. 2011). APEX and HSPF also require wind-speed data to estimate soil $\mathrm{NH}_{4}^{+}$loss via volatilization (Bicknell et al. 1996; Williams et al. 2015). By contrast, AnnAGNPS simulates the soil content of inorganic $\mathrm{N}\left(\mathrm{NH}_{4}^{+}\right.$and $\left.\mathrm{NO}_{3}^{-}\right)$as a lump sum, and thus it does not account for the loss of $\mathrm{NH}_{4}^{+}$through volatilization, nor for the transformation of $\mathrm{NH}_{4}^{+}$to $\mathrm{NO}_{3}^{-}$(Bingner et al. 2018). Two sink processes of $\mathrm{NO}_{3}^{-}$(denitrification and plant uptake) are considered from all the watershed models with an explicit $\mathrm{N}$ cycle (see above and Table 5). Denitrification is a process mediated by anaerobic bacteria, and is assumed to occur only when moisture levels in the soil are high. For example, the denitrification process in AnnAGNPS is set to be activated when the moisture content of the soil is greater than $90 \%$ of soil porosity, and the rate is defined as a function of soil temperature and organic C content (Bingner et al. 2018). While the mathematical description of denitrification is rather consistent, plant $\mathrm{N}$ uptake can vary among the models with respect to the differential uptake of the various inorganic nitrogen pools. For example, plant uptake in HSPF, INCA-N, and MIKE SHEDAISY use both forms of inorganic nitrogen $\left(\mathrm{NO}_{3}^{-}\right.$and $\mathrm{NH}_{4}^{+}$), whereas other models either consider $\mathrm{NO}_{3}^{-}$or the total inorganic nitrogen content. $\mathrm{NH}_{4}^{+}$is generally considered to be adsorbed to particles in most soil layers, and thus plants preferentially take up $\mathrm{NO}_{3}^{-}$(Thirup et al. 2014), but the difference in the outputs among these models may be negligible. The amount of inorganic $\mathrm{N}$ lost through plant uptake in AnnAGNPS, APEX, MIKE SHE-DAISY, and SWAT is calculated by the nitrogen demand of the plant/crops, estimated as the difference between the optimal mass of nitrogen stored in plant tissues for a given growth stage, soil depth, and the available inorganic N (Abrahamsen and Hansen 2000; Neitsch et al. 2011; Williams et al. 2015; Bingner et al. 2018). By contrast, INCA-N does not consider the above-mentioned regulatory factors of plant uptake, and instead calculates the mass of inorganic $\mathrm{N}$ taken up as a function of the degree of soil moisture saturation and seasonality of plant growth (Wade et al. 2002a). HSPF differentiates the plant uptake between $\mathrm{NO}_{3}^{-}$and $\mathrm{NH}_{4}^{+}$and uses three optional methods: (i) first-order kinetics with temperature-correction factor; (ii) a yield-based algorithm; and (iii) Michaelis-Menten kinetics (Bicknell et al. 1996). The selection of each method determines the response of the model to nutrient management strategies. The yield-based method is less sensitive to soil-nutrient levels and fertilizer/ manure application rates, because the soil moisture conditions can be a significant covariate of the nutrient uptake by plants (Bicknell et al. 1996). Of all the models that consider plant N uptake, APEX, HSPF, MIKE SHE-DAISY, and SWAT calculate the return of plant $\mathrm{N}$ to soil organic pools through decomposition (see the section below on Plant growth: seasonality and succession).

Transport of inorganic $\mathrm{N}$ is generally described as the concentration of inorganic $\mathrm{N}$ in the volume of flowing water in each pathway such as runoff, leaching, and lateral flow (see the sections below on Surface runoff and Subsurface processes). A typical assumption by the majority of models is that the prevalent form of soil inorganic $\mathrm{N}$ in solution is $\mathrm{NO}_{3}^{-}$as the retention (adsorption) of this anion by soil particles is minimal, whereas the transport of $\mathrm{NH}_{4}^{+}$is considered to be negligible, owing to its strong adsorption capacity (Abrahamsen and Hansen 2000; Neitsch et al. 2011; Williams et al. 2015). Loss of $\mathrm{NO}_{3}^{-}$to the subsurface water largely depends on the volume of mobile (percolating) water. For example, AnnAGNPS uses the ratio of percolation loss to excess soil-water content as a weight for quantifying the leaching of inorganic N (Bingner et al. 2018). SWAT estimates the volume of percolating water as a function of the excess soil water relative to the time required to travel through the soil layer (Neitsch et al. 2011), which in turn is multiplied by the predicted concentrations of $\mathrm{NO}_{3}^{-}$in the surface, lateral, and percolation waters to calculate the mass of $\mathrm{NO}_{3}^{-}$carried through the corresponding fluxes. APEX allows for a user-specified ratio between horizontal and vertical concentrations of $\mathrm{NO}_{3}^{-}$, which are then multiplied by the corresponding water flows to derive the associated $\mathrm{NO}_{3}^{-}$fluxes. The vertical flow also transports the inorganic $\mathrm{N}$ to the groundwater storage. Apart from AnnAGNPS, watershed models estimate $\mathrm{N}$ in the saturated soil layer (or groundwater) as the residual of the collective losses through the vertical water transport, multiplied by the corresponding concentrations (Williams et al. 2015). SWAT simulates the transport of $\mathrm{NO}_{3}^{-}$as the net output of recharge from shallow to deep aquifers, transport with groundwater flow into the main channel, or upward movement from shallow aquifers into the soil zone due to water deficiencies (Neitsch et al. 2011). SWAT also assumes that the time delay of aquifer recharge contributes to the delays in the movement of $\mathrm{NO}_{3}^{-}$from the soil profile to aquifers (Neitsch et al. 2011). SWAT also accounts for inorganic $\mathrm{N}$ losses in the shallow aquifers due to biological (bacterial) and chemical (redox-potential) processes by postulating first-order kinetics (Neitsch et al. 2011). Although AnnAGNPS does not have a groundwater component, it does simulate the loss of inorganic $\mathrm{N}$ to subsurface zone by two processes: loss to subsurface drainage system (tile drainage), and loss to subsurface lateral flow. Inorganic $\mathrm{N}$ estimated in HYPE is subject to denitrification in the aquifer, as well as discharge to the main channel.

Among the models that consider $\mathrm{NH}_{4}^{+}$as one of the inorganic $\mathrm{N}$ pools (APEX, HSPF, INCA-N, MIKE SHE-DAISY, and SWAT), only HSPF and MIKE SHE-DAISY provide explicit description of the adsorption/ desorption processes for $\mathrm{NH}_{4}^{+}$. HSPF uses first-order kinetics with temperature-corrected reaction flux, or the Freundlich-isotherm method, which postulates an instantaneous equilibrium among dissolved and adsorbed $\mathrm{NH}_{4}^{+}$(Bicknell et al. 1996). MIKE SHEDAISY also provides the Langmuir isotherm, the linear isotherm, 
Table 6. Representation of the soil P cycle with watershed models.

\begin{tabular}{|c|c|c|c|c|}
\hline Model & Phases & Processes & Sources to soil & Loss pathways \\
\hline AnnAGNPS & $\begin{array}{l}\text { Organic P: } \\
\text { - Fresh } \\
\text { - Humic } \\
\text { Inorganic P: } \\
\text { - SRP (solution) } \\
\text { - Active (uolid) } \\
\text { - Stable (solid) }\end{array}$ & $\begin{array}{l}\text { Decomposition, humification, sorption/ } \\
\text { desorption }\left(P_{\text {inorg }}\right) \text {, plant uptake, leaching } \\
\text { Sorption/desorption: solution } P_{i} \text { with } 3 \text { empirical } \\
\text { PAI }^{a} \text { equations for soil } \mathrm{pH}>7.8^{b}, \mathrm{pH}<5 \text { and } \\
5<\mathrm{pH}<7.8 \\
\text { Slow adsorption rate constant } 0.00076 \text { days }^{-1} \text { for } \\
\text { calcareous soil }(\mathrm{pH}>7.8)^{c}\end{array}$ & Plant residue, fertilizer/manure & $\begin{array}{l}\text { Plant uptake, humification, soil } \\
\text { erosion, surface runoff } \\
\text { Leaching is not considered due to } \\
\text { low mobility }\end{array}$ \\
\hline APEX & $\begin{array}{l}\text { Organic P: } \\
\text { - Fresh } \\
\text { - Active } \\
\text { (microbial) } \\
\text { - Stable } \\
\text { Inorganic P: } \\
\text { - SRP (solution) } \\
\text { - Active (solid) } \\
\text { - Stable (solid) }\end{array}$ & $\begin{array}{l}\text { Decomposition, mineralization, plant uptake, } \\
\text { sorption/desorption, leaching } \\
\text { Sorption/desorption: solution } P_{i} \text { with four } \\
{\text { empirical PAI }{ }^{a} \text { equations for calcareous }}^{b} \text { and } \\
\text { noncalcareous slightly, moderately and highly } \\
\text { weathered soils; Langmuir isotherm for large } \\
\text { soil P-concentrations } \\
\text { Slow adsorption rate constant } 0.0076 \text { days }^{-1} \text { for } \\
\text { calcareous soil }(\mathrm{pH}>7.8)^{c}\end{array}$ & Fertilizer/manure, plant residues & $\begin{array}{l}\text { Plant uptake, soil erosion, surface } \\
\text { runoff }{ }^{d} \text {, leaching }\end{array}$ \\
\hline HSPF & $\begin{array}{l}\text { Organic P: } \\
\text { - Soil } \\
\text { Inorganic P: } \\
\text { - SRP (solution) } \\
\text { - Adsorbed } \\
\text { (solid) }\end{array}$ & $\begin{array}{l}\text { Mineralization, immobilization, plant uptake, } \\
\text { sorption/desorption, leaching } \\
\text { Adsorption/desorption: first-order kinetics or } \\
\text { Freundlich isotherm }\end{array}$ & $\begin{array}{l}\text { Specification as changes to storage } \\
\text { variables and (or) as atmospheric } \\
\text { deposition }\end{array}$ & $\begin{array}{l}\text { Plant harvest, soil erosion, surface } \\
\text { runoff, interflow, return flow, } \\
\text { deep groundwater recharge }\end{array}$ \\
\hline HYPE & $\begin{array}{l}\text { Organic P: } \\
\text { - } \text { Fast turnover } \\
\text { - Slow turnover } \\
\text { Inorganic P: } \\
\text { - SRP (solution) } \\
\text { - Adsorbed } \\
\text { (solid) }\end{array}$ & $\begin{array}{l}\text { Decomposition, mineralization, plant uptake, } \\
\text { decay through soil layers, sorption/desorption, } \\
\text { leaching } \\
\text { Sorption/desorption: Freundlich isotherm }\end{array}$ & $\begin{array}{l}\text { Plant residues, fertilizer/manure, } \\
\text { dry and wet atmospheric } \\
\text { deposition, rural household load }\end{array}$ & $\begin{array}{l}\text { Plant uptake, soil erosion, surface } \\
\text { runoff, tile drainage, } \\
\text { groundwater }\end{array}$ \\
\hline INCA-P & $\begin{array}{l}\frac{\text { Organic P: }}{\text { - }} \text { Labile } \\
\text { - Inactive } \\
\text { Inorganic P: } \\
\text { - TDP=SRP+DOP } \\
\text { (solution) } \\
\text { - Labile (solid) } \\
\text { - Inactive (solid) }\end{array}$ & $\begin{array}{l}\text { Mineralization, immobilization, plant uptake, } \\
\text { sorption/desorption, leaching } \\
\text { Sorption/desorption: Freundlich isotherm }\end{array}$ & $\begin{array}{l}\text { Plant residue, fertilizer/manure, } \\
\text { dry and wet atmospheric } \\
\text { deposition }\end{array}$ & $\begin{array}{l}\text { Plant uptake, soil erosion, surface } \\
\text { runoff, return flow }\end{array}$ \\
\hline
\end{tabular}


or even no adsorption option, and the selection of each strategy entails different trade-offs between accuracy and complexity (Abrahamsen and Hansen 2000). Additional movement of inorganic $\mathrm{N}$ considered among the reviewed models is an upward movement of $\mathrm{NO}_{3}^{-}$via the evaporation of soil water. APEX and SWAT allows $\mathrm{NO}_{3}^{-}$to be transported from lower to upper soil layers as water evaporates from the soil surface (Neitsch et al. 2011; Williams et al. 2015). The amount of $\mathrm{NO}_{3}^{-}$added to upper soil layer is estimated as a fraction of water loss by evaporation relative to the water content in the upper soil layer (Neitsch et al. 2011).

Runoff - mass-transport models, such as DLBRM, DWSM, GWLF-E and SWMM, comprise three components: hydrology, soil erosion and sediment transport, and hydrologically driven transport of nutrients and pesticides. Biogeochemical transformations are not considered and thus soil nutrient dynamics are tightly connected with the surface runoff and sediment transport (Borah et al. 1999; Croley and He 2005; Croley et al. 2005). Nitrogen pools are classified into two phases based on their solubility (dissolved $\mathrm{N}$ ) and reactivity (adsorbed to clay-size particle) in each modelled medium; soil, subsurface water, groundwater, and instream. Dissolved and adsorbed phases of nitrogen are considered in equilibrium, governed by a linear-adsorption isotherm, and mathematically expressed as firstorder kinetics (Borah et al. 1999). Transport of dissolved nitrogen is then determined by the retention of soil and hydrological storage (Croley and He 2005; Croley et al. 2005). DLBRM and DWSM simulate the daily $\mathrm{N}$-concentrations in the flowing water using the mass conservation principle at each time step (Croley and He 2005; Croley et al. 2005), whereas GWLF-E calculates monthly sediment and nutrient loads based on daily water balance and empirical average nutrient concentrations for each land use (Evans and Corradini 2016). GWLF-E considers urban nitrogen cycling as the net outcome of nutrient "build-up" and "wash-off", based on the potential accumulation of nutrients on impervious urban surfaces from various sources (atmospheric deposition, animal litter, street refuse) and washed off by rainfall events (Evans and Corradini 2016). The advantages of these runoff - mass-transport models are their parsimonious and ease-of-use mathematical structure. However, the lack of consideration of the seasonal variability (i.e., temperature) of all the major biogeochemical processes can significantly bias the predictive outputs (e.g., nutrient concentrations, plant/crop productivity), and thus their fidelity in assessing scenarios of climate change and best management practices.

\section{Phosphorus cycle}

$P$ is required for the synthesis of essential nucleic acids (e.g., DNA and RNA) and energy transfer, and has no substitute in agriculture to support high crop yields. $\mathrm{P}$ is a non-renewable mineral that exists naturally in the Earth's crust as phosphate rock (Liu et al. 2008). The current world reserves of 70000 million tons of mineral ore $\left(\mathrm{P}_{2} \mathrm{O}_{5}\right)$ can meet the needs of the world-mine production of 270 million tons per year (U.S. Geological Survey 2019), but the active mines in the US and planned mines in Canada are expected to be depleted within the next 30 years (Ross and Omelon 2018). In pristine ecosystems, the $P$ cycle is regarded as a "closed" loop, with $\mathrm{P}$ flows occurring slowly, due to natural weathering events, and P stocks in soils remain quantitatively stable. The intensive agricultural practices, however, cannot be sustainably supported by the natural $\mathrm{P}$ pool, and therefore the application of commercial fertilizers and manure plays an essential role in maintaining high soil fertility with bioavailable P. Intensive agriculture and changes to the water cycle in urban areas has converted the historically "closed" $\mathrm{P}$ cycle into a more open-loop system (Liu et al. 2008; Zhou et al. 2016). This in turn has disturbed the balance between P sources and sinks in watersheds, and the elevated tributary P-loading fuels the primary productivity in the receiving waterbodies, thereby shifting their trophic state from oligotrophic to mesotrophic or even eutrophic. The 
capacity of watershed water quality models to simulate external $\mathrm{P}$ loading from agricultural and urban areas is thus critical for watershed management. The reviewed models differ in terms of the description of $\mathrm{P}$ inputs, speciation, transformation processes, and pathways of hydrological transport, and, similar to the $\mathrm{C}$ - and $\mathrm{N}$-cycle models, can be grouped into two basic categories: runoffdriven empirical (GWLF-E and SWWM) models, and dynamic soil P-cycle models (AnnAGNPS, APEX, HSPF, HYPE, INCA-P, SWAT, see Table 6).

Runoff-driven empirical models do not simulate soil P dynamics, and instead require specification of the empirical P-concentrations in soil (GWLF-E), groundwater (GWLF-E), and surface runoff (GWLF-E, SWWM) to quantify P loading from predicted flows. The specification of the empirical P-concentrations is similar in both GWLF-E and SWWM models, but GWLF-E implements daily or monthly average P-concentrations, whereas SWWM considers event-mean P-concentration (EMC) values to relate individual rainfall events with P loading. Given that the default EMCs in SWWM originated from sampling studies performed in 1978-1983 (US EPA 1983), it is recommended to assign updated region-specific values. Additionally, the SWWM, GWLF-E, HSPF, and SWAT models provide options for estimating P-loading in urban impervious areas with empirical nonlinear equations for P-buildup and wash-off. For that purpose, MIKE SHE can be coupled with MIKE URBAN, which allows to simulate the effect of urban drainage and sewer systems on stream water quality.

Dynamic soil $\mathrm{P}$ models are primarily applied in pervious agricultural areas, and consider different sources of P-forms and inputs, transformation mechanisms, and pathways of hydrological transport. P-inputs in the soil surface involve plant residues, mineral fertilizers, and animal manure; HSPF, HYPE, and INCA-P additionally consider atmospheric deposition of P. EPIC-based models (AnnAGNPS, APEX, and SWAT) assign manure to the organic P inputs; HYPE distinguishes between inorganic and organic $P$ in manure; and INCA-P distinguishes between liquid inorganic and generic solid P (Table 6). None of the models distinguish between manure slurry and liquid manure, nor do they consider biosolids by default. APEX, as a field-scale agricultural model, includes manure management subroutines for confined and unconfined animals, as well as animal movement between grazing areas and feeding lots. Incorporation of manure inputs can be an important feature for any local modelling exercise, given that the applied amount of manure in mixed agriculture in Ontario has been increased to meet crop demands for N (van Bochove et al. 2010), and therefore the likelihood of experiencing excessive input of $\mathrm{P}$ (above crop requirements) is high (van Bochove et al. 2012). Consequently, our general recommendation is to constrain the Great Lakes watershed models with regional estimates for the application rates of manure P based on reported crop yields, crop $\mathrm{N}$ deficits, spatially variable livestock data, animal diets with P-regulating supplements (phosphatase), and animal-specific N:P ratios in manure (Bruulsema et al. 2011; van Bochove et al. 2012).

The speciation of $\mathrm{P}$ in the soil in all of the models examined distinguishes between soluble $\mathrm{P}$, which is directly taken-up by plants, and solid-phase P. INCA-P is the only model to specify soluble $\mathrm{P}$ as total dissolved $\mathrm{P}$ (TDP), comprising both chemically active soluble reactive $\mathrm{P}$ (SRP) and dissolved organic $\mathrm{P}$ (DOP). AnnAGNPS, APEX, HSPF, HYPE, and SWAT specify the soluble P pool as representing chemically active ions, $\mathrm{H}_{2} \mathrm{PO}_{4}^{-}$and $\mathrm{HPO}_{4}^{-2}$, which is equivalent to the SRP classification. A recent HYPE version additionally introduced a particulate organic $\mathrm{P}$ pool in soil water. It should also be noted that INCA-P users convert TDP to SRP with constant empirical SRP:TDP ratios. According to our recent event-based tributary sampling in Wilton Creek, Ontario, the SRP and TDP fractions varied significantly and, on average, accounted for $39 \%$ and $73 \%$ of the total $\mathrm{P}$ loading in the tributary, respectively. Thus, the latter variability between TDP and SRP fractions should be handled with caution in any modelling exercise, because their bioavailability is different and could potentially be one of the drivers of the recent trend to re-eutrophications in Lake Erie. The definition of solidphase P differs among AnnAGNPS, APEX, HSFP, HYPE, INCA-P, and SWAT. INCA-P lumps inorganic and organic $P$ pools together, whereas other models (AnnAGNPS, APEX, HSFP, HYPE, and SWAT) separate solid-phase $P$ into inorganic $\left(P_{\text {inorg }}\right)$ and organic $\left(P_{\text {org }}\right)$ pools of different reactivity. HSPF employs an intermediate complexity approach to solid-phase $P$ speciation with single $P_{\text {inorg }}$ and $P_{\text {org }}$ pools, whereas HYPE incorporates one solid-phase $P_{\text {inorg }}$ pool and two $P_{\text {org }}$ pools of slow and fast reactivity. AnnAGNPS and APEX implement a simplified $P$ speciation comprising two solid-phase

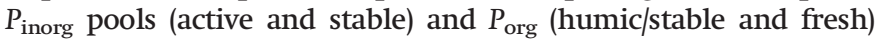
pools, whereas SWAT implements Jones et al.'s (1984) original P speciation with two $P_{\text {inorg }}$ pools (active and stable) and three $P_{\text {org }}$ (active, stable, and fresh organic) pools. Manure inputs of $\mathrm{P}$ contribute to solid-phase active $P_{\text {org }}$ in SWAT, and solid-phase humic $P_{\text {org }}$ in AnnAGNPS; HYPE and INCA-P also allow manure-P to replenish the soluble-P pool. Recently, Collick et al. (2016) implemented the manure P subroutines in SWAT as described by Vadas et al. (2012), which partitioned manure-P inputs into four additional P-fractions; namely, water-extractable and solid-phase $P_{\text {inorg }}$ and $P_{\text {org }}$ pools. Collick et al. (2016) showed that the new manure subroutines can improve our predictive capacity, and thus recommended source code augmentation for SWAT and other models. Importantly, the $P_{\text {org }}$ pools in all of the reviewed models are not constrained by field measurements, which was the main reason for INCA-P to lump organic and inorganic fractions together into a single generic solid-phase P-pool (Jackson-Blake et al. 2016). Finally, the plant residues contribute to fresh solid-phase $P_{\text {org }}$ pool in AnnAGNPS, APEX and SWAT; fast and slow solid-phase $P_{\text {org }}$ in HYPE; and generic solidphase labile $P$ in INCA-P.

The design of soil-P models that are conceptually on par with the actual measurable components represents one of the problems that needs to be rectified in the current watershed modelling practice (Tiessen et al. 1984; Jackson-Blake et al. 2017). In particular, the conceptual definitions of solid-phase P in all models does not match the sequential $\mathrm{P}$ fractionations in geochemistry, such as the six $P_{\text {inorg }}$ and three $P_{\text {org }}$ pools proposed by Hedley and Stewart (1982; see the Supplementary data, Table $S 4^{2}$ ), which poses challenges for the modelled P-pools to be properly constrained by the available field measurements. In this regard, Muenich et al. (2016) suggested that the sum of dissolved $P_{\text {inorg }}$ and solid-phase active $P_{\text {inorg }}$ in SWAT could represent the agronomical soil test phosphorus (STP). Based on the latter suggestion, other EPIC-based models with similar soil-P subroutines (AnnAGNPS, APEX) could also consider STP data for constraining inorganic soil P pools. Although the actual measured STP data in Ontario are not publicly available, van Bochove et al. (2010) published estimates of STP for Canadian soil landscape polygons as part of the IROWC-P (Indicator of Risk of Water Contamination by Phosphorus) study.

Biogeochemical processes of P-transformations in soils include sorption/desorption [on clays, $\mathrm{Al}$ and $\mathrm{Fe}$ (hydr)oxides, Ca], ion exchange, and surface complexation; mineral dissolution and precipitation reactions as $\mathrm{Ca}-, \mathrm{Mg}-$, Fe-, and Al-phosphates and apatites; redox reactions of microbe-mediated mineralization/ immobilization (Horst et al. 2001). The mathematical formulation of these P-transformation processes is simplified in all of the models examined relative to multicomponent, reactive-transport models (RTM) for porous media (Holzbecher 2005). Many drivers of soil-P reaction kinetics, such as physical (porosity and soil texture), chemical $(\mathrm{pH}$, redox potential, amount of organic ligands, buffering capacity of the soil with $\mathrm{Fe}, \mathrm{Al}, \mathrm{Ca}$, and $\mathrm{Mg}$ ions), and biological (microbial activity and soil fauna) properties of the soil, are also not explicitly considered. Moreover, the P-cycle is independently simulated, postulating minimal interaction with $\mathrm{C}$ - and $\mathrm{N}$-cycles, whereas the biogeochemical reactions are mainly considered in rapid equilibrium (between $P_{\text {inorg }}$ pools) or as conceptual net processes (between $P_{\text {org }}$ pools). Furthermore, the redox reactions 
Table 7. Representation of water, pipe, and sediment routing with the watershed models reviewed.

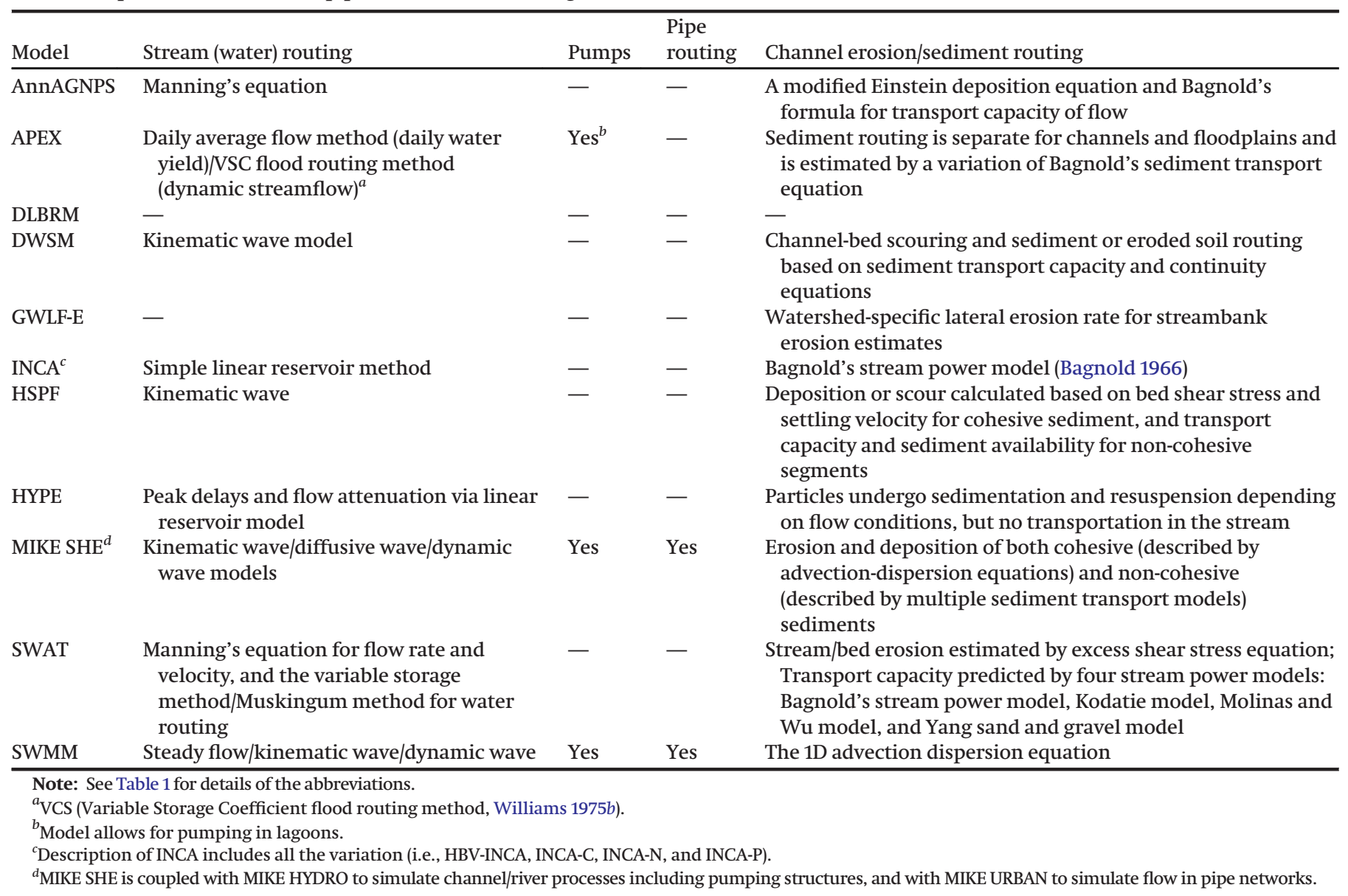

of organic matter mineralization do not affect soil $\mathrm{pH}$, which in turn controls P solubility, and thus all models effectively operate under the assumption of a field $\mathrm{pH}$ within the recommended range $(6<\mathrm{pH}<7.5$; Havlin et al. 1999).

As previously mentioned, MIKE SHE is the only model with a generic RTM framework for nutrients, but counter to the existence of multiple studies on catchment $\mathrm{N}$ dynamics (Hansen et al. 2009; Windolf et al. 2011; Vervloet et al. 2018), we could not find MIKE SHE applications on soil-P. Generally, the broader adoption of complex soil-P models is hindered by the limited availability of spatial data (Beven 2019); incomplete understanding of soil P cycles (Horst et al. 2001; Lewis and McGechan 2002; Das et al. 2019); the mismatch between modelled soil $P$ pools and measurable soil P fractions (Tiessen et al. 1984; Das et al. 2019); and high uncertainty of kinetic parameters resulting from limited field-scale experimental data (Holzbecher 2005; Das et al. 2019). Originally presented by Jones et al. (1984), AnnAGNPS, APEX, and SWAT are based on empirical relationships that were derived from multiple plot/field studies and scaled up to recreate plant-available soil-P in farms and large catchments. The capacity of these subroutines to simulate soil $\mathrm{P}$ at a field level allowed APEX to first estimate total-P losses at the subcatchment level and then aggregate them to predict loading values at regional scales in USA (Santhi et al. 2014; USDA-NRCS 2017). APEX and SWAT, as models with the largest number of soil-P fractions, defined the amount of plant-available dissolved $P_{\text {inorg }}$ as the net balance of plant uptake, sorption/desorption processes with solid-phase active (labile) $P_{\text {inorg}}$, and net mineralization of organic matter from active and fresh $P_{\text {org }}$ pools. By contrast, soil $\mathrm{P}$ subroutines in HSPF, HYPE, and INCA-P were directly developed as part of catchment-scale models without extensive validation against plot/field data.

All of the models that explicitly consider solid-phase $P_{\text {org }}$ (AnnAGNPS, APEX, HSFP, HYPE, and SWAT) define the mineralization rates of organic matter in conjunction with the $\mathrm{C}$ - and $\mathrm{N}$ cycles. The associated $P_{\text {inorg }}$ flux represents the net output of the catabolic reactions pertaining to microbial degradation (Berner 1980), but none of the models explicitly considers bacterial biomass and dissolved $P_{\text {org }}$, such as exudates from roots (Lewis and McGechan 2002). Moreover, none of the models explicitly distinguishes between dissolved $P_{\text {inorg }}$ binding with $\mathrm{Al}$ and Fe (hydr) oxides under lower soil $\mathrm{pH}(\mathrm{pH}<7)$ and with $\mathrm{Ca}$ minerals under high $\mathrm{pH}(\mathrm{pH}>7)$, and instead consider a generic P sorption/ desorption on clays, $\mathrm{Al}$ and $\mathrm{Fe}$ (hydr)oxides, calcium carbonates in acid, and neutral and calcareous soils. Except for HYPE and HSPF, all of the models consider the precipitation and dissolution of lumped secondary P minerals (Ca-, Mg- , Fe- and Al-phosphates) and primary P-minerals (e.g., apatite, goethite), which in turn are either defined as slow adsorption of solid-phase stable $P_{\text {inorg }}$ pools in AnnAGNPS, APEX, SWAT, or as generic inactive$P$ weathering and immobilization in INCA-P (representing both $P_{\text {inorg }}$ and recalcitrant $\left.P_{\text {org }}\right)$.

EPIC-based models (AnnAGNPS, APEX, SWAT) and HSPF considered rapid equilibrium between dissolved and active $P_{\text {inorg }}$ with first-order reaction kinetics. The Freundlich isotherm method with iterative calculation of dissolved $P_{\text {inorg }}$ is incorporated in HSPF, HYPE, and INCA-P, and the Langmuir isotherm in APEX for high soil P-concentrations. Owing to the conceptual differences among the simulated P-pools, the parameters of the Freundlich isotherm in HSPF, HYPE, and INCA-P may not be directly 
comparable, and in reality, the calibrated values have no physical meaning (Jackson-Blake et al. 2016). The subroutines in EPICbased models establish a rapid equilibrium between dissolved and solid phase $P_{\text {inorg }}$ using an empirical soil- and year-specific partitioning coefficient (P availability index, PAI), where a default PAI of 0.4 reflects a $40 \%$ increase in dissolved $P_{\text {inorg }}$ after initial $100 \%$ soil fertilization and 6-month incubation. Similar to the parameter-estimation practices followed for the Freundlich isotherm, EPIC-based models typically estimate PAI as part of the calibration exercise without experimental validation. Vadas and White (2010) proposed two additional empirical PAI formulations to account for spatial variability of the binding capacity of $P$ in weathered and calcareous soils, which considered the percentages of clay, organic $\mathrm{C}$, dynamic dissolved $P_{\text {inorg }}$ concentration (for weathered soils), and the percentage of $\mathrm{CaCO}_{3}$ (for calcareous soils). The latter PAI augmentation for weathered soils was incorporated in SWAT, whereas APEX and AnnAGNPS considered changes in P-binding in calcareous soils with $\mathrm{CaCO}_{3}$. Importantly, SWAT, by default, defines $\mathrm{PAI}$ at the basin scale, which assumes a uniform binding capacity for $\mathrm{P}$ across all soils within the basin, with an option to empirically estimate year-specific PAI from empirical regression for weathered soils. Moreover, because EPIC-based models do not account for the degree of soil P saturation a dynamic PAI formulation may be critical for simulating P-accumulation (Muenich et al. 2016; Scavia et al. 2017). To simulate legacy-P with Freundlich isotherms, Jackson-Blake et al. (2016) advocated the use of dynamic formulations of dissolved $P_{\text {inorg }}$ at equilibrium concentration, at which no adsorption or desorption occurs. Finally, notwithstanding the presence of elaborate dissolved $P_{\text {inorg }}$ formulations, none have been validated against empirical data in Ontario soils, which appear to display a change-point in their buffering capacity for soil-P (Wang 2015).

\section{Water/sediment routing and instream processes}

Open channel flow is defined as the flow of water through a canal or waterway with an open surface to the atmosphere (e.g., flow in streams, rivers, and pipes). The hydraulics of open channels are complex because the principles of channel flow involve complicated nonlinear equations, and therefore solutions of flow rates are highly dependent on shape and structure (Chiu and Tung 2002). Natural channels are usually characterized by irregular shapes, varying from parabolic to trapezoidal, as well as by strong interactions between the channel water and surrounding environment, including the transportation of solid materials, air and water mixing, and chemical dispersal (Chanson 2004). In addition, channel morphology can be modified over time by sediment inputs from upslope reaches (i.e., sediment supply), the ability to transport these loads to reaches downslope (i.e., transport capacity), and vegetation effects on channel processes. Examples of channel modifications include changes in the width, depth, bed slope, roughness, velocity, and sediment size (Montgomery and Buffington 1998). Considering the differences in morphology, channels share the following fundamental processes: water routing, sediment routing, and instream-P. Apart from DLBRM, the watershed models can simulate channel processes (Table 7); however, the following sections will highlight that not all models can represent all of the fundamental processes, and even when they are able to do so, the models differ significantly in terms of their complexity.

\section{Water routing}

Channel routing is not considered with GWLF-E because it models processes in a single, lumped stream segment, and therefore its applicability in large catchments is limited. Water routing simulation strategies in the remaining watershed models can be divided into the following four strategies, based on their complexity: (i) full dynamic wave model; (ii) diffusive wave model; (iii) kinematic wave model and variations; and (iv) other methods (Table 7; see also Glossary). The full dynamic wave model, known as the Saint-Venant equations, is the basic flow-governing model comprising the continuity and momentum equations for shallow water flow (Tayfur et al. 1993). The full dynamic wave model is widely recognized as the most complex physically based waterrouting representation. Given the difficulty in obtaining analytical solutions for the Saint-Venant equations, numerical approximations are used, with inevitably increased computational demands and numerical errors (Garcia and Kahawita 1986). The diffusive wave model, derived from the full dynamic wave equation, uses simplified momentum equations by omitting the local and convective acceleration. Similar to the dynamic wave model, the solutions of the diffusive wave model are usually approximated with numerical approaches (Santillana and Dawson 2010). The kinematic wave model uses the most simplified momentum equation, which ignores the pressure gradient and acceleration terms (Miller 1984), but this model cannot describe pressurized flow and backwater effects. The kinematic wave model has an analytical solution, which makes it easier to use relative to the complex full dynamic and diffusive models. MIKE SHE (coupled with MIKE HYDRO or MIKE URBAN) and SWMM, the only two models incorporating the full dynamic wave model, can simulate water routing in both open channels and closed pipes, and include pumps for flood protection. SWAT provides the option of selecting two variations of the kinematic wave model for water routing: the variable storage method based on a continuity equation, and the Muskingum method based on the continuity equation and an empirical linear storage equation (Neitsch et al. 2011). APEX offers two methods for water routing through channels and floodplains: a daily time step with an averaged-flow method and a short (0.1-1.0 h) time interval, and a variable storage coefficient (VSC) flood-routing method (Williams 1975a; Williams et al. 2015). When deciding between the two methods, if the main goal is to simulate long-term water yields from agricultural farms, then the daily time step method may be a more appropriate choice because it can provide realistic estimates without requiring heavy computational demands. For areas where flooding is a concern, VSC is recommended because it can recreate dynamic streamflow and may therefore provide more robust pollutant transport estimates. HYPE and INCA reproduce the storage effects with a simple linear reservoir model, which has been modified to account for flows from sewage treatment plants (INCA) or to attenuate flow (HYPE). Nonetheless, apart from MIKE SHE and SWMM, which are based on the full dynamic wave model, the watershed models generally ignore backwater effects, are not capable of simulating pressurized flow, and can potentially underestimate river discharge during flood events (Zhao et al. 2017). There is also a large heterogeneity in the way that the different models describe the channels: from models like INCA that does not require a shape to be defined; to SWAT, which forces a trapezoidal shape for the channel (0.5 slope on the edge) and floodplain ( 0.25 slope on the edge), to SWMM that allows for the selection of a pre-defined channel shape that is more suitable for the system being modelled.

\section{Channel erosion/sediment routing}

The simplified Bagnold's equation is the default method in SWAT, whereby the sediment transport capacity is estimated based on the peak flow rate (Bagnold 1977). The ratio of the average to peak flow is determined by hydrologic records or calibration. When Bagnold's equation is selected, bank and bed erosions are not partitioned (although sediment originating from the stream is distinguished from sediment derived from overland sources), nor is particle size distribution taken into account, because the equation assumes silt size particles only. Streambank erosion in GWLF-E is estimated using an empirically derived lateral erosion rate (LER), which is specific to the site of interest and is calculated 
Fig. 7. Classification of data-driven models into (i) risk-based, (ii) material and substance flow analysis, (iii) statistical, and (iv) hybrid semi-empirical models.

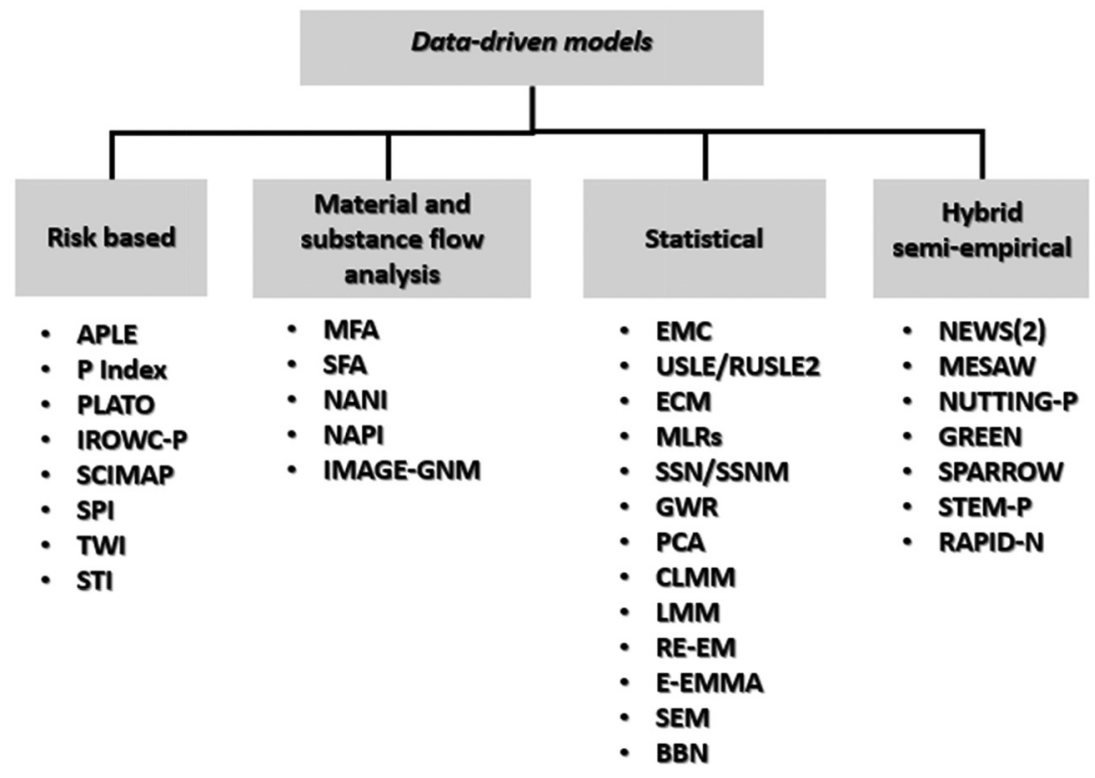

based on the percentage of developed land in the watershed, animal density, average curve number value, average soil erodibility factor value, and mean topographic slope of the watershed (Evans and Corradini 2016). Sediment load generated via streambank erosion for the watershed is computed as the product of LER, the total stream length $(\mathrm{m})$, average streambank height $(\mathrm{m})$, and average soil bulk density $\left(\mathrm{kg} / \mathrm{m}^{3}\right)$. SWAT also provides three other more complex options for calculating transport capacity, i.e., Kodatie, Molinas and $\mathrm{Wu}$, and the Yang sand and gravel models (Seo et al. 2014). The model also estimates the band and bed erosion rate using the methods of Hanson and Simon (2001) and Eaton and Millar (2004) for potential and effective excess shear stress. AnnAGNPS also employs the Bagnold's equation to estimate transport capacity, which is integrated with Einstein's modified deposition equation (Pease et al. 2010). HSPF divides sediments into two categories: non-cohesive (sand), and cohesive (silt and clay) solids. Resuspension and settling of cohesive solids is simulated based on settling velocity and critical shear stress, whereas the ability to be transported with a particular flow is first computed for noncohesive solids and then resuspension or settling is simulated based on the difference between particles in suspension and the carrying capacity of the system (Bicknell et al. 1996). MIKE SHE uses MIKE HYDRO for 1D to 3D sediment transport processes, which is conceptually analogous to the approach introduced by HSPF. HYPE simulates sediment routing with a Bagnold-type approach, where the transport capacity is estimated using the daily flow proportion of bankfull flow. HYPE assumes that suspended particles are not removed. and instead are only redistributed between the sediment and water column over time. The particles are collected in a sediment pool through sedimentation under low water flows and resuspended back to the water column under high flow conditions. Sediment routing in DWSM is governed by the mass for the sediment load and material on the channel bed (Borah et al. 1999). Most of the models in our review can simulate sediment routing based on different sediment size groups, but the group-division methods may differ. For instance, SWAT and AnnAGNPS incorporate five particle-size classes (i.e., sand, large aggregates, small aggregates, silt, and clay) whereas APEX only considers three sediment groups, including sands $(200 \mu \mathrm{m})$, silt $(10 \mu \mathrm{m})$, and clay $(2 \mu \mathrm{m})$ (Supplementary data, Table $\mathrm{S}^{2}$ ). More subtle divisions of sediment groups could contribute to a more accurate representation of the diverse routing patterns of suspended solids, such as the routing patterns for different sediment groups in HSPF. For instance, the net output from settling and resuspension for silt and clay is calculated by considering the shear stress at the sediment-water column interface, as opposed to sand, where the difference between suspended material and transport capacity with a given flow is considered.

\section{Instream $P$}

Among the reviewed models, SWMM and DWSM use a 1D advection-dispersion equation for chemical transport, whereas AnnAGNPS adopts a simple first-order equilibrium model. In AnnAGNPS, GWLF-E, and DWSM, instream chemicals are divided into dissolved and particulate phases. HSPF, HYPE, SWAT, and INCA-P are not only capable of tracking physical processes within the P-cycle, but also consider instream $P$ processes through the growth and decay of algae. In SWAT, the death of phytoplankton transforms intracellular-P to organic-P, which can undergo mineralization to form soluble-P that can be taken-up again by algae or be removed from the stream flow. SWAT, however, does not consider interactions between dissolved-P and $\mathrm{P}$ in suspended sediments. In INCA-P, TDP can be converted to particulate phosphorus (PP) through sorption reactions and back to TDP from PP through desorption in the instream water column, stream bed, and sediments. Loss of instream-P from the water column can occur through TDP uptake by biological components (epiphytic algae, phytoplankton, or macrophytes), TDP exchange to the streambed and sediments, or settling of PP. Gain of P back to the water can occur through TDP exchange or resuspension of PP. The death of biological components contributes to the PP-pool in the sediments and in the river bed. Similar to INCA, HSPF includes a comprehensive representation of the instream-P processes by taking into account the benthic release of dissolved $\mathrm{P}$, sorption/ desorption rates for suspended sediments depending on particle size fraction, settling of the suspended sediment, sediment scouring of the river bed and bank, and P-uptake by benthic algae or phytoplankton together with the release of inorganic $\mathrm{P}$ by zooplankton. In comparison, instream processes are poorly modelled in GWLF-E and are limited to transformation between dissolved and particulate P during low-flow conditions. Despite their greater complexity relative to AnnAGNPS, DWSM, and GWLF-E, the 
approaches taken by HSPF, INCA-P, and SWAT are still simplified, especially for the simulation of in-stream algal dynamics. With INCA-P, in-stream algal growth is only dependent on temperature and ambient $\mathrm{P}$, and ignores light requirements and the concentrations of other nutrients (Jackson-Blake et al. 2016). HSPF also includes a module for simulating the grazing and death of zooplankton, which can predominantly shape the nature of phytoplankton assemblages, but does not take into account the uptake by and death of benthic algae (Reddy et al. 1999). Generally, the main factors modulating P-dynamics are assumed to be biological, and therefore the sorption/desorption processes are downplayed. These mechanisms may exert significant influence on Ptransformations in streams, which in turn could downplay instream-P dynamics in the winter when biological activity is minimal (Green et al. 1978; Zafar et al. 2016; Tang et al. 2017). Lastly, coupling MIKE HYDRO with MIKE ECO Lab can offer a customizable aquatic ecosystem modelling tool to describe water quality and eutrophication dynamics.

\section{Data-driven watershed modelling}

In the Great Lakes area, the watershed-management paradigm has predominantly relied upon deterministic projections reflective of a "predict-then-act" mindset (Lempert et al. 2004). Nonetheless, critical viewpoints advocate the broader adoption of adaptive-management frameworks as a pragmatic strategy that not only acts as a hedge against the ubiquitous uncertainty surrounding the study of open environmental systems, but also paves the way for the dual pursuit of management and learning (Arhonditsis et al. 2019a, 2019b). The emerging support for adaptive implementation of remedial measures in the Great Lakes stems from the appeal of the iterative monitoring-modellingassessment cycles, whereby scientific learning progressively advances from research, monitoring, modelling, and impartial evaluation of the outcomes of past and on-going management actions. Our analysis of the available spatially distributed models reinforced the notion that the current generation of water quality, process-based models can be classified into two categories: (i) simpler approximations of the multifaceted, nonlinear dynamics of nutrient fate and transport that place more emphasis on the advanced representation of the water cycle; and (ii) explicit biogeochemical models that are founded upon simplified strategies to recreate the role of critical hydrological processes (Li et al. 2017; Jain and Singh 2017; Bao et al. 2017; Li 2019). With either category, the significant disparity between what we want to tease out from these models and the amount of data required to constrain them with the appropriate spatiotemporal granularity undermines their ability to be used for extrapolative tasks (Beven 2019). Thus, until the data that are necessary to characterize critical watershed processes with physically based models become available, the design of mitigation strategies of urban and agricultural nonpoint sources should be viewed in terms of "decision making under deep uncertainty" or DMDU (Polasky et al. 2011).

In our view, embedding DMDU principles into an adaptive watershed management framework requires coupling mechanistic watershed models with comprehensive exploratory analysis (Marchau et al. 2019). This implementation of exploratory analysis during the planning stage can be mainly realized with datadriven (or empirical) watershed models that represent an appealing complementary tool for process-based modelling. In particular, more parsimonious empirical models would provide a statistically rigorous means to identify overlooked or newly appeared nutrient "hot spots" or "hot moments" and potential critical pathways (Kovacs et al. 2012; Long et al. 2015). Outputs of data-driven watershed models can also be used to highlight the necessary improvements in subroutines of complex overparameterized models and pinpoint the information required to constrain, validate, and verify them (Arhonditsis et al. 2019a, 2019b). Taking into account the diverse range of data-driven models and underlying techniques, we can classify the empirical watershed modelling tools into four main categories (Fig. 7): (i) risk-based, (ii) material- and substance-flow analyses, (iii) statistical, and (iv) hybrid semi-empirical models. Below we will provide an overview of these models and their applicability for adaptive watershed management.

\section{Risk-based models}

Risk-based models serve to evaluate the risk of nutrient losses from agricultural fields, based on existing empirical relationships. This type of models represents a deductive reasoning process when setting BMPs in a particular location based on empirical equations with a set of relevant predictors, e.g., soil texture, hydrological soil groups, carbon content, residual soil-P content, catchment slope, degree of soil mixing, and agricultural practices. These models can either assess the risk of contaminant losses through specific pathways (tile drainage, surface runoff, splash, sheet, rill or gully erosion), estimate the risk of potential nutrient losses with P index (PI) models (Reid 2011; Reid et al. 2018), or quantify potential edge-of-field nutrient export with the Annual Phosphorus Loss Estimator (APLE) tool (Vadas et al. 2012; Benskin et al. 2014). The major advantage of these models is their capacity to support analysis with high-resolution spatial data at the level of individual farms, thereby allowing the engagement of farmers to share their private data and empirical knowledge that would otherwise be unavailable for watershed planning.

The revised Ohio PI represents an exemplary case of a regionspecific risk index supported by long-term (3 year) and edge-offield (>2000 field samples) monitoring studies (Williams et al. 2017). Based on APLE application, the Ohio PI considers the potential for soil-erosion, site-specific soil tests for P, agricultural-soil disturbances from different crop-management practices, and manure application from animal operations, and supersedes more complex models in their capacity to quantify potential losses of reactive-dissolved and sediment-bound particulate-P, both in surface runoff and tile drainage. This risk-based approach has three advantages: $(i)$ the parsimonious model structure provides the flexibility to iteratively revise parameters based on new findings, such as limiting manure application on fields with insufficient ground cover (Cela et al. 2016); (ii) ability to incorporate nonlinear relationships with environmental thresholds/changepoints, such as the relationship between dissolved reactive phosphorus (DRP; same as SRP) in surface runoff, and water-extractable $\mathrm{P}$ in soils, soil-P tests, degree of soil-P saturation, and P-buffering capacity (PBC) (Beaudin et al. 2008; van Bochove et al. 2010; Wang et al. 2016). For example, the Canadian risk indicator of water contamination by phosphorus considers a higher risk of P-desorption in acidic to neutral soils with a degree of soil-P saturation $>25 \%$, and a lower risk with levels of water-extractable P in soils below 4 ppm (van Bochove et al. 2010). The empirical studies in calcareous Ontario soils identified a similar critical PBC threshold, when DRP in runoff increased significantly in soils with a $\mathrm{PBC}<0.3 \mathrm{~L} \cdot \mathrm{mg}^{-1}$ (Wang et al. 2016); and (iii) the uncertainty or variability associated with predictions from field-based empirical studies can be easily incorporated into PI models (Sharpley 2013b). Ultimately, the identification of breakpoints and long-term patterns in nutrient losses allows for their subsequent integration in more complex processbased models, such as the adoption of time-dependent phosphorus partitioning coefficient in SWAT (Daloğlu et al. 2012).

\section{Material- and substance-flow analysis (MFA/SFA) models}

Material- and substance-flow analysis (MFA/SFA) models facilitate the depiction of the entire mass flow of nutrients at global (Chen and Graedel 2016; Lun et al. 2018), national (Antikainen et al. 2005; Cordell et al. 2013; Sipert and Cohim 2019), or administrative/ divisional scales (Bruulsema et al. 2011; Senthilkumar et al. 2012) that can be further downscaled to subregional levels (Bolinder et al. 2000; Van Bochove et al. 2012). The MFA/MSA models provide a 
detailed inventory of nutrient supplies, consumptions, and accumulated stocks, which is essential information for the development of long-term plans for sustainable nutrient cycles within the waterenergy-food nexus (Scholz et al. 2013). The MFA/SFA models typically represent interdisciplinary analyses of nutrient sources and sinks within the context of economic, social and environmental factors (Sutton et al. 2013; Reddy et al. 2018), such as the large-scale MFA studies of food production/consumption systems which identified a disbalance in $\mathrm{P}$ between agricultural inputs and the levels in harvested crops of $200 \mathrm{Gg} \cdot \mathrm{year}^{-1}\left(1 \mathrm{Gg}=10^{6} \mathrm{~kg}\right)$ in the conterminous USA, $660 \mathrm{Gg} \cdot$ year $^{-1}$ in Europe, and $46 \mathrm{Gg} \cdot \mathrm{year}^{-1}$ in Canada during the 2002-2010 period, or net P-accumulation in agricultural soils of $1.46,2.78$, and $1.39 \mathrm{~kg} \mathrm{P} \cdot \mathrm{ha}^{-1} \cdot \mathrm{year}^{-1}$, respectively (van Dijk et al. 2016; Metson et al. 2017; Lun et al. 2018).

A characteristic example of how process-based modelling can benefit from MFA studies is the recent identification of a continuous $\mathrm{P}$ buildup in the croplands of Ontario, Michigan, and Ohio prior to the 1990s, followed by a P-deficit after the 1990s (Brulsema et al. 2011). The recent decline in estimated soil-P levels in the Lake Erie basin coincided with contemporaneous increase in crop productivity with elevated P-uptake by the crops, which suggests that soil-P processes should be characterized in a way that allows models to recreate long-term, non-steady-state trends in agricultural soil-P stock (Chen and Graedel 2016), and therefore the current calibration practices that are based on $<5$-year windows under a steadystate assumption for P-stock is likely problematic. Likewise, MFA studies highlighted the significant spatial heterogeneity in Lake Erie basin for P-inputs, such as livestock manure production of $23.5 \mathrm{~kg} \mathrm{P} \cdot \mathrm{ha}^{-1}$ in the Upper Grand, $11.8 \mathrm{~kg} \mathrm{P} \cdot \mathrm{ha}^{-1}$ in the Lower Grand, and $5 \mathrm{~kg}$ P.ha ${ }^{-1}$ in the Lower Thames (Agriculture and Agri-Food Canada and Statistics Canada 2016), and therefore the typical practice of constraining watershed models with average literature or province-wide application rates is clearly erroneous. Moreover, long-term MFA estimates of legacy P can assist in comparative assessments of environmental impairment, such as the IPNI (2014) finding that the cumulative soil-P surplus of $85 \mathrm{~kg} \mathrm{P} \cdot \mathrm{ha}^{-1}$ between 1972 and 2013 in Ontario, under an average agricultural nutrient export rate of $0.25 \mathrm{~kg} \mathrm{P} \cdot \mathrm{ha}^{-1}$ (Winter and Duthie 2000), is equivalent to 340 years of nutrient impairment. Similarly, the MFA estimates of accumulated P stock (8.5 tons of phosphorus per square kilometre in Ontario between 1972 to 2013) can lead to the identification of empirical breaking points in watershed buffering capacity (2.1 tons of phosphorus per square kilometre in the Laurentian Great Lakes) that separate sustainable from nonsustainable watershed functioning (Goyette et al. 2018).

Statistical models encompass a wide range of statistical techniques to quantify measures of central tendency and uncertainty analysis with event-mean concentrations (Lee et al. 2011); assemble databases of average nutrient-export coefficients per land use/land cover (Reckhow et al. 1980; Harmel et al. 2008; Hertzberger et al. 2019); test BMP effectiveness with analysis of variance (ANOVA) (Maniquiz et al. 2010a); conduct concentration-discharge analysis with linear regression techniques to identify chemostatic and chemodynamic patterns, threshold responses, and hysteresis effects (Moatar et al. 2017); employ multivariate statistical methods for source identification (Mudge 2007; Chen et al. 2013); develop multiple linear regressions, spatial-stream networks, and geographically weighted regression models to identify which landscape metrics correlate with nutrient pollution (Isaak et al. 2014; Scown et al. 2017); relate event-mean concentrations to rain intensity (Maniquiz et al. 2010b); compute daily, monthly, seasonal, annual, and decadal nutrient loads (Lee et al. 2016); conduct socio-geospatial modelling studies (Wilson 2015); investigate the disparity between overall nutrient loading reduction and a lack of improvement in ecological status of water bodies with regression trees for clustered data, compositional linear mixed models, and ordinary linear mixed models (Glendell et al. 2019); test multiple working hypotheses to investigate causality between main stressors and environment with structural equation modelling (Fan et al. 2016; Ryberg 2017); apply Bayesian Belief Networks to reproduce nonlinear impacts from implementation of BMP and generate cascade effects on ecosystem services (Nash and Hannah 2011; Landuyt et al. 2013).

The hybrid semi-empirical models occupy a unique intermediate position in our model classification exercise by combining parsimonious structures of nonlinear regression models with extensive 2D spatial coverage, and dissect the watershed behavior into a small subset of fundamental processes (Supplementary data, Fig. $S 1^{2}$ ). These models can incorporate major sources and sinks of point and nonpoint sources, simulate delivery fluxes from sources to tributaries, and predict subsequent downstream fate and transport within hydrological networks from headwater stream reaches to basin outlets. They are specifically designed to assimilate tributary water quality data from entire networks of monitoring stations, which permit researchers to draw inference regarding the source apportionment between point and nonpoint sources. The advanced capacity of these models to characterize spatial patterns of nutrient fluxes is traded for their coarser temporal resolution, whereby daily nutrient loading outputs are replaced with long-term average, annual, or decadal estimates of nutrient fluxes. This category of models includes NEWS (Global Nutrient Export from WaterSheds model; Seitzinger et al. 2005), MESAW (Matrix Equations for Source Apportionment on Watershed; Kaur et al. 2017), and SPARROW (SPAtially Referenced Regressions On Watershed attributes model; Smith et al. 1997) as well as its multiple augmentations over time (Grizzetti et al. 2005; Wellen et al. 2012; Dupas et al. 2015; Kim et al. 2017).

Owing to their parsimonious structure, these models can support statistically rigorous parameter identification from collected tributary water quality data and prior information of nutrient-mass input (and subsequently export) from different land uses, land-to-water coefficients, and instream attenuation rates (Zobrist and Reichert 2006; Kim et al. 2017). Depending on the quality of spatial-temporal data, nutrient inputs per land use could be either represented as the total annual amount of applied mineral fertilizers, manure, and atmospheric deposition (Robertson and Saad 2011), as the annual difference between applied and nutrients taken up by crops (Grizzetti et al. 2005), or as the area occupied by specific land use/land cover (Kim et al. 2017). The land-to-stream delivery coefficient can account for the unexplained spatial variability of nutrient fluxes due to landscape characteristics, and therefore the selection of the suitable predictors requires an iterative exploratory analysis of landscape covariates, such as catchment slope, soil permeability, texture, or even the mean expected mitigation effect of the implemented BMPs (Robertson and Saad 2011; García et al. 2016). Settling losses and, more generally, attenuation rates within the stream network of nested catchments can vary depending on the runoff rates, stream-channel sizes, stream-bed erodibility, and other factors (Behrendt and Opitz 1999; Alexander et al. 2000; Benoy et al. 2016). Thus, owing to their capacity to characterize nutrient fate and transport along the catchment-river continuum, semiempirical hybrid models have adequate mechanistic basis to offer complementary tools in guiding decisions on delineating priority management areas (Robertson et al. 2009; Wellen et al. 2014a; Kim et al. 2017). The spatial structure of semi-empirical models allows to compare their nutrient flux estimates against those from process-based models. Specifically, the nutrient delivery can be compared at the edge-of-streams, within nested catchments along the stream network, and as delivered to the downstream outlets (Supplementary data, Fig. $S 1^{2}$ ). The recent augmentation of SWAT+ to accommodate a tier-based approach from conceptual to more detailed analysis at the level of individual fields allowed for direct comparison of the nutrient export coefficients and delivery ratios between semi-empirical models and SWAT+ (Bieger et al. 2017). In terms of the post-implementation control of agricultural and urban BMPs, García et al. (2016) 
advocated the comparison of data-driven models against predictions from field-scale analysis, by drawing parallels between predicted edge-of-stream nutrient loading reductions from APEX and the landscape delivery factors derived from SPARROW (Supplementary data, Fig. $S 1^{2}$ ).

In terms of scalability, the semi-empirical models, like SPARROW, have been applied to both small- and large-scale watersheds (Alexander et al. 2004; Qian et al. 2005; Wellen et al. 2012; Kim et al. 2017). Watersheds are first divided into subwatersheds, each of which drains to a water quality monitoring station. Each subwatershed is then disaggregated into reach catchments drained by a particular stream segment, and the attributes of each reach catchment are used as predictor variables for water quality in-stream and downstream. Maximum likelihood and bootstrapping methods have been typically used to obtain mean estimates of the governing watershed processes along with the associated uncertainty (Alexander et al. 2002; McMahon et al. 2003; Robertson and Saad 2011). Bayesian inference techniques have recently introduced significant conceptual and operational advancements in the SPARROW practice, such as the control of the covariance effect of model parameters on the inference drawn; the characterization of the spatial structure of model residuals due to autocorrelated forcing factors, e.g., climate, soils, agricultural practices, and year-to-year variability; the use of prior knowledge on parameter values in assisting model calibration; the propagation of the error/uncertainty associated with model calibration data (Qian et al. 2005; Wellen et al. 2014a). Regarding the significance of the parameter covariance problem, Qian et al. (2005) provided compelling evidence by showing that three of the SPARROW parameters were highly correlated and concentrated around a narrow "banana shaped" region of the examined parameter space. The uncertainty pertaining to calibration datasets along with the challenges for supporting predictions in areas that have been modestly monitored is another topic of great practical importance, given that most watersheds of management interest are understudied, and existing mean annual load estimates are often obtained by rating curves with considerable associated errors (Cohn et al. 1989; Cohn et al. 1992; Alexander et al. 2004; Moatar and Meybeck 2005). To overcome the latter issues, Bayesian techniques confer a major advantage through a series of statistical (measurement error) formulations that explicitly consider the analytic uncertainty, sampling error, interannual variability or even the uncertainties stemming from the use of noncontemporaneous measurements of flow and concentration (Carroll et al. 2006; Wellen et al. 2014a; Kim et al. 2017).

\section{Challenges and next steps for the watershed modelling in Lake Erie}

During the initial stage of adaptive management, the application of watershed models offers a first approximation of the benefits of already implemented or newly proposed conservation practices at the basin scale. In the next phase, the collection of tributary data allows researchers to reflect on critical knowledge gaps and erroneous assumptions that are intricately linked with the predictive uncertainty and to redesign the field work/experimentation accordingly. Based on our experience thus far from Lake Erie, we summarize how this iterative process can improve our capacity to design a strategy to reduce nutrient loading.

\section{Is the use of multiple applications of the same model the answer?}

Notwithstanding the diverse range of process-based models presented in the international literature, the characterization of water budgets and nutrient cycles in the major catchments of Lake Erie has been overwhelmingly based on the use of the SWAT model. In particular, the watershed modelling work in the Maumee River Watershed comprised five independent SWAT applications, reflecting different input assumptions and process characterizations, to determine the watershed attributes and functioning that modulate P loading export (Scavia et al. 2017). Being based on the same mathematics (i.e., SWAT equations), this strategy bears conceptual resemblance to a sensitivity analysis, whereby we typically evaluate how parametric uncertainty shapes the predictions of a given complex model regarding the environmental management problem at hand. Thus, even though the practice of basing environmental forecasts on multiple applications of the same mechanistic model deviates from the typical definition of an ensemble tool, we believe that it represents a prudent first step to delineate the uncertainty band associated with the equifinality problem. Consistent with the general findings of this review, Arhonditsis et al. (2019b) asserted that the next iteration of the watershed modelling framework in Lake Erie should consider the different strengths of the available process-based models, and therefore SWAT could be complemented by the modules of other watershed models, especially for surface runoff, groundwater, and sediment-erosion processes. Modellers can further capitalize on the availability of multiple options and modifications of SWAT/SWAT+ source codes, and (or) consider the application of several alternative models to enrich the structural complexity of model ensembles. The spatial granularity should also shift from lumped approaches in BMP analysis, such as HRU in SWAT, towards field-level analysis of geographically fixed BMPs in order predict the post-implementation trends in tributary water quality. Some of the critical processes for modelling nutrient losses in individual watersheds in the Great Lakes can include simulation of runoff in subfield areas (e.g., MIKE SHE, SWAT-VSA in Easton et al. 2008), tracking nutrient losses at EOF and EOS nodes (APEX, AnnAGNPS, SWAT+), representing fieldand farm-level structural BMPs as spatial objects (APEX, AnnAGNPS, MIKE SHE, SWAT+, field-scale SWAT in Merriman et al. 2018), improved representation of groundwater and surface water interactions in tile-drained landscapes with high water tables (HYPE, MIKE SHE, SWAT+), and related simulations of nutrient losses associated with tile-drainage (e.g., SWATDRAIN modification in Golmohammadi et al. 2016), consideration of spatiotemporally explicit soil erosion routines (SWAT modification by Qi et al. 2017; AnnAGNPS, MIKE SHE), augmentation of reactive nutrient transport dynamics in agricultural land, such as the modified SWAT in Collick et al. (2016) or the modified EPIC in Wang et al. (2019).

Prior to invoking any additional complexity by introducing alternative conceptual or mathematical representations of watershed processes with other models, there are several interesting lessons learned from the recent modelling work in the Maumee River that could offer meaningful pointers for future improvement of the SWAT-ensemble strategy (Arhonditsis et al. 2019a, 2019b):

- The five SWAT applications were characterized by nearly excellent goodness-of-fit against monthly flow rates and phosphorus loading empirical estimates based on a single downstream station, but little evidence was provided with respect to their ability to reproduce the hydrological or nutrient loading conditions with a finer (daily) temporal resolution, and even less so in capturing the impact of episodic/extreme precipitation events (see also following discussion). The five SWAT applications coalesced in their projections of the northwestern and southern parts of the Maumee River watershed as high-risk areas with greater propensity for TP export and downstream delivery rates, as well as the tendency of the predominantly agricultural central areas for higher DRP export rates. However, these spatial projections require further ground truthing by considering multiple sites across the Maumee River watershed to recalibrate the models. Regarding the practice of calibrating spatially distributed models against data from the basin outlet alone, Wellen et al. (2015) cautioned that likely leads 
to an overconfident assessment of our ability to constrain overland and (or) in-stream fluxes of water and waterborne pollutants. A characteristic example is the recent comparison of a multisite SWAT calibration strategy using flow-discharge data from three tributaries and six gauging stations vis-à-vis two single-site applications of the same model in the Hamilton Harbour watershed (Wellen et al. 2014a; Dong et al. 2019). While the model fit after the training phase was similar between the two studies, the multi-site exercise led to distinctly higher performance within the validation domain. It is thus important to bear in mind that watershed-process characterization, derived from multiple sources of information that explicitly accommodate the variability in time and space, may render greater predictive capacity and could thus be more effective for evaluating land-use management scenarios and source attributions (Vaze and Chiew 2003; Shrestha et al. 2016; Bai et al. 2017).

- Considering the main reason of using multiple applications of the same mechanistic model is to accommodate the lack of unique characterization of the major hydrological and nutrient transport/transformation processes, Arhonditsis et al. (2019a, 2019b) showed that this endeavor may be confounded by the uncertainty arising from different data inputs used and assumptions made (e.g., fertilizer/manure application rates, agricultural tile drainage network, land-use/land-cover data) across the five SWAT applications in the Maumee River watershed. In the next iteration of the modelling framework, it is important to distinguish between the targeted variability that ensembles (or ensemble-like) aim to introduce into the decision making process (i.e., uncertainty envelope stemming from the inherent under-determination of complex mathematical models) and the "nuisance" factors associated with the mischaracterization of boundary conditions and forcing functions from a subset of the members of a model ensemble.

- Another plausible way for reducing the model uncertainty involves maintaining consistency among critical parameters for which empirical estimates can be derived from the study site. In this regard, one of the interesting lessons learned from the sensitivity analysis exercises conducted in neighboring watersheds (Maumee River, Sandusky River, Rock Creek, Honey Creek) in Lake Erie has shown that the parameter ranking according to their sensitivity to flow, sediments, and nutrient loading predictions can differ depending on the location modelled, parameter values assigned during the model training phase, and input data used (Confesor et al. 2011; Scavia et al. 2016). Nonetheless, there are several parameters that are consistently identified as being particularly influential (e.g., threshold water level in shallow aquifer for baseflow and (or) revap, Manning's roughness for the main channel, effective hydraulic conductivity, $\mathrm{CN}$ for antecedent runoff condition II (CN2), depth to subsurface tile drain, snow melt temperature, initial organic and soluble phosphorus in soil, and the coefficient of soil partitioning for P between the surface soil and surface runoff), and several of those can be directly measured in the field or experimentally quantified.

- As discussed in the previous section, coupled with the current (or future) mechanistic models for the Maumee River watershed, empirical (SPARROW-like) models parameterized to depict basin-specific (rather than continental or regional) nutrient export rates can offer a multitude of complementary benefits, such as delineation of the actual uncertainty of processes/fluxes pertaining to nutrient export from different land uses, land-towater delivery, and in-stream attenuation rates; validation of the hot-spots with higher susceptibility for nutrient export; and derivation of predictive statements constrained within the bounds of data-based parameter estimation (Arhonditsis et al. 2019a, 2019b).
Legacy nutrients: linking past management practices with future water quality conditions

Nutrient dynamics and the build-up of legacy pools within a given watershed are dependent upon a suite of input, transport, storage, and removal processes operating along the terrestrialaquatic continuum (Chen et al. 2018). Driven by the need to meet the energy and food demands of an increasingly urbanized population, anthropogenic nutrient inputs (i.e., fertilizer/manure application) have dramatically increased, and their soil accumulation is further accentuated by hydrologic and biogeochemical legacy effects (Sattari et al. 2012; Condron et al. 2013). The former effects refer to the travel time required for nutrient delivery from the original terrestrial sources to the receiving waters through a multitude of surface and subsurface hydrologic pathways (Van Meter and Basu 2015; Chen et al. 2018). Major biogeochemical processes that drive nutrient cycles within and among soil/sediment, water, and biota, thereby resulting in long turnover times and legacy nutrient accumulation, are the litter or decomposition by plant roots, uptake by plants and soil microbial community, ammonification of the organic matter in soils, nitrification/denitrification, mineral precipitation/dissolution, sorption/ desorption, and molecular diffusion (Seitzinger et al. 2006; Sharpley et al. 2013a; Chen et al. 2018). In the same context, Frossard et al. (2000) showed that the unique facet of P biogeochemistry is that the high sorption (iron oxyhydroxides) or the potential for co-precipitation with minerals (calcium carbonate) and clay particles is several orders of magnitude greater than the corresponding concentration of $\mathrm{P}$ dissolved in pore waters. Overall, the increasing presence of "residual" nutrients in soils can lead to the prevalence of inorganic forms and distinct shifts in the elemental ratios of $\mathrm{C}$, $\mathrm{N}$, and $\mathrm{P}$ delivered into downstream waterbodies, which in turn can shape the nature of the autotrophic assemblages (Dodds et al. 2010; Sharpley et al. 2013a; Haygarth et al. 2014). Currently the issue of legacy nutrients has become a cornerstone for the development of sustainable agroecosystem management plans, and many skeptics have cast doubt on the capacity and expected timing of the on-going water quality remediation measures to provide tangible improvements in Lake Erie and more broadly in the Great Lakes (Arhonditsis et al. 2019a, 2019b; Mohamed et al. 2019).

Considering the emerging evidence on the importance of legacy nutrients, the current generation of watershed models should improve our ability to quantify the underlying hydrological and biogeochemical processes in order to design and put in place efficient nutrient-management practices at the watershed scale. However, both data-driven and process-based models generally lack one or other important mechanisms or use simple assumptions to recreate the legacy nutrient dynamics and delivery lags (Meals et al. 2010; Wellen et al. 2012; Kleinman et al. 2015). Lumped or statistical watershed models postulate that the nutrient cycles are in a steady state over the course of varying time windows (e.g., 1 or 5 year averaged nutrient-export coefficients), but the specification of the optimal length of a multiyear period that reasonably satisfies the steady-state assumption can vary significantly, depending on the watershed considered (Chen et al. 2018). For example, Van Meter and Basu (2015) showed that the lag time between anthropogenic $\mathrm{N}$ inputs to a watershed and riverine export associated with biological and hydrological processes can be significantly longer than the typical time-averaging windows used by the vast majority of lumped and statistical models. Likewise, legacy effects are also not suitably addressed and mathematically formulated by the majority of the commonly utilized process-based models, which do not consider critical biogeochemical mechanisms to either account for such nutrient legacies or to predict time-lags in both urbanized and agricultural landscapes (Grizzetti et al. 2005; Chen et al. 2014). Most current models are not capable of representing the mechanisms responsible for P wash-off (incidental transfer) rates, soil stratification 
and accumulation of nutrients at the soil surface layer, in-stream stores, and sinks (Vadas et al. 2013; Haggard et al. 2007; Daloğlu et al. 2012). Consequently, several fundamental processes modulating the nutrient legacy dynamics (e.g., nutrient vulnerability to runoff from the soil surface layer) are approximated by a small number of parameters, such as the soil partitioning coefficients (i.e., the ratio of the soluble nutrient concentration in the soil surface layer to that in surface runoff), $P$ availability index, nutrient percolation coefficients, and initial concentrations in the surface soil layer (Radcliffe et al. 2009; Vadas and White 2010). Wellen et al. (2015) argued that the primary weakness of mechanistic models stems from the uncertainty surrounding the characterization of the various components of the water cycle (e.g., evapotranspiration, groundwater flow, overland flow, and return flow), given that the typical practice involves calibration solely against stream flow data, and therefore their ability to realistically reproduce the hydrological residence times and nutrient lag delivery effects is unclear.

\section{Long-term trends in dissolved reactive phosphorus loads: causes and consequences}

Recent empirical evidence suggests increasing DRP loading trends in several major tributaries of Lake Erie (e.g., Maumee, Sandusky, and Raisin rivers), although the TP-concentrations have been relatively stable (Baker et al. 2014; Stow et al. 2015). Interestingly, the same constant (or even decreasing) trend has been registered with respect to the application rates of $\mathrm{P}$ fertilizer in the area (Han et al. 2012). Likewise, a SWAT multimodel exercise evaluated the achievability of the March-July DRP and TP loading targets of 186 and 860 metric tonnes in the Maumee River watershed (Scavia et al. 2017), which provided more promising predictions for the TP loading threshold relative to the one for DRP under a series of BMP scenarios (Arhonditsis et al. 2019a). This increasing DRP trend has been attributed to both direct and synergistic effects of a suite of mechanisms, including (i) the increased frequency of storm events, especially during the fall and spring seasons; (ii) the timing of fertilizer/manure application, in that fertilizers applied in the fall would have longer exposure to precipitation and subsequently to runoff; (iii) the gradual establishment of preferential (macropore) flow pathways mediating the hydrological connectivity between labile $\mathrm{P}$ at the soil surface and subsurface drainage; and (iv) implementation of management practices (reduced tillage, increased tile drainage) that appear to increase soil stratification and $\mathrm{P}$ accumulation at the soil surface (Daloğlu et al. 2012; Baker et al. 2017; Jarvie et al. 2017). In the same context, an important "unknown" is the role of legacy $\mathrm{P}$ as an important determining factor of the DRPconcentrations in the soils. As previously mentioned, historical applications of $\mathrm{P}$ fertilizer can result in accumulated legacy $\mathrm{P}$, which can elevate the amount of dissolved $P$ either by being released into the soil solution over time (direct effect) or by shaping the nature of the microbial reactions and ultimately promoting the rapid transformation of the contemporary $\mathrm{P}$ fertilizer inputs from labile into available pools (indirect effect) that are more susceptible to losses (King et al. 2017). In light of this evidence, one particularly challenging aspect for the evaluation of scenarios with the current generation of process-based models is the proper consideration of legacy $\mathrm{P}$ (e.g., initialization that accommodates the spatial variability of $\mathrm{P}$ in soil, sufficient model warm-up period, parameter specification that reproduces the gradual P build-up in the soils, active microbial transformation) and its broader implications for DRP loading.

The pattern of increasing DRP loading could be further exacerbated by the adopted best management practices aiming to reduce sediment erosion from agricultural fields, i.e., conservation tillage and no-till practices (Daloğlu et al. 2012). Notwithstanding the reduction in flow-adjusted concentrations of suspended solids and particulate phosphorus in Lake Erie tributaries (Richards et al. 2008), no-till practices together with surface application (broadcasting) of $\mathrm{P}$ fertilizers and manure can increase soil stratification and the accumulation of residual fertilizer $\mathrm{P}$ at the top of the soil profile, and potentially intensify DRP runoff (Sharpley et al. 2013a; Jarvie et al. 2017). Because this prospect casts doubt on management practices intended to reduce top-soil levels of $\mathrm{P}$, periodic soil inversion tillage to thoroughly mix the soil in the plow layer and (or) consistent subsurface placement (instead of broadcast) P fertilizer application has been suggested, thereby eliminating the development of stratification increments (Baker et al. 2017). Another challenge with the existing watershed management practices in Lake Erie is the recent evidence that no-till practices coupled with the increased tile drainage can increase labile $\mathrm{P}$ fractions at the soil surface and transport of soluble P via subsurface drainage (Smith et al. 2015), although the latter pattern can differ significantly depending on the rainfall amount/intensity and antecedent soil moisture conditions (i.e., greater and more rapid tile drainflows are generated by greater rainfall amounts/intensities and wet soils), soil texture (i.e., greater drainflows typically occur on coarse-textured soils due to higher permeability, but finetextured soils may also result in preferential flow pathways), cropping and tillage practices (i.e., greater tile drainflows occur from grassland and no-till cropland owing to the prevalence of preferential flow pathways), and drainage system design (i.e., shallow drains tend to respond more quickly to precipitation than deep drains, while drainage volume tends to be lower from shallow and wide-spaced designs) (Moore 2016). Thus, another important facet of the local modelling work to draw reliable DRP predictions is the capacity to reproduce all of the critical hydrological and biogeochemical transformation mechanisms that shape $P$ distribution between surface and subsurface layers, and will ultimately determine the future TP versus DRP loading trends in the area. Yet, we cannot identify any of the available mechanistic models as properly equipped to reproduce the major pathways operating in artificially drained fields (Radcliffe et al. 2015).

\section{Effects of changing climate on runoff, sediment, and nutrient export along the watershed-aquatic continuum}

The Great Lakes are experiencing long-term climatic trends consistent with the projected human-induced climate change. Annual temperatures are rising at both rural and urban locations, more frequent extreme heat waves bring record high temperatures, and the growing season is becoming longer (Palecki et al. 2001; Robeson 2002; Hayhoe 2010). Evapotranspiration is a major component of the water balance, and warmer temperatures are expected to increase the associated water losses (Marshall and Randhir 2008; Wallace et al. 2017). Increased frequencies of heavy rainfall events along with a general declining trend in ice and snow cover/duration are indicative of a profound hydrologic response to warming climate, whereby snowmelt and runoff shift to earlier in the year and subsequently affect the magnitude and timing of runoff volume, soil erosion, and nutrient export at the watershed scale (Kunkel et al. 1999; Argyilan and Forman 2003; Hayhoe 2010). In Southern Ontario, it has been hypothesized that nutrient loading may change from a bimodal delivery pattern in cold winters, when a quiescent period is followed by intense spring freshet, to a more continuous tributary response and nutrient export pattern during warm winters (Long et al. 2014, 2015). Climate warming could thus increase the vulnerability of soils to erosion in winter (snowpack decrease, early onset of spring snowmelt, frequent rainfall events, and snowmelt episodes), and consequently the contemporaneous sediment and nutrient loadings relative to current levels (Bosch et al. 2014; Verma et al. 2015). While this empirical evidence is on par with recent modelling projections, other hypotheses suggest that elevated winter air temperatures would likely lead to increased surface permeability (as opposed to an impermeable frozen surface), resulting in a greater potential for infiltration and (or) recharge and not necessarily to an increase in runoff and (or) erosion events 
(Gombault et al. 2015). Given the wide range of possibilities regarding the impact of climate change on water quantity and quality from the Lake Erie watershed, it is critical to improve our understanding of the potential changes in the interplay among catchment state, land use, and nutrient export patterns induced by a changing climate, and communicate the associated uncertainty accordingly (Woznicki and Pouyan Nejadhashemi 2014; Arhonditsis et al. 2019a).

General circulation models (GCMs) are popular numerical tools for simulating the effects of increasing concentrations of greenhouse gases on the climate system (Tzabiras et al. 2016), but the associated projections are subject to uncertainties originating from model, scenarios, and intrinsic system variabilities, and their relative importance varies among variables of interest, location, lead time, and temporal scales (Hawkins and Sutton 2009; Giuntoli et al. 2018). Model (also known as response) uncertainty refers to the projection of distinct climate responses by different GCM models, despite being driven by identical external forcing. This difference in GCM outputs stems from the model structure and parameterization constrains that are postulated in light of incomplete knowledge of the geophysical processes underlying global change (Hingray and Saïd 2014). Scenario uncertainty arises from our incomplete understanding of the external conditions that influence the climate system, such as the unpredictable future trajectories of greenhouse gases, land-use changes, and stratospheric ozone concentrations (Giuntoli et al. 2018). Intrinsic variability (or climate noise) is the natural variability in the climate system that results from nonlinear dynamic and stochastic processes pertaining to the atmosphere, ocean, and the coupled stratospheretroposphere system. Model and scenario uncertainties become dominant sources at longer time scales for both regional and larger spatial domains, whereas internal variability generally becomes more significant within shorter time spans and smaller spatial scales (Hawkins and Sutton 2009). Recognizing the significant uncertainties associated with any climate forecasting exercise, several weighted ensemble methods have been used to combine projections of a wide range of GCMs to reduce the likelihood of Type I (a valid alternative model may be omitted from the decision making process) or Type II (use of an erroneous mathematical construct that we failed to reject in an earlier stage) model errors (Dayon et al. 2018; Her et al. 2019; Beigi et al. 2019). A common feature of all the conventional GCM weighting strategies is their dependence upon the assessment of model performance against historical records of multiple climatic variables (Colorado-Ruiz et al. 2018). From a watershed hydrology perspective, this approach pose challenges limitations because climate models usually serve for a wide range of field applications (e.g., risks of floods and droughts, projections of water quality), and therefore the local modelling community should determine the focal variable (s) for the GCM error assessment or even the establishment of performance standards for the same variable(s) based on research goals, prior experience, and knowledge of the system (Fig. 8).

A great deal of the investigations into climate-induced changes on watershed hydrology have revolved around the characterization of the flow discharge - nutrient concentration relationships depending on the watershed physiography, land-use patterns, and antecedent soil moisture conditions (Green et al. 2007; Godsey et al. 2009; Long et al. 2014, 2015). TP concentrations correlate strongly with flow, because particulate constituents are generally transported by overland flow or via soil macropores to tile drains, and can be remobilized from the streambed/bank (Green et al. 2007; Macrae et al. 2007; Vidon and Cuadra 2010). Dissolved forms of phosphorus have also been linked to overland flow, but the registered concentrations display a weaker relationship with stream discharge during high-flow regimes (Tesoriero et al. 2009; Meybeck and Moatar 2012). Counter to our understanding of $\mathrm{P}$ fate and transport, an overarching flow-concentration paradigm for $\mathrm{N}$ is less clear, given that a greater fraction of $\mathrm{TN}$ is found in the dissolved phase. Owing to their high solubility, nitrite/nitrate can be transported by overland, subsurface, or groundwater flow pathways and typically display chemostatic behavior, i.e., apparent stability of the concentrations relative to the flow variability (Godsey et al. 2009; Long et al. 2014). Other N species (ammonium, total Kjeldahl nitrogen) are relatively insoluble and (or) less amenable to subsurface leaching because of immobilization by clay or other soil chemical constituents, and levels may therefore be distinctly higher during precipitation and snowmelt events (Long et al. 2014). Given that the relative contribution of different $\mathrm{N}$ species from the major subwatersheds in Lake Erie (e.g., Grand, Maumee, Sandusky, and Raisin rivers) is likely to be one of the regulatory factors of the downstream water quality conditions, e.g., the composition of the phytoplankton community (Bosch et al. 2014; Verma et al. 2015), it is important to establish the nature of the $\mathrm{N}$ concentrationdischarge relationships as well as to improve the characterization of the processes associated with the $\mathrm{N}$ cycle under a changing climate.

In the same context, another challenge with the existing processbased watershed modelling work in Lake Erie is the aforementioned underestimation of the event-flow rates and associated nutrient loading. The characterization of surface runoff and subsurface processes during flow events is particularly critical, in light of recent evidence that both TP and phosphate loads can vary by three orders of magnitude between wet and dry conditions, with storm events and spring freshets driving peak daily loads in urban and agricultural watersheds, respectively (Long et al. 2014, 2015). One of the research priorities to rectify the misrepresentation of event-flow conditions should thus be the design of high frequency, event-based, water quality sampling coupled with water-stable isotope analysis $\left({ }^{18} \mathrm{O}\right.$ and $\left.{ }^{2} \mathrm{H}\right)$ to distinguish between baseline and extreme-event conditions, especially if the frequency of such meteorological events will continue to increase with climate change (Klaus and McDonnell 2013; Long et al. 2015). A number of recent studies have advocated the finer granularity of this framework to effectively integrate across the different scales of interest between climate and water quality research (Michalak 2016; Ockenden et al. 2017). From a modelling standpoint, the fact that different surface and subsurface runoff generation mechanisms underlie extreme and "regular" stream flows has been proposed as a mechanistic explanation of why calibration exercises rarely find an "ideal" parameter vector (i.e., process characterization) that will simultaneously recreate both conditions (e.g., Cibin et al. 2010; Zhang et al. 2011). In particular, small runoff events are typically associated with slow flow through the soil-matrix continuum (McDonnell 1990), whereas macropore-driven processes regulated by several controlling factors (e.g., antecedent wetness, rainfall intensity, vegetation, soil stability) appear to prevail during larger events (Zehe et al. 2001). Depending on the magnitude of storm events, macropore flow may account for $11 \%-50 \%$ of the total water movement at tile-drained field sites (Vidon and Cuadra 2010), where water enters the preferential flow paths from the soil matrix once the threshold of soil-water capacity is exceeded (Klaus and McDonnell 2013).

There are two major strategies that have been proposed to accommodate threshold behavior in watershed models (Zehe and Sivapalan 2009). The first strategy is explicit through the introduction of a two-domain conceptualization of soil water movement into numerical watershed models, whereby flow through the soil matrix or macropore flow is responsible for small- and large-runoff events, respectively (Zehe et al. 2001). The second approach posits that the watershed operates in multiple states or modes of behavior, the identification of which is a component of the model calibration process (Ali et al. 2013). A characteristic example of the latter strategy is the Bayesian hierarchical calibration methodology presented by Wellen et al. (2014b), which postulated that the watershed response to precipitation occurs in distinct states, and thus a threshold of precipitation exists above which the watershed is characterized by different 
Fig. 8. Examination of the effects of a changing climate on runoff, sediment, and nutrient export with an ensemble of climate and watershed models. Ensemble modelling is the process of running two or more related models with respect to their conceptual/structural characterization and input specification, and then synthesizing the results into a single score or spread to improve the accuracy of predictive analytics and data mining applications. Recognizing the significant uncertainties associated with any analysis of climate scenarios (inset diagram), several weighted ensemble methods have been used to combine projections of global circulation models (GCMs). A common feature of all the conventional GCM weighting strategies is their dependence upon the model performance assessment against historical records of multiple climatic variables. Given that climate models usually serve for a wide range of field applications (e.g., risks of floods and droughts, water quality projections), one of challenges of the modelling community is to determine the focal variable(s) for the GCM error assessment or establishment of performance standards for the same variable(s) based on research goals, prior experience, and system knowledge.

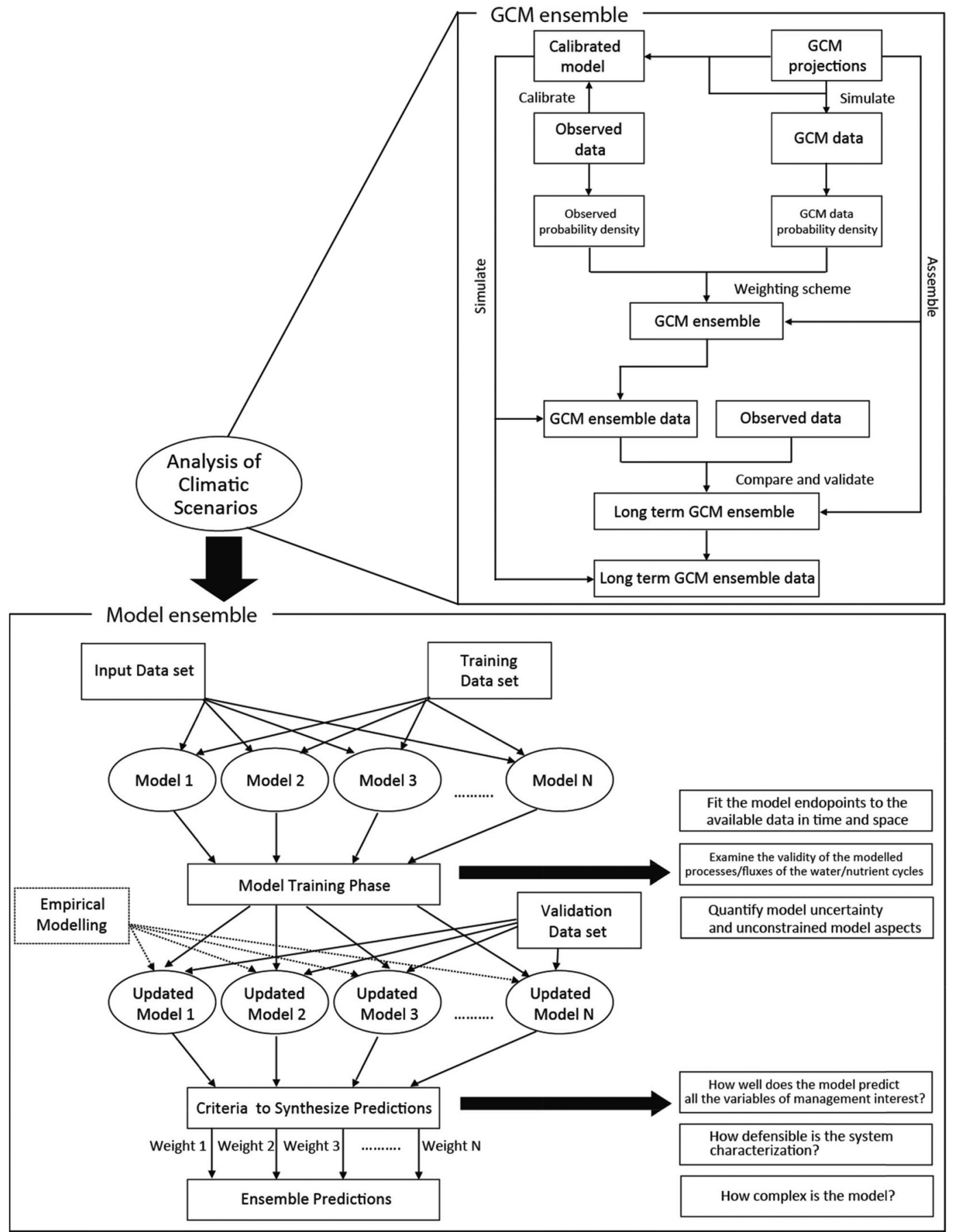


Fig. 9. Ensemble of complementary watershed models with a three-level hierarchical structure. The first level aims to provide large-scale approximations or exploratory analysis of the studied watershed (nutrient export, land-to-water delivery, in-stream attenuation) with coarse spatial (reach, subwatershed) and temporal (year) resolution using empirical models (SPARROW) or simple hydrological nutrient models (GWLF-E). The second level is designed to assist with the hot-spot delineation and best management practices assessment within a watershed context, based on models that can accommodate finer spatial $\left(\mathrm{km}^{2}\right)$ or temporal (days) resolution, like SWAT, INCA, HYPE, MIKE SHE. The third level comprises complex models with sophisticated physical, chemical, and biological components and fine granularity in time (hour) and space $\left(\mathrm{m}^{2}\right)$ that are intended to recreate specific facets of watershed functioning, such as the underlying processes at the farm level (AnnAGNPS, APEX) or extreme flow events (DWSM, HSPF, MIKE SHE, SWMM).

\section{Watershed model application}

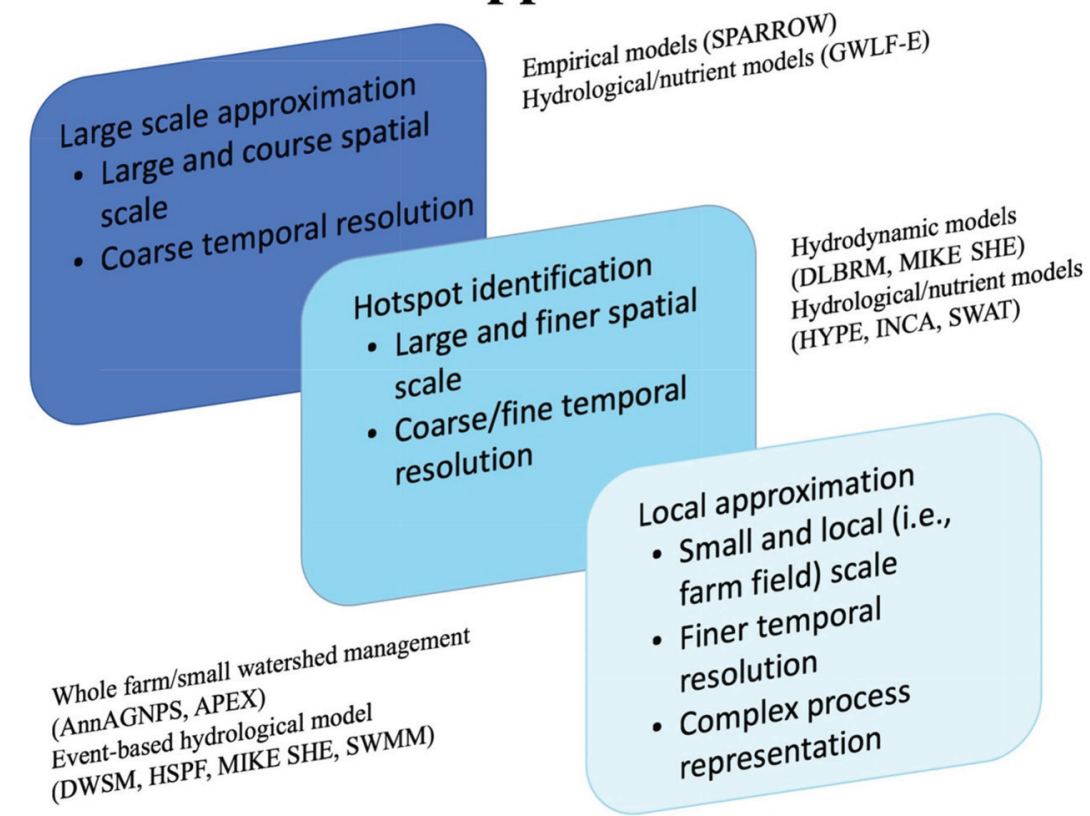

parameter values relative to those used to reproduce the watershed below the threshold. However, the values of a particular parameter are not independent among the watershed states or modes of behavior but are characterized by a covariance structure to be identified during model calibration. This calibration framework was operationalized with the SWAT model by introducing a precipitation threshold, above which the watershed is characterized by a different CN2 value relative to the one used below the threshold. In doing so, Wellen et al. (2014b) identified precipitation thresholds that trigger shifts to alternative watershed states with a higher propensity for runoff generation. Considering the well-documented structural deficiency of SWAT for reproducing critical hydrological and sediment processes in urban settings, the two-domain process characterization, as determined by a precipitation-based breakpoint, could be a more suitable strategy for the latter land-use category. In agricultural catchments however, Dong et al. (2019) presented an alternative calibration strategy that based the identification of the different modes of behavior on the landscape changes occurring between the growing and dormant seasons. In particular, they showed that the value assigned to the CN2 parameter reflecting the dormant season was $45 \%$ higher than the value specified for the growing season, which is indicative of a greater conversion of rainfall to surface runoff during the dormant period of the year (Dong et al. 2019).

\section{Building an ensemble of watershed models in Lake Erie}

Notwithstanding the various differences in their conceptual and structural foundation, the watershed models examined can be broadly classified into two categories, based on the degree of sophistication of the critical hydrological (empirical or semi-empirical versus physically based) and biogeochemical (empirical versus explicit reactive-transport) processes. Within a given setting (e.g., catchment features, predominant land uses, data/ empirical knowledge available, intended use of the model), each model category displays different strengths and weaknesses in realizing a robust characterization of the watershed attributes and functioning. It has thus been postulated that the mean predictions and associated uncertainty envelope derived from an ensemble strategy provide a better framework for evaluating the efficiency of alternative BMP scenarios (Scavia et al. 2017). In this context, Arhonditsis et al. (2019a) highlighted the importance of three critical steps related to the development of multimodel ensembles, involving $(i)$ identification of the conceptual or structural differences of the available models, thereby ensuring that the prospective ensemble members are actually diverse; (ii) determination of the most suitable calibration/validation domain for evaluating model performance in time/space, and synthesize the predictions among different models based on their ability to be used for extrapolative tasks, i.e., forecast conditions distinctly different from those currently prevailing in the watershed modelled; and (iii) establishment of an optimal weighting scheme to assign weights to each ensemble member, when integrating over the individual predictions, and determine the most likely outcome along with the associated uncertainty bounds.

In reviewing the pertinent literature, our study showed that there are models with more sophisticated strategies for representing surface runoff, groundwater, and sediment erosion processes than those in SWAT (Wellen et al. 2015; Arhonditsis et al. $2019 b$ ). Assuming that local empirical knowledge is available to constrain the additional parameters, MIKE SHE provides the most comprehensive 3D representation of the interplay between surface and subsurface hydrological processes with a full dynamic description, whereby we can recreate the solute transport that infiltrates from the surface to the unsaturated soil layer 
and subsequently percolates into the saturated layer. Likewise, the physically based submodels designed to dynamically represent the sediment detachment and erosion/removal processes (DWSM, HBV-INCA, HSPF, HYPE, and MIKE SHE) offer a distinct alternative that could be combined with a USLE-type empirical strategy under a model-ensemble construct. We also note the advantage of SWAT for explicitly simulating daily plant growth, which in turn facilitates the reproduction of soil P dynamics as the net balance of sources (fertilizers, manure, and plant residues) and sinks (plant uptake, water flow, and soil erosion). This mechanistic augmentation should be combined with dynamic representation of the impact of chemical and physical soil properties (e.g., $\mathrm{pH}$ and temperature) or the soluble-P concentrations on adsorption/desorption processes (Wade et al. 2002b; Vadas and White 2010). The consideration of dynamic $P$ subroutines can be quite critical when evaluating the long-term watershed responses to various agricultural management strategies (Arhonditsis et al. 2019b). Drawing parallels with the (sub)surface and sediment erosion processes, a more complicated physically based approach, e.g., the dynamic wave model provided by MIKE SHE and SWMM (Refsgaard and Storm 1995; Rossman and Huber 2016a), may also be more appropriate to realistically simulate pressurized flow and the backwater effects of water routing in both open channels and closed pipes. While all of our propositions seem to favor the inclusion of more complex models that can in principle exacerbate the equifinality problem, we believe that this issue can be counterbalanced by the consideration of simpler empirical models that can either constrain the plausible values of individual processes (e.g., see "statistical models" in the section above on Data-driven watershed modelling), improve the characterization of land use versus runoff/nutrient export patterns (e.g., risk-based models derived from edge-of-field studies), and validate macroscale processes (e.g., land-to-water delivery or instream attenuation estimates provided by hybrid semi-empirical models).

In terms of model diversity, the existing watershed modelling work in the Maumee River watershed, comprising five applications of the same complex mathematical (SWAT) model, represents an attempt to capture the uncertainty of the model input (parameter values assigned, assumptions made regarding critical forcing functions, e.g., manure/fertilizer application rates), but the predictions drawn are effectively shaped by the same structural foundation, and thus can only partly advance our understanding of watershed dynamics. A true ensemble should instead consist of a wide range of data-driven and process-based models to ensure that adequate structural model diversity is in place (Fig. 8). In the same line of reasoning, Arhonditsis et al. (2019a) contended that the true diversity of a model ensemble is not solely determined from the complexity of the mathematics or the number of system components simulated, but also from the characterization of the ecosystem processes, as determined by the parameter values assigned during the calibration and validation phase of the individual models, which ultimately determine the forecasts derived to guide the policy-making process. In this context, we propose the development of an ensemble of complementary watershed models with a three-level hierarchical structure that spans a wide range of spatiotemporal scales and granularity in the study of the interplay among physical, chemical, and biological components (Fig. 9). The first level would provide large-scale approximations or exploratory analysis of the studied watershed (nutrient export, land-to-water delivery, instream attenuation) with coarse spatial (reach, subwatershed) and temporal (year) resolution using empirical models (SPARROW) or simple hydrological nutrient models (GWLF-E). The second level is designed to assist with delineating hot-spots and assessing BMP within a watershed context, based on models that accommodate finer spatial $\left(\mathrm{km}^{2}\right)$ or temporal (days) resolution, such as SWAT, INCA, HYPE, and MIKE SHE. The third level would comprise complex models with sophisticated physical, chemical, and biological/ mechanistic foundations and fine granularity in time (hours) and space $\left(\mathrm{m}^{2}\right)$ that are intended to recreate specific facets of watershed functioning, such as the underlying processes at the farm level (AnnAGNPS, APEX) or extreme flow events (DWSM, HSPF, SWMM). The proposed ensemble of complementary models would offer a comprehensive framework with a logical flow, starting with simpler and gradually undertaking more complex research questions, which is also on par with the typical advancement of our knowledge in any given watershed. In doing so, we also put in place a more effective strategy for controlling the uncertainty in a modelbased watershed management process, rather than opting for unjustifiably complex models that cannot be constrained by the local empirical knowledge and data. The resource constraints for establishing model ensembles can be partly overcome by relying on currently developed catchment models, such as SWAT and HYPE applications through the Great Lakes Runoff Intercomparison Project (Gaborit et al. 2017) and by establishing partnerships between active watershed modelling groups in the area from governmental agencies, universities, and industry (Scavia et al. 2016, 2017).

Consistent with the practice followed in the Maumee River watershed, the use of identical validation time periods across all the ensemble members is desirable, as it (partly) insures comparability for the purposes of a post-hoc ensemble synthesis (Scavia et al. 2017). In terms of the consideration of space, even though a basin-outlet calibration strategy may be reasonably defensible for the western Lake Erie watershed, as it encompasses very homogenous landscape with a flat and predominant agricultural land (Daggupati et al. 2015), it should be cautioned that the likelihood to get "good results for wrong reasons" is much higher than with a spatial-explicit calibration strategy (Dong et al. 2019). In particular, recent research has shown that calibrating distributed, process-based models against data from multiple stations within a nested basin context can reduce the uncertainty of the water quality predictions and also improve the accuracy at the upstream stations (Pettersson et al. 2001; Jiang et al. 2014). Likewise, Wellen et al. (2015) showed that the metrics of fit tend to be higher when calibrating only to the basin outlet, but the associated results likely offer an overconfident assessment of a distributed model's ability to reproduce the internal dynamics of the basin as well as the delineation of areas with high risk of nutrient export. Thus, using information from multiple locations in space to constrain model predictions is an important step to improve the credibility of the source attributions and land use scenarios (Dong et al. 2019). An alternative (but not mutually exclusive) strategy is to use the derived spatial patterns of nutrient export from empirical (SPARROW-like) models geared to depict basinspecific (rather than continental or regional) nutrient loading conditions. This can offer a multitude of complementary benefits, such as validating the spatial delineation of hot-spots with higher propensity for nutrient export, narrowing down the uncertainty of processes/fluxes parameterized by mechanistic models, and obtaining predictive statements constrained within the bounds of data-based parameter estimation (Arhonditsis et al. 2019b).

On a final note, one of the critical decisions from a technical standpoint involves the selection of the averaging scheme to objectively synthesize the predictions of multiple models (Wilks 2002; Raftery et al. 2005; Roulston and Smith 2003). Some of the outstanding challenges involve the development of ground rules for the features of the calibration and validation model domain (Ramin et al. 2012), the inclusion of penalties for model complexity that will allow building forecasts upon parsimonious models (McDonald and Urban 2010; Paudel and Jawitz 2012), and performance assessment that does not exclusively consider model endpoints but also examines the plausibility of the values derived for major processes of the water budget and biogeochemical cycles (Wellen et al. 2015). Generally, our thesis is that model ensembles should not be based merely on simple averaging of 
individual model predictions, but should also consider their goodness-of-fit and bias (Arhonditsis et al. 2019a). Not only do we stress the importance of considering the error of the individual models as a weighting factor to determine their corresponding influence on the ensemble predictions, but we also argue that their skill assessment should be done separately against baseline and event conditions. A promising advancement towards a rigorous synthesis of multiple model predictions is the Bayesian averaging framework used by Scavia et al. (2017), whereby the weights of each of the SWAT models for the Maumee River watershed were based on their predictive performance either for TP or DRP loading over a selected validation dataset. In our recent work (Ramin et al. 2012), we have also opted for a strategy that considers performance over all the model endpoints rather than the variables more closely related to the environmental management problem at hand. While this approach may entail the risk of downplaying the impact of the best performing model for a particular variable, we believe that a fair assessment of the value of all the models integrated in an ensemble environmental forecast should strive for balanced performance over their entire structure. This approach aims to penalize the likelihood of calibration bias, whereby the maximization of the fit for a specific variable (e.g., flow, suspended solids) may be accompanied by high error for other variables (dissolved or particulate phosphorus), and thus avoids forecasts founded upon models with misleadingly high weights that conceal fundamentally flawed representations of the watershed behavior. Future efforts to develop weighting schemes suitable for the synthesis of watershed model predictions should also factor in the model complexity either expressed as the number of model state variables or as the "effective" number of parameters that have been used during the calibration exercise (Ramin et al. 2012).

\section{Conclusions}

Watershed process-based modelling has been an indispensable tool to shed light on the causal linkages among hydrological changes, agricultural management practices, and downstream nutrient delivery. Our examination of eleven spatially distributed models is suggestive of a tradeoff between the representation of the water cycle and the associated biogeochemical processes within a watershed context; namely, either simpler approximations of the nutrient fate and transport are combined with advanced representation of the hydrological processes, or a greater degree of realism with the simulated biogeochemistry is counterbalanced by a simplified representation of the role of critical hydrological and (or) sediment-erosion processes. Recognizing that there is no "perfect" watershed process-based model, but rather several adequate descriptions of different conceptual basis and structure, the adoption of a multi-model framework is specifically designed to address the uncertainty inherent in the model selection process. Nonetheless, the presence of multiple models on its own cannot ensure that the decision-making process is reliably supported, as there are several methodological steps required in order (i) to identify the conceptual or structural differences of the existing models, and thus determine the actual diversity (or rule out the likelihood of "pseudo-replication") collectively characterizing a multi-model ensemble; (ii) to determine the most suitable calibration/validation domain and resolution for evaluating model performance in time and space; and (iii) to establish an optimal weighting scheme to assign weights to individual models, when integrating over their corresponding predictions, and subsequently determine the most likely outcome along with the associated uncertainty bounds.

Notwithstanding the popularity of SWAT, owing to its conceptual and operational advantages, our study showed that it could be complemented by the modules of other watershed models, especially for surface runoff, groundwater and sediment erosion processes. In particular, MIKE SHE seems to be more up-to-date with respect to the hydrological and sediment mechanisms considered, assuming that local empirical knowledge is available to constrain the additional parameters. It should also be noted that the applicability of MIKE SHE is predominantly constrained to the evaluation of structural BMPs with limited capacity to assess the potential mitigation effects of non-structural conservation practices (Liu et al. 2016; Singh and Bhattarai 2019). Regarding the simulated P cycle, SWAT has the advantage in explicitly simulating the daily plant growth, but it could be further improved by adopting a dynamic P equilibrium concentration. MIKE SHE and SWMM are superior to SWAT in channel routing because of their capability to realistically simulate pressurized flow and backwater effects of water routing in both open channels and closed pipes. Our propositions are admittedly in favor of the inclusion of more complex models that can in principle exacerbate the equifinality problem, but we believe that this issue can be offset by the consideration of simpler empirical models that can either constrain the plausible values of individual processes by statistical models, improve the characterization of land use versus runoff/ nutrient export patterns from edge-of-field studies, and validate macroscale processes against estimates provided by hybrid semiempirical models. Critical facets of the watershed functioning, such as the role of legacy $\mathrm{P}$, the causes and consequences of the increasing long-term trends in dissolved reactive phosphorus loading, the challenges in reproducing spring-freshet or eventflow conditions, and the dynamic characterization of water/ nutrient cycles under the non-stationarity of a changing climate, will require special attention from the on-going watershed modelling work in Lake Erie. Our companion paper by Arnillas et al. (2021) addresses a complementary topic pertaining to the capacity of the current generation of process-based models to recreate the potential structural and functional changes in the water/nutrient cycles, along with the associated uncertainties, induced by the implementation of candidate BMPs in Lake Erie. Although BMP implementation is typically based on the stipulation that both short- and long-term effectiveness are guaranteed, emerging evidence is suggestive of moderate water quality improvements in many watersheds and significant variability in their performance, often much lower compared to the specs of the original design from experimental studies. Given this uncertainty in regard to the BMP life-cycle performance, we contend that another challenge of the contemporary modelling practice is to introduce more pragmatic methods to assess the likelihood of the achievability of the proposed nutrient loading reduction goals.

\section{Acknowledgements}

This project has received funding support from Environment and Climate Change Canada (Request for Proposal \#5000046715). We are grateful to Mary Thorburn, Jennifer Winter, Mark Peacock, Anna Crolla, Karen Alexander, Alyssa Cousineau, Stephen Marklevitz, Joanne Rzadki, and Pamela Joosse for their constructive input during an Adaptive Management and Modelling Workshop held on March 3, 2020.

\section{References}

Abrahamsen, P., and Hansen, S. 2000. DAISY: an open soil-crop-atmosphere system model. Environ. Model. Softw. 15: 313-330. doi:10.1016/S1364-8152 (00)00003-7.

Agriculture and Agri-Food Canada and Statistics Canada. 2016. Interpolated Census of Agriculture related to National Hydro Network (NHN) for 2016. Available from https://open.canada.ca/data/en/dataset/9c285bb1-7919-426ab6c0-29a4d2edde48.

Akan, A.O., and Houghtalen, R.J. 2003. Urban hydrology, hydraulics, and stormwater quality: engineering applications and computer modelling. John Wiley \& Sons, Hoboken, N.J. 
Alexander, R.B., Smith, R.A., and Schwarz, G.E. 2000. Effect of stream channel size on the delivery of nitrogen to the Gulf of Mexico. Nature, 403: 758-761. doi:10.1038/35001562. PMID:10693802.

Alexander, R.B., Elliott, A.H., Shankar, U., and McBride, G.B. 2002. Estimating the sources and transport of nutrients in the Waikato River Basin, New Zealand. Water Resour. Res. 38: 4-1-4-23. doi:10.1029/2001WR000878.

Alexander, R.B., Smith, R.A., and Schwarz, G.E. 2004. Estimates of diffuse phosphorus sources in surface waters of the United States using a spatially referenced watershed model. Water Sci. Technol. 49: 1-10. doi:10.2166/ wst.2004.0150. PMID:15053093.

Ali, G., Oswald, C.J., Spence, C., Cammeraat, E.L.H., McGuire, K.J., Meixner, T., and Reaney, S.M. 2013. Towards a unified threshold-based hydrological theory: Necessary components and recurring challenges. Hydrol. Process. 27: 313-318. doi:10.1002/hyp.9560.

Allaire, E.S., Van Bochove, E., Denault, J.T., Dadfar, H., Thériault, G., Charles, A., and De Jong, R. 2011. Preferential pathways of phosphorus movement from agricultural land to water bodies in the Canadian Great Lakes basin: A predictive tool. Can. J. Soil Sci. 91(3): 361-374. doi:10.4141/cjss09121.

Allen, R.G., Pereira, L.S., Raes, D., and Smith, M. 1998. Crop evapotranspiration (guidelines for computing crop water requirements). FAO Irrigation and Drainage Paper 56. FAO, Rome.

Andersson, L., Rosberg, J., Pers, B.C., Olsson, J., and Arheimer, B. 2005. Estimating catchment nutrient flow with the HBV-NP model: sensitivity to input data. Ambio, 34(7): 521-532. doi:10.1579/0044-7447-34.7.521. PMID:16435741.

Antikainen, R., Lemola, R., Nousiainen, J.I., Sokka, L., Esala, M., Huhtanen, P., and Rekolainen, S. 2005. Stocks and flows of nitrogen and phosphorus in the Finnish food production and consumption system. Agric. Ecosyst. Environ. 107: 287-305. doi:10.1016/j.agee.2004.10.025.

Argyilan, E.P., and Forman, S.L. 2003. Lake level response to seasonal climatic variability in the Lake Michigan-Huron system from 1920 to 1995 . J. Great Lakes Res. 29: 488-500. doi:10.1016/S0380-1330(03)70453-5.

Arheimer, B., Löwgren, M., Pers, B.C., and Rosberg, J. 2005. Integrated catchment modeling for nutrient reduction: scenarios showing impacts, potential, and cost of measures. Ambio, 34: 513-520. doi:10.1579/00447447-34.7.513. PMID:16435740.

Arhonditsis, G.B., Qian, S.S., Stow, C.A., Lamon, E.C., and Reckhow, K.H. 2007. Eutrophication risk assessment using Bayesian calibration of process-based models: Application to a mesotrophic lake. Ecol. Modell. 208: 215-229. doi:10.1016/j.ecolmodel.2007.05.020.

Arhonditsis, G.B., Neumann, A., Shimoda, Y., Kim, D.K., Dong, F., Onandia, G., et al. 2019a. Castles built on sand or predictive limnology in action? Part A: Evaluation of an integrated modelling framework to guide adaptive management implementation in Lake Erie. Ecol. Inform. 53: 100968. doi:10.1016/j. ecoinf.2019.05.014.

Arhonditsis, G.B., Neumann, A., Shimoda, Y., Kim, D.-K., Dong, F., Onandia, G., et al. 2019b. Castles built on sand or predictive limnology in action? Part B: Designing the next monitoring-modelling-assessment cycle of adaptive management in Lake Erie. Ecol. Inform. 53: 100969. doi:10.1016/j.ecoinf.2019.05.015.

Arnillas, C.A. 2019. Determinism vs. stochasticity in community assembly processes: The role of species phylogeny and dominance. Ph.D. thesis, University of Toronto. Available from https://tspace.library.utoronto.ca/ handle $/ 1807 / 95735$

Arnillas, C.A., Yang, C., Zamaria, S.A., Neumann, A., Javed, A., Shimoda, Y., et al. 2021. Integrating watershed and ecosystem service models to assess best management practice efficiency: guidelines for Lake Erie managers and watershed modellers. Envir. Rev. 29: 31-63. doi:10.1139/er-2020-0071.

Arnold, J.G., Srinivasan, R., Muttiah, R.S., and Williams, J.R. 1998. Large area hydrologic modeling and assessment part I: Model development. J. Am. Water Resour. Assoc. 34: 73-89. doi:10.1111/j.1752-1688.1998.tb05961.x.

Arnold, J.G., Youssef, M.A., Yen, H., White, M.J., Sheshukov, A.Y., Sadeghi, A.M., et al. 2015. Hydrological processes and model representation: impact of soft data on calibration. Trans. ASABE. doi:10.13031/trans.58.10726.

Babovic, V., and Savic, D. 2009. Hydroinformatics in hydrology, hydrogeology and water resources. No. 331. IAHS-AISH Publishing.

Bagnold, R.A. 1966. An approach to the sediment transport problem from general physics. U.S. Geol. Surv. Prof. Pap. 422-I.

Bagnold, R.A. 1977. Bed load transport by natural rivers. Water Resour. Res. 13: 303-312. doi:10.1029/WR013i002p00303.

Bai, J., Shen, Z., and Yan, T. 2017. A comparison of single- and multi-site calibration and validation: a case study of SWAT in the Miyun Reservoir watershed, China. Front. Earth Sci. 11: 592-600. doi:10.1007/s11707-0170656-X.

Bailey, R.G. 2014. Ecoregions: The ecosystem geography of the oceans and continents. Springer, New York. doi:10.1007/978-1-4939-0524-9.

Baker, D.B., Confesor, R., Ewing, D.E., Johnson, L.T., Kramer, J.W., and Merryfield, B.J. 2014. Phosphorus loading to Lake Erie from the Maumee, Sandusky and Cuyahoga rivers: The importance of bioavailability. J. Great Lakes Res. 40: 502-517. doi:10.1016/j.jglr.2014.05.001.

Baker, D.B., Johnson, L.T., Confesor, R.B., and Crumrine, J.P. 2017. Vertical stratification of soil phosphorus as a concern for dissolved phosphorus runoff in the Lake Erie basin. J. Environ. Qual. 46: 1287-1295. doi:10.2134/ jeq2016.09.0337. PMID:29293833.

Baltas, E.A., Dervos, N.A., and Mimikou, M.A. 2007. Technical Note: Determination of the SCS initial abstraction ratio in an experimental watershed in Greece. Hydrol. Earth Syst. Sci. 11(6): 1825-1829. doi:10.5194/hess-111825-2007.

Bao, C., Li, L., Shi, Y., and Duffy, C. 2017. Understanding watershed hydrogeochemistry: 1. Development of RT-Flux-PIHM. Water Resour. Res. 53: 2328-2345. doi:10.1002/2016WR018934.

Beaudin, I., Giroux, M., Michaud, A., and Beaudet, P. 2008. Les sources, les formes et la gestion du phosphore en milieu agricole. Technical factsheet, IRDA et CRAAQ. Available from https://www.craaq.qc.ca/data/ DOCUMENTS/EVC019.pdf.

Behrendt, H., and Opitz, D. 1999. Retention of nutrients in river systems: dependence on specific runoff and hydraulic load. In Man and river systems. Springer, Dordrecht, the Netherlands. pp. 111-122. doi:10.1007/97894-017-2163-9_13.

Beigi, E., Tsai, F.T.C., Singh, V.P., and Kao, S.C. 2019. Bayesian hierarchical model uncertainty quantification for future hydroclimate projections in Southern Hills-Gulf region, USA. Water, 11: 268. doi:10.3390/w11020268.

Benavidez, R., Jackson, B., Maxwell, D., and Norton, K. 2018. A review of the (Revised) Universal Soil Loss Equation ((R)USLE): With a view to increasing its global applicability and improving soil loss estimates. Hydrol. Earth Syst. Sci. 22: 6059-6086. doi:10.5194/hess-22-6059-2018.

Benoy, G.A., Jenkinson, R.W., Robertson, D.M., and Saad, D.A. 2016. Nutrient delivery to Lake Winnipeg from the Red-Assiniboine River Basin - A binational application of the SPARROW model. Can. Water Resour. J. 41: 429-447. doi:10.1080/07011784.2016.1178601.

Benskin, C.M.H.W.H., Roberts, W.M., Wang, Y., and Haygarth, P.M. 2014. Review of the Annual Phosphorus Loss Estimator tool - a new model for estimating phosphorus losses at the field scale. Soil Use Manage. 30: 337341. doi:10.1111/sum.12128.

Bergström, S. 1976. Development and application of a conceptional runoff model for scandinavian catchments. Report RHO7. Swedish Meterological and Hydrological Institute, Norrköping, Schweden. 134 pp.

Berner, R.A. 1980. Early diagenesis. Theoretical approach. Princeton University Press. doi:10.1515/9780691209401.

Bertani, I., Obenour, D.R., Steger, C.E., Stow, C.A., Gronewold, A.D., and Scavia, D. 2016. Probabilistically assessing the role of nutrient loading in harmful algal bloom formation in western Lake Erie. J. Great Lakes Res. 42: 1184-1192. doi:10.1016/j.jglr.2016.04.002.

Beven, K. 2006. A manifesto for the equifinality thesis. J. Hydrol. 320: 18-36. doi:10.1016/j.jhydrol.2005.07.007.

Beven, K. 2019. How to make advances in hydrological modelling. Hydrol. Res. 50: 1481-1494. doi:10.2166/nh.2019.134.

Beven, K., and Germann, P. 2013. Macropores and water flow in soils revisited. Water Resour. Res. 49: 3071-3092. doi:10.1002/wrcr.20156.

Beven, K.J., and Kirkby, M.J. 1979. A physically based, variable contributing area model of basin hydrology / Un modèle à base physique de zone d'appel variable de l'hydrologie du bassin versant. Hydrol. Sci. Bull. 24(1): 43-69. doi:10.1080/02626667909491834.

Beven, K., and Lamb, R. 2017. The uncertainty cascade in model fusion. Geol. Soc. London, Spec. Publ. 408: 255-266. doi:10.1144/SP408.3.

Bicknell, B.R., Imhoff, J.C., Kittle, J.L., Jr., Jobs, T.H., and Donigian, A.S. 1996. Hydrological simulation program-FORTRAN: HSPF Version 11 user's manual. Aqua Terra Consultants, Mountain View, Calif.

Bieger, K., Arnold, J.G., Rathjens, H., White, M.J., Bosch, D.D., Allen, P.M., et al. 2017. Introduction to SWAT+, a completely restructured version of the soil and water assessment tool. J. Am. Water Resour. Assoc. 53(1): 115-130. doi:10.1111/1752-1688.12482.

Bingner, R.L., Wells, R.R., Momm, H.G., Theurer, F.D., and Frees, L.D. 2010. [July.] Development and application of gully erosion components within the USDA AnnAGNPS watershed model for precision conservation. In The 10th International Conference on Precision Agriculture.

Bingner, R.L., Drive, M., Theurer, F.D., Yuan, Y., and Taguas, E.V. 2018. AnnAGNPS Technical processes. Version 5.5. Available from https://www. wcc.nrcs.usda.gov/ftpref/wntsc/H\&H/AGNPS/downloads/AnnAGNPS_Technical_ Documentation.pdf.

Blöschl, G. 2005. Statistical upscaling and downscaling in hydrology. In Encyclopedia of hydrological sciences. John Wiley \& Sons, Ltd., Chichester, U.K. doi:10.1002/0470848944.hsa008.

Bolinder, M.A., Simard, R.R., Beauchemin, S., and MacDonald, K.B. 2000. Indicator of risk of water contamination by P for Soil Landscape of Canada polygons. Can. J. Soil Sci. 80(1): 153-163. doi:10.4141/S99-040.

Boomer, K.M., Weller, D.E., Jordan, T.E., Linker, L., Liu, Z.-J., Reilly, J., et al. 2013. Using multiple watershed models to predict water, nitrogen, and phosphorus discharges to the Patuxent estuary. J. Am. Water Resour. Assoc. 49: 15-39. doi:10.1111/j.1752-1688.2012.00689.x.

Borah, D.K., and Bera, M. 2003. Watershed-scale hydrologic and nonpointsource pollution models: Review of mathematical bases. Trans. Am. Soc. Agric. Eng. 46: 1553-1566. doi:10.13031/2013.15644.

Borah, D.K., Bera, M., Shaw, S., and Keefer, L. 1999. Dynamic modeling and monitoring of water, sediment, nutrients, and pesticides in agricultural watersheds during storm events. ISWS Contract Report CR 655.

Borah, D.K., Xia, R., and Bera, M. 2002. DWSM - A dynamic watershed simulation model, Mathematic. Water Resources Publications, LLC, Highlands Ranch, Colorado.

Borah, D.K., Arnold, J.G., Bera, M., Krug, E.C., and Liang, X.Z. 2007. Storm event and continuous hydrologic modeling for comprehensive and efficient 
watershed simulations. J. Hydrol. Eng. 12: 605-616. doi:10.1061/(ASCE)10840699(2007)12:6(605).

Bosch, N.S., Evans, M.A., Scavia, D., and Allan, J.D. 2014. Interacting effects of climate change and agricultural BMPs on nutrient runoff entering Lake Erie. J. Great Lakes Res. 40: 581-589. doi:10.1016/j.jglr.2014.04.011.

Breuer, L., Huisman, J.A., Willems, P., Bormann, H., Bronstert, A., Croke, B.F.W., et al. 2009. Assessing the impact of land use change on hydrology by ensemble modeling (LUCHEM). I: Model intercomparison with current land use. Adv. Water Resour. 32: 129-146. doi:10.1016/j.advwatres.2008.10.003.

Bruulsema, T.W., Mullen, R.W., O’Halloran, I.P., and Warncke, D.D. 2011. Agricultural phosphorus balance trends in Ontario, Michigan and Ohio. Can. J. Soil Sci. 91(3): 437-442. doi:10.4141/cjss10002.

Buda, A.R. 2013. 7.7 Surface-runoff generation and forms of overland flow. In Treatise on Geomorphology. Edited by J.F. Shroder. Academic Press, San Diego, Calif. pp. 73-84. doi:10.1016/B978-0-12-374739-6.00151-2.

Campbell, E.E., and Paustian, K. 2015. Current developments in soil organic matter modeling and the expansion of model applications: a review. Environ. Res. Lett. 10: 123004. doi:10.1088/1748-9326/10/12/123004.

Canale, R.P., Redder, T., Swiecki, W., and Whelan, G. 2010. Phosphorus budget and remediation plan for Big Platte Lake. J. Water Resour. Plann. Manage. 136: 576-586. doi:10.1061/(ASCE)WR.1943-5452.0000071.

Carroll, R.J., Ruppert, D., Stefanski, L.A., and Crainiceanu, C.M. 2006. Measurement error in nonlinear models: A modern perspective. 2nd ed. CRC Press.

Cela, S., Ketterings, Q.M., Czymmek, K.J., Weld, J., Beegle, D.B., and Kleinman, P.J.A. 2016. Nutrient management planners' feedback on New York and Pennsylvania phosphorus indices. J. Soil Water Conserv. 71: 281-288. doi:10.2489/jswc.71.4.281.

Chaffin, J.D., Bridgeman, T.B., and Bade, D.L. 2013. Nitrogen constrains the growth of late summer cyanobacterial blooms in Lake Erie. AiM, 03: 16-26. doi:10.4236/aim.2013.36A003.

Chanson, H. 2004. Environmental hydraulics for open channel flows. Elsevier. 488 pp. doi:10.1016/B978-0-7506-6165-2.X5028-0.

Chapi, K., Rudra, R.P., Ahmed, S.I., Khan, A.A., Gharabaghi, B., Dickinson, W.T., and Goel, P.K. 2015. Spatial-temporal dynamics of runoff generation areas in a small agricultural watershed in Southern Ontario. J. Water Resour. Prot. 07(01): 14-40. doi:10.4236/jwarp.2015.71002.

Chapin, F.S., III, Matson, P.A., and Vitousek, P. 2011. Principles of terrestrial ecosystem ecology. Springer Science \& Business Media.

Chaplot, V. 2005. Impact of DEM mesh size and soil map scale on SWAT runoff, sediment, and $\mathrm{NO}_{3}-\mathrm{N}$ loads predictions. J. Hydrol. 312: 207-222. doi:10.1016/j.jhydrol.2005.02.017.

Chen, D., Hu, M., and Dahlgren, R.A. 2014. A dynamic watershed model for determining the effects of transient storage on nitrogen export to rivers. Water Resour. Res. 50(10): 7714-7730. doi:10.1002/2014WR015852.

Chen, D., Shen, H., Hu, M., Wang, J., Zhang, Y., and Dahlgren, R.A. 2018. Legacy nutrient dynamics at the watershed scale: principles, modeling, and implications. In Advances in agronomy. Elsevier Inc. pp. 237-313. doi:10.1016| bs.agron.2018.01.005

Chen, H., Teng, Y., Yue, W., and Song, L. 2013. Characterization and source apportionment of water pollution in Jinjiang River. Environ. Monit. Assess. 185(11): 9639-9650. doi:10.1007/s10661-013-3279-z. PMID:23737126.

Chen, M., and Graedel, T.E. 2016. A half-century of global phosphorus flows, stocks, production, consumption, recycling, and environmental impacts. Glob. Environ. Change, 36: 139-152. doi:10.1016/j.gloenvcha.2015.12.005.

Chiu, C.-L., and Tung, N.-C. 2002. Maximum velocity and regularities in open-channel flow. J. Hydraul. Eng. 128: 390-398. doi:10.1061/(ASCE)07339429(2002)128:4(390)

Christiansen, S.J., Thorsen, M., Clausen, T., Hansen, S., and Christian Refsgaard, J. 2004. Modelling of macropore flow and transport processes at catchment scale. J. Hydrol. 299: 136-158. doi:10.1016/j.jhydrol.2004.04.029.

Cibin, R., Sudheer, K.P., and Chaubey, I. 2010. Sensitivity and identifiability of stream flow generation parameters of the SWAT model. Hydrol. Process. 24: 1133-1148. doi:10.1002/hyp.7568.

Cohn, T.A., Delong, L.L., Gilroy, E.J., Hirsch, R.M., and Wells, D.K. 1989. Estimating constituent loads. Water Resour. Res. 25: 937-942. doi:10.1029/ WR025i005p00937.

Cohn, T.A., Caulder, D.L., Gilroy, E.J., Zynjuk, L.D., and Summers, R.M. 1992. The validity of a simple statistical model for estimating fluvial constituent loads: An Empirical study involving nutrient loads entering Chesapeake Bay. Water Resour. Res. 28: 2353-2363. doi:10.1029/92WR01008.

Collick, A.S., Veith, T.L., Fuka, D.R., Kleinman, P.J.A., Buda, A.R., Weld, J.L., et al. 2016. Improved simulation of edaphic and manure phosphorus loss in SWAT. J. Environ. Qual. 45: 1215-1225. doi:10.2134/jeq2015.03.0135. PMID:27380069.

Colorado-Ruiz, G., Cavazos, T., Salinas, J.A., De Grau, P., and Ayala, R. 2018. Climate change projections from Coupled Model Intercomparison Project phase 5 multi-model weighted ensembles for Mexico, the North American monsoon, and the mid-summer drought region. Int. J. Climatol. 38: 56995716. doi:10.1002/joc.5773.

Condron, L.M., Spears, B.M., Haygarth, P.M., Turner, B.L., and Richardson, A.E. 2013. Role of legacy phosphorus in improving global phosphorus-use efficiency. Environ. Dev. 8: 147-148. doi:10.1016/j.envdev.2013.09.003.

Confesor, R.B., Richards, R.P., Arnold, J.G., and Whittaker, G.W. 2011. Modeling dissolved phosphorus exports in Lake Erie watersheds. In 2011 Louisville,
Kentucky, August 7 - August 10, 2011. American Society of Agricultural and Biological Engineers, St. Joseph, Mich. doi:10.13031/2013.37404.

Cordell, D., Jackson, M., and White, S. 2013. Phosphorus flows through the Australian food system: Identifying intervention points as a roadmap to phosphorus security. Environ. Sci. Pol. 29: 87-102. doi:10.1016/j.envsci.2013.01.008.

Corwin, D.L. 1995. Sensitivity analysis of a simple layer-equilibrium model for the one-dimensional leaching of solutes. J. Environ. Sci. Health Part A, 30: 201-238. doi:10.1080/10934529509376196.

Coustau, M., Ricci, S., Borrell-Estupina, V., Bouvier, C., and Thual, O. 2013. Benefits and limitations of data assimilation for discharge forecasting using an event-based rainfall-runoff model. Nat. Hazards Earth Syst. Sci. 13: 583-596. doi:10.5194/nhess-13-583-2013.

Croley, T.E., and He, C. 2005. Distributed-parameter large basin runoff model. I: Model development. J. Hydrol. Eng. 10: 173-181. doi:10.1061/ (ASCE)1084-0699(2005)10:3(173).

Croley, T.E., He, C., and Lee, D.H. 2005. Distributed-Parameter Large Basin Run-off Model. II: Application. J. Hydrol. Eng. 10: 182-191. doi:10.1061/ (ASCE)1084-0699(2005)10:3(182)

Crossman, J., Futter, M.N., Oni, S.K., Whitehead, P.G., Jin, L., Butterfield, D., et al. 2013. Impacts of climate change on hydrology and water quality: Future proofing management strategies in the Lake Simcoe watershed, Canada. J. Great Lakes Res. 39: 19-32. doi:10.1016/j.jglr.2012.11.003.

Crossman, J., Eimers, M.C., Watmough, S.A., Futter, M.N., Kerr, J., Baker, S.R., and Dillon, P.J. 2016. Can recovery from disturbance explain observed declines in total phosphorus in Precambrian Shield catchments? Can. J. Fish. Aquat. Sci. 73(8): 1202-1212. doi:10.1139/cjfas-2015-0312.

Culbertson, A.M., Martin, J.F., Aloysius, N., and Ludsin, S.A. 2016. Anticipated impacts of climate change on 21st century Maumee River discharge and nutrient loads. J. Great Lakes Res. 42: 1332-1342. doi:10.1016/j.jglr.2016.08.008.

Dabney, S.M., Yoder, D.C., Vieira, D.A.N., and Bingner, R.L. 2011. Enhancing RUSLE to include runoff-driven phenomena. Hydrol. Process. 25: 13731390. doi:10.1002/hyp.7897.

Daggupati, P., Yen, H., White, M.J., Srinivasan, R., Arnold, J.G., Keitzer, C.S., and Sowa, S.P. 2015. Impact of model development, calibration and validation decisions on hydrological simulations in West Lake Erie Basin. Hydrol. Process. 29: 5307-5320. doi:10.1002/hyp.10536.

Daloglu, I., Cho, K.H., and Scavia, D. 2012. Evaluating causes of trends in long-term dissolved reactive phosphorus loads to Lake Erie. Environ. Sci. Technol. 46: 10660-10666. doi:10.1021/es302315d. PMID:22962949.

Dansk Hydraulisk Institut (DHI). 2017a. MIKE SHE. Volume 1: User guide. Available from https://manuals.mikepoweredbydhi.help/2017/Water_Resources/ MIKE_SHE_Printed_V1.pdf.

Dansk Hydraulisk Institut (DHI). 2017b. MIKE SHE. Volume 2: Reference Guide. Available from https://manuals.mikepoweredbydhi.help/2017/Water Resources/MIKE_SHE_Printed_V2.pdf.

Darcy, H. 1856. Les fontaines publiques de la ville de Dijon. Dalmont, Paris.

Das, B., Huth, N., Probert, M., Condron, L., and Schmidt, S. 2019. Soil phosphorus modeling for modern agriculture requires balance of science and practicality: A perspective. J. Environ. Qual. 48: 1281-1294. doi:10.2134/ jeq2019.05.0201. PMID:31589725.

Dayon, G., Boé, J., Martin, É., and Gailhard, J. 2018. Impacts of climate change on the hydrological cycle over France and associated uncertainties. Comp. Rend. Geosci. 350: 141-153. doi:10.1016/j.crte.2018.03.001.

Depew, D.C., Houben, A.J., Guildford, S.J., and Hecky, R.E. 2011. Distribution of nuisance Cladophora in the lower Great Lakes: Patterns with land use, near shore water quality and dreissenid abundance. J. Great Lakes Res. 37: 656-671. doi:10.1016/j.jglr.2011.08.011.

Devia, G.K., Ganasri, B.P., and Dwarakish, G.S. 2015. A Review on hydrological models. Aquat. Procedia, 4: 1001-1007. doi:10.1016/j.aqpro.2015.02.126.

Dodds, W.K., Clements, W.H., Gido, K., Hilderbrand, R.H., and King, R.S. 2010. Thresholds, breakpoints, and nonlinearity in freshwaters as related to management. J. N. Am. Benthol. Soc. 29: 988-997. doi:10.1899/09-148.1.

Dong, F., Neumann, A., Kim, D.-K.K., Huang, J., and Arhonditsis, G.B. 2019. A season-specific, multi-site calibration strategy to study the hydrological cycle and the impact of extreme-flow events along an urban-to-agricultural gradient. Ecol. Inform. 54: 100993. doi:10.1016/j.ecoinf.2019.100993.

Douglas-Mankin, K.R., Roy, S.K., Sheshukov, A.Y., Biswas, A., Gharabaghi, B., Binns, A., et al. 2020. A comprehensive review of ephemeral gully erosion models. Catena, 195: 104901. doi:10.1016/j.catena.2020.104901.

Duchene, O., Vian, J.-F., and Celette, F. 2017. Intercropping with legume for agroecological cropping systems: Complementarity and facilitation processes and the importance of soil microorganisms. A review. Agric. Ecosyst. Environ. 240: 148-161. doi:10.1016/j.agee.2017.02.019.

Dupas, R., Delmas, M., Dorioz, J.-M.M., Garnier, J., Moatar, F., and Gascuel-Odoux, C. 2015. Assessing the impact of agricultural pressures on $\mathrm{N}$ and $\mathrm{P}$ loads and eutrophication risk. Ecol. Indic. 48: 396-407. doi:10.1016/j.ecolind.2014.08.007.

Easton, Z.M., Fuka, D.R., Walter, M.T., Cowan, D.M., Schneiderman, E.M., and Steenhuis, T.S. 2008. Re-conceptualizing the soil and water assessment tool (SWAT) model to predict runoff from variable source areas. J. Hydrol. 348(3-4): 279-291. doi:10.1016/j.jhydrol.2007.10.008.

Eaton, B.C., and Millar, R.G. 2004. Optimal alluvial channel width under a bank stability constraint. Geomorphology, 62: 35-45.

Evans, B.M., and Corradini, K.J. 2016. MapShed Version 1.5 Users Guide. Penn State Institutes of Energy and the Environment, University Park, Pa. 
Fan, Y., Chen, J., Shirkey, G., John, R., Wu, S.R., Park, H., and Shao, C. 2016. Applications of structural equation modeling (SEM) in ecological studies: an updated review. Ecol. Process. 5: 19. doi:10.1186/s13717-016-0063-3.

Follett, R.F., and Hatfield, J.L. (Editors). 2001. Nitrogen in the environment: sources, problems and management. Elsevier Science. p. 538.

Foster, G.R., Toy, T.E., and Renard, K.G. 2003. Comparison of the USLE, RUSLE1.06c, and RUSLE2 for application to highly disturbed lands. Available from https://www.tucson.ars.ag.gov/icrw/proceedings/foster.pdf. Proc. Interag. Conf. Res. Watersheds.

Frossard, E., Condron, L.M., Oberson, A., Sinaj, S., and Fardeau, J.C. 2000. Processes governing phosphorus availability in temperate soils. J. Environ. Qual. 29: 15-23. doi:10.2134/jeq2000.00472425002900010003x.

Fu, C., James, A.L., and Yao, H. 2014. SWAT-CS: Revision and testing of SWAT for Canadian Shield catchments. J. Hydrol. 511: 719-735. doi:10.1016/j. jhydrol.2014.02.023.

Futter, M.N., Butterfield, D., Cosby, B.J., Dillon, P.J., Wade, A.J., and Whitehead, P.G. 2007. Modeling the mechanisms that control in-stream dissolved organic carbon dynamics in upland and forested catchments. Water Resour. Res. 43: 1-16. doi:10.1029/2006WR004960. PMID:20300476.

Futter, M.N., Erlandsson, M.A., Butterfield, D., Whitehead, P.G., Oni, S.K. and Wade, A.J. 2014. PERSiST: A flexible rainfall-runoff modelling toolkit for use with the INCA family of models. Hydrol. Earth Syst. Sci. 18: 855873. doi:10.5194/hess-18-855-2014.

Gaborit, É., Fortin, V., Tolson, B., Fry, L., Hunter, T., and Gronewold, A.D. 2017. Great Lakes Run-off Inter-comparison Project, phase 2: Lake Ontario (GRIP-O). J. Gt. Lakes Res. 43(2): 217-227. doi:10.1016/j.jglr.2016.10.004.

Gao, Y., Merz, C., Lischeid, G., and Schneider, M. 2018. A review on missing hydrological data processing. Environ. Earth Sci. 77: 47. doi:10.1007/ s12665-018-7228-6.

García, A.M., Alexander, R.B., Arnold, J.G., Norfleet, L., White, M.J., Robertson, D.M., and Schwarz, G. 2016. Regional effects of agricultural conservation practices on nutrient transport in the Upper Mississippi River Basin. Environ. Sci. Technol. 50(13): 6991-7000. doi:10.1021/acs.est.5b03543. PMID:27243625.

Garcia, R., and Kahawita, R.A. 1986. Numerical solution of the St. Venant equations with the MacCormack finite-difference scheme. Int. J. Numer. Methods Fluids, 6(5): 259-274. doi:10.1002/fld.1650060502.

Gassman, P.W., Reyes, M.R., Green, C.H., Arnold, J.G., Gassman, P.W., Reyes, M.R., et al. 2007. The Soil and Water Assessment Tool: historical development, applications, and future research directions. Trans. Am. Soc. Agric. Biol. Eng. (ASABE), 50: 1211-1250. doi:10.13031/2013.23637.

Gebremariam, S.Y., Martin, J.F., DeMarchi, C., Bosch, N.S., Confesor, R., and Ludsin, S.A. 2014. A comprehensive approach to evaluating watershed models for predicting river flow regimes critical to downstream ecosystem services. Environ. Model. Softw. 61: 121-134. doi:10.1016/j.envsoft.2014.07.004.

Gellis, A.C., and Gorman-Sanisaca, L. 2018. Sediment fingerprinting to delineate sources of sediment in the agricultural and forested Smith Creek watershed, Virginia, USA. J. Am. Water Resour. Assoc. 54: 1197-1221. doi:10.1111/17521688.12680

Giri, S., Qiu, Z., Prato, T., and Luo, B. 2016. An integrated approach for targeting critical source areas to control nonpoint source pollution in watersheds. Water Resour. Manag. 30(14): 5087-5100. doi:10.1007/s11269016-1470-z.

Giuntoli, I., Villarini, G., Prudhomme, C., and Hannah, D.M. 2018. Uncertainties in projected runoff over the conterminous United States. Clim. Change, 150: 149-162. doi:10.1007/s10584-018-2280-5.

Glendell, M., Palarea-Albaladejo, J., Pohle, I., Marrero, S., McCreadie, B., Cameron, G., and Stutter, M. 2019. Modeling the ecological impact of phosphorus in catchments with multiple environmental stressors. J. Environ. Qual. 48: 1336-1346. doi:10.2134/jeq2019.05.0195. PMID:31589719.

Godsey, S.E., Kirchner, J.W., and Clow, D.W. 2009. Concentration-discharge relationships reflect chemostatic characteristics of US catchments. Hydrol. Process, 23: 1844-1864. doi:10.1002/hyp.7315.

Golmohammadi, G., Prasher, S.O., Madani, A., Rudra, R.P., and Youssef, M.A 2016. SWATDRAIN, a new model to simulate the hydrology of agricultural Lands, model development and evaluation. Biosyst. Eng. 141: 31-47. doi:10.1016/ j.biosystemseng.2015.11.003.

Gombault, C., Sottile, M.F., Ngwa, F.F., Madramootoo, C.A., Michaud, A.R., Beaudin, I., and Chikhaoui, M. 2015. Modelling climate change impacts on the hydrology of an agricultural watershed in southern Québec. Can. Water Resour. J. 40: 71-86. doi:10.1080/07011784.2014.985509.

Gonzalez, V.I., Carkovic, A.B., Lobo, G.P., Flanagan, D.C., and Bonilla, C.A. 2016. Spatial discretization of large watersheds and its influence on the estimation of hillslope sediment yield. Hydrol. Process. 30(1): 30-39. doi:10.1002/hyp.10559.

Gougoulias, C., Clark, J.M., and Shaw, L.J. 2014. The role of soil microbes in the global carbon cycle: tracking the below-ground microbial processing of plant-derived carbon for manipulating carbon dynamics in agricultural systems. J. Sci. Food Agric. 94: 2362-2371. doi:10.1002/jsfa.6577. PMID:24425529.

Goyette, J.O., Bennett, E.M., and Maranger, R. 2018. Low buffering capacity and slow recovery of anthropogenic phosphorus pollution in watersheds. Nat. Geosci. 11: 921-925. doi:10.1038/s41561-018-0238-x.

Granato, G.E. 2012. Estimating basin lagtime and hydrograph-timing indexes used to characterize stormflows for runoff-quality analysis. U.S.
Geological Survey Scientific Investigations Report 2012-5110. Available from http://pubs.usgs.gov/sir/2012/5110/. 47 pp.

Green, D.B., Logan, T.J., and Smeck, N.E. 1978. Phosphate adsorption-desorption characteristics of suspended sediments in the Maumee river basin of Ohio. J. Environ. Qual. 7: 208-212. doi:10.2134/jeq1978.00472425000700020011x.

Green, M.B., Nieber, J.L., Johnson, G., Magner, J., and Schaefer, B. 2007. Flow path influence on an N:P ratio in two headwater streams: A paired watershed study. J. Geophys. Res. Atmos. 112: G03015. doi:10.1029/2007JG000403.

Green, W.H., and Ampt, G. 1911. Studies of soil physics, part I - the flow of air and water through soils. J. Agric. Sci. 4: 1-24. doi:10.1017/S0021859600001441.

Grizzetti, B., Bouraoui, F., de Marsily, G., and Bidoglio, G. 2005. A statistical method for source apportionment of riverine nitrogen loads. J. Hydrol. 304: 302-315. doi:10.1016/j.jhydrol.2004.07.036.

Gupta, H.V., Perrin, C., Blöschl, G., Montanari, A., Kumar, R., Clark, M., and Andréassian, V. 2014. Large-sample hydrology: a need to balance depth with breadth. Hydrol. Earth Syst. Sci. 18: 463-477. doi:10.5194/hess-18-4632014.

Gyssels, G., Poesen, J., Bochet, E., and Li, Y. 2005. Impact of plant roots on the resistance of soils to erosion by water: a review. Prog. Phys. Geogr. Earth Environ. 29: 189-217. doi:10.1191/0309133305pp443ra.

Haggard, B.E., Smith, D.R., and Brye, K.R. 2007. Variations in stream water and sediment phosphorus among select Ozark catchments. J. Environ. Qual. 36: 1725-1734. doi:10.2134/jeq2006.0517. PMID:17940273.

Haith, D.A., and Shoemaker, L.L. 1987. Generalized watershed loading functions for stream flow nutrients. J. Am. Water Resour. Assoc. 23: 471-478. doi:10.1111/j.1752-1688.1987.tb00825.x.

Haith, D.A., Mandel, R., and Wu, R.S. 1992. GWLF: Generalized Watershed Loading Functions, Version 2.0, User's Manual. Dept. Agric. Biol. Eng., Cornell University, Ithaca, New York.

Han, H., Allan, J.D., Bosch, N.S., Allan, D.J., and Bosch, N.S. 2012. Historical pattern of phosphorus loading to Lake Erie watersheds. J. Great Lakes Res. 38: 289-298. doi:10.1016/j.jglr.2012.03.004.

Hansen, J.R., Refsgaard, J.C., Ernstsen, V., Hansen, S., Styczen, M., and Poulsen, R.N. 2009. An integrated and physically based nitrogen cycle catchment model. Hydrol. Res. 40: 347-363. doi:10.2166/nh.2009.035.

Hanson, G.J., and Simon, A. 2001. Erodibility of cohesive streambeds in the loess area of the midwestern USA. Hydrol. Process. 15: 23-38. doi:10.1002/ hyp.149.

Harmel, D., Qian, S., Reckhow, K., and Casebolt, P. 2008. The MANAGE database: Nutrient load and site characteristic updates and runoff concentration data. J. Environ. Qual. 37: 2403-2406. doi:10.2134/jeq2008.0079. PMID:18948496.

Havlin, J.L., Beaton, J.D., and Tisdale, S.L. 1999. Soil fertility and fertilizers: an introduction to nutrient management. 6th ed. Prentice Hall, New Jersey.

Hawkins, E., and Sutton, R. 2009. The potential to narrow uncertainty in regional climate predictions. Bull. Am. Meteor. Soc. 90: 1095-1108. doi:10.1175/ 2009BAMS26071.

Haygarth, P.M., Jarvie, H.P., Powers, S.M., Sharpley, A.N., Elser, J.J., Shen, J., et al. 2014. Sustainable phosphorus management and the need for a longterm perspective: The legacy hypothesis. Environ. Sci. Technol. 48: 84178419. doi:10.1021/es502852s. PMID:25001016.

Hayhoe, K. 2010. A standardized framework for evaluating the skill of regional climate downscaling techniques. Available from http://hdl.handle. net/2142/16044.

Haynes, R.J. 2005. Labile organic matter fractions as central components of the quality of agricultural soils: an overview. Adv. Agron. 85: 221-268. doi:10.1016/S0065-2113(04)85005-3.

He, C., and DeMarchi, C. 2010. Modeling spatial distributions of point and nonpoint source pollution loadings in the Great Lakes Watersheds. Int. J. Environ. Sci. 2: 24-30.

Hedblom, M., Lindberg, F., Vogel, E., Wissman, J., and Ahrné, K. 2017. Estimating urban lawn cover in space and time: Case studies in three Swedish cities. Urban Ecosyst. 20: 1109-1119. doi:10.1007/s11252-017-0658-1.

Hedley, M.J., and Stewart, J.W.B. 1982. Method to measure microbial phosphate in soils. Soil Biol. Biochem. 14: 377-385. doi:10.1016/0038-0717(82) 90009-8.

Henshaw, P.C., Charlson, R.J., and Burges, S.J. 2000. Water and the Hydrosphere. Int. Geophysics. 72: 109-131. doi:10.1016/S0074-6142(00)80112-6.

Her, Y., Yoo, S.H., Cho, J., Hwang, S., Jeong, J., and Seong, C. 2019. Uncertainty in hydrological analysis of climate change: multi-parameter vs. multi-GCM ensemble predictions. Sci. Rep. 9: 4974. doi:10.1038/s41598019-41334-7. PMID:30899064.

Hertzberger, A., Pittelkow, C.M., Harmel, R.D., and Christianson, L.E. 2019. The MANAGE drain concentration database: A new tool compiling North American drainage nutrient concentrations. Agric. Water Manage. 216: 113-117. doi:10.1016/j.agwat.2019.01.021.

Hession, W.C., Storm, D.E., and Haan, C.T. 1996. Two-phase uncertainty analysis: an example using the universal soil loss equation. Trans. ASAE, 39(4): 1309-1319. doi:10.13031/2013.27622.

Higgins, S.N., Hecky, R.E., and Guildford, S.J. 2005. Modeling the growth, biomass, and tissue phosphorus concentration of Cladophora glomerata in eastern Lake Erie: Model description and field testing. J. Great Lakes Res. 31: 439-455. doi:10.1016/S0380-1330(05)70275-6.

Higgins, S.N., Malkin, S.Y., Todd Howell, E., Guildford, S.J., Campbell, L., Hiriart-Baer, V., and Hecky, R.E. 2008. An ecological review of Cladophora 
glomerata (Chlorophyta) in the Laurentian Great Lakes. J. Phycol. 44: 839-854. doi:10.1111/j.1529-8817.2008.00538.x. PMID:27041601.

Hingray, B., and Saïd, M. 2014. Partitioning internal variability and model uncertainty components in a multimember multimodel ensemble of climate projections. J. Clim. 27: 6779-6798. doi:10.1175/JCLI-D-13-00629.1.

Holzbecher, E. 2005. Reactive transport in porous media-concepts and numerical approaches. In Transport phenomena in porous media III. Elsevier. pp. 305-340.

Horst, W.J., Kamh, M., Jibrin, J.M., and Chude, V.O. 2001. Agronomic measures for increasing P availability to crops. Plant Soil, 237: 211-223. doi:10.1023/ A:1013353610570.

Horton, R.E. 1933. The role of infiltration in the hydrologic cycle. Trans. Am. Geophys. Union, 14: 446-460. doi:10.1029/TR014i001p00446.

Hough, M.N., and Jones, R.J.A. 1997. The United Kingdom Meteorological Office rainfall and evaporation calculation system: MORECS version 2.0an overview. Hydrol. Earth Syst. Sci. Discuss. 1: 227-239. doi:10.5194/hess1-227-1997.

Hu, G.R., and Li, X.Y. 2018. Subsurface flow. In Observation and measurement: ecohydrology. Edited by X. Li and H. Vereecken. Springer, Berlin, Heidelberg.

International Plant Nutrition Institute (IPNI). 2014. Crop nutrient balance. Ontario. Phosphorus. 1973-2013. Available from http://phosphorus.ipni. net/article/NANE-3043.

Isaak, D.J., Peterson, E.E., Ver Hoef, J.M., Wenger, S.J., Falke, J.A., Torgersen, C.E., et al. 2014. Applications of spatial statistical network models to stream data. Wiley Interdiscip. Rev. Water, 1: 277-294. doi:10.1002/wat2.1023.

Jackson-Blake, L.A., Wade, A.J., Futter, M.N., Butterfield, D., Couture, R.-M., Cox, B.A., et al. 2016. The INtegrated CAtchment model of phosphorus dynamics (INCA-P): Description and demonstration of new model structure and equations. Environ. Model Softw. 83: 356-386. doi:101016/j.envsoft.2016.05.022.

Jackson-Blake, L.A., Sample, J.E., Wade, A.J., Helliwell, R.C., and Skeffington, R.A. 2017. Are our dynamic water quality models too complex? A comparison of a new parsimonious phosphorus model, SimplyP, and INCA-P. Water Resour. Res. 53: 5382-5399. doi:10.1002/2016WR020132.

Jain, S.K., and Singh, V.P. 2017. Hydrological cycles, models and applications to forecasting. In Handbook of hydrometeorological ensemble forecasting. Edited by Q. Duan, F. Pappenberger, J. Thielen, A. Wood, H.L. Cloke, and J.C. Schaake. Springer, Berlin, Heidelberg. pp. 1-28. doi:10.1007/978-3642-40457-3_20-1.

Jarvie, H.P., Johnson, L.T., Sharpley, A.N., Smith, D.R., Baker, D.B., Bruulsema, T.W., and Confesor, R. 2017. Increased soluble phosphorus loads to Lake Erie: unintended consequences of conservation practices? J. Environ. Qual. 46: 123-132. doi:10.2134/jeq2016.07.0248. PMID:28177409.

Jetten, V., Govers, G., and Hessel, R. 2003. Erosion models: quality of spatial predictions. Hydrol. Process. 17: 887-900. doi:10.1002/hyp.1168.

Jiang, S., Jomaa, S., and Rode, M. 2014. Modelling inorganic nitrogen leaching in nested mesoscale catchments in central Germany. Ecohydrology, 7: 1345-1362. doi:10.1002/eco.1462.

Johnson, M.S., Coon, W.F., Mehta, V.K., Steenhuis, T.S., Brooks, E.S., and Boll, J. 2003. Application of two hydrologic models with different runoff mechanisms to a hillslope dominated watershed in the northeastern US: a comparison of HSPF and SMR. J. Hydrol. 284(1-4): 57-76. doi:10.1016/j. jhydrol.2003.07.005

Jones, C.A., Cole, C.V., Sharpley, A.N., and Williams, J.R. 1984. A simplified soil and plant phosphorus model: I. Documentation. Soil Sci. Soc. Am. J. 48: 800-805. doi:10.2136/sssaj1984.03615995004800040020x.

Kale, G.D., and Vadsola, S.N. 2012. Modelling of soil erosion by non-conventional methods. Int. J. Geol. Environ. Eng. 6: 139-145. doi:10.5281/zenodo.1058737.

Kampf, S.K., and Burges, S.J. 2007. A framework for classifying and comparing distributed hillslope and catchment hydrologic models. Water Resour. Res. 43(5). doi:10.1029/2006WR005370.

Kannan, N., Chinnasamy, S., White, M., Wang, X., Arnold, J., and Di Luzio, M. 2011. Documentation on calibration and validation of CEAP-HUMUS for various river basins in the United States. USDA Doc. 169. Available from https:/| www.nrcs.usda.gov/Internet/FSE_DOCUMENTS/stelprdb1044544.pdf.

Kaur, K., Vassiljev, A., Annus, I., and Stålnacke, P. 2017. Source apportionment of nitrogen in Estonian rivers. J. Water Supply Res. Technol. Aqua, 66(7): 469-480. doi:10.2166/aqua.2017.036.

Keitzer, S.C., Ludsin, S.A., Sowa, S.P., Annis, G., Arnold, J.G., Daggupati, P., et al. 2016. Thinking outside of the lake: Can controls on nutrient inputs into Lake Erie benefit stream conservation in its watershed? J. Great Lakes Res. 42: 1322-1331. doi:10.1016/j.jglr.2016.05.012.

Kim, D.-K., Kaluskar, S., Mugalingam, S., Blukacz-Richards, A., Long, T. Morley, A., and Arhonditsis, G.B. 2017. A Bayesian approach for estimating phosphorus export and delivery rates with the SPAtially Referenced Regression On Watershed attributes (SPARROW) model. Ecol. Inform. 37: 77-91. doi:10.1016/j.ecoinf.2016.12.003.

King, K.W., Williams, M.R., Johnson, L.T., Smith, D.R., LaBarge, G.A., and Fausey, N.R. 2017. Phosphorus availability in Western Lake Erie Basin drainage waters: Legacy evidence across spatial scales. J. Environ. Qual. 46: 466-469. doi:10.2134/jeq2016.11.0434. PMID:28380548.

Kiniry, J.R., Williams, J.R., Gassman, P.W., and Debaeke, P. 1992. A general, process-oriented model for two competing plant species. Trans. ASAE. 35: 801-810. doi:10.13031/2013.28665.
Kiniry, J.R., Macdonald, J.D., Kemanian, A.R., Watson, B., Putz, G., and Prepas, E.E. 2008. Plant growth simulation for landscape-scale hydrological modelling. Hydrol. Sci. J. 53: 1030-1042. doi:10.1623/hysj.53.5.1030.

Kirnak, H. 2002. Comparison of erosion and runoff predicted by WEPP and AGNPS models using a geographic information system. Turkish J. Agric. For. 26: 261-268. doi:10.3906/tar-0110-4.

Klaus, J., and McDonnell, J.J. 2013. Hydrograph separation using stable isotopes: Review and evaluation. J. Hydrol. 505: 47-64. doi:10.1016/j.jhydrol.2013.09.006.

Kleinman, P.J.A., Sharpley, A.N., Withers, P.J.A., Bergström, L., Johnson, L.T., and Doody, D.G. 2015. Implementing agricultural phosphorus science and management to combat eutrophication. Ambio, 44: 297-310. doi:10.1007| s13280-015-0631-2. PMID:25366246.

Kovacs, A., Honti, M., Zessner, M., Eder, A., Clement, A., and Blöschl, G. 2012. Identification of phosphorus emission hotspots in agricultural catchments. Sci. Total Environ. 433: 74-88. doi:10.1016/j.scitotenv.2012.06.024. PMID:22771465.

Kronvang, B., Behrendt, H., Andersen, H.E., Arheimer, B., Barr, A., Borgvang, S.A., et al. 2009. Ensemble modelling of nutrient loads and nutrient load partitioning in 17 European catchments. J. Environ. Monit. 11: 572. doi:10.1039/ b900101h. PMID:19280035.

Kunkel, K.E., Andsager, K., and Easterling, D.R. 1999. Long-term trends in extreme precipitation events over the conterminous United States and Canada. J. Climate, 12: 2515-2527. doi:10.1175/1520-0442(1999)012<2515: lttiep $>2.0 . \mathrm{co} ; 2$

Landuyt, D., Broekx, S., D’hondt, R., Engelen, G., Aertsens, J., and Goethals, P.L.M. 2013. A review of Bayesian belief networks in ecosystem service modelling. Environ. Model. Softw. 46: 1-11. doi:10.1016/j.envsoft.2013.03.011.

Lee, C.J., Hirsch, R.M., Schwarz, G.E., Holtschlag, D.J., Preston, S.D., Crawford, C.G., and Vecchia, A.V. 2016. An evaluation of methods for estimating decadal stream loads. J. Hydrol. 542: 185-203. doi:10.1016/j.jhydrol.2016.08.059.

Lee, J.G., Nietch, C.T., and Panguluri, S. 2017. SWMM modeling methods for simulating green infrastructure at a suburban headwatershed. User's Guide 157.

Lee, J.Y., Kim, H., Kim, Y., and Han, M.Y. 2011. Characteristics of the event mean concentration (EMC) from rainfall runoff on an urban highway. Environ. Pollut. 159: 884-888. doi:10.1016/j.envpol.2010.12.022. PMID:21247680.

Lempert, R., Nakicenovic, N., Sarewitz, D., and Schlesinger, M. 2004. Characterizing climate-change uncertainties for decision-makers. An editorial essay. Clim. Change, 65: 1-9. doi:10.1023/B:CLIM.0000037561.75281.b3.

Leonard, B.P. 1979. A stable and accurate convective modelling procedure based on quadratic upstream interpolation. Comput. Methods Appl. Mech. Eng. 19: 59-98. doi:10.1016/0045-7825(79)90034-3.

Leonard, R.A., Knisel, W.G., and Still, D.A. 1987. GLEAMS: Groundwater loading effects of agricultural management systems. Trans. Am. Soc. Agric. Biol. Eng. (ASABE), 30: 1403-1418. doi:10.13031/2013.30578.

Lewis, D.R., and McGechan, M.B. 2002. A review of field scale phosphorus dynamics models. Biosyst. Eng. 82: 359-380. doi:10.1006/bioe.2002.0102.

Li, L. 2019. Watershed reactive transport. Rev. Mineral. Geochem. 85: 381418. doi:10.2138/rmg.2018.85.13.

Li, L., Bao, C., Sullivan, P.L., Brantley, S., Shi, Y., and Duffy, C. 2017. Understanding watershed hydrogeochemistry: 2. Synchronized hydrological and geochemical processes drive stream chemostatic behavior. Water Resour. Res. 53: 2346-2367. doi:10.1002/2016WR018935.

Li, M., Hai, X., Hong, H., Shao, Y., Peng, D., Xu, W., et al. 2019. Modelling soil detachment by overland flow for the soil in the. Sci. Rep. 9: 8063. doi:10.1038/s41598-019-44586-5. PMID:31147592.

Lim, K.J., Engel, B.A., Muthukrishnan, S., and Harbor, J. 2006. Effects of initial abstraction and urbanization on estimated runoff using CN technology. J. Am. Water Resour. Assoc. 42: 629-643. doi:10.1111/j.1752-1688.2006.tb04481.X.

Lindström, G., Johansson, B., Persson, M., Gardelin, M., and Bergström, S. 1997. Development and test of the distributed HBV-96 hydrological model. J. Hydrol. 201: 272-288. doi:10.1016/S0022-1694(97)00041-3.

Lindström, G., Rosberg, J., and Arheimer, B. 2005. Parameter precision in the HBV-NP model and impacts on nitrogen scenario simulations in the Rönneå River, southern Sweden. AMBIO A J. Hum. Environ. 34: 533-537. doi:10.1579/0044-7447-34.7.533.

Lindström, G., Pers, C., Rosberg, J., Strömqvist, J., and Arheimer, B. 2010. Development and testing of the HYPE (Hydrological Predictions for the Environment) water quality model for different spatial scales. Hydrol. Res. 41: 295-319. doi:10.2166/nh.2010.007.

Liu, J., Liu, T., Bao, A., De Maeyer, P., Feng, X., Miller, S.N., and Chen, X. 2016. Assessment of different modelling studies on the spatial hydrological processes in an arid alpine catchment. Water Resour. Manage. 30(5): 1757-1770. doi:10.1007/s11269-016-1249-2.

Liu, Y., Villalba, G., Ayres, R.U., and Schroder, H. 2008. Global phosphorus flows and environmental impacts from a consumption perspective. J. Indic. Ecol. 12: 229-247. doi:10.1111/j.1530-9290.2008.00025.x.

Liu, Y., Yang, W., Qin, C., and Zhu, A. 2016. A review and discussion on modeling and assessing agricultural best management practices under global climate change. J. Sustain. Dev. 9: 245-255. doi:10.5539/jsd.v9n1p245.

Lohse, K.A., Brooks, P.D., McIntosh, J.C., Meixner, T., and Huxman, T.E. 2009. Interactions Between Biogeochemistry and Hydrologic Systems. Annu. Rev. Environ. Resour. 34: 65-96. doi:10.1146/annurev.environ.33.031207.111141.

Long, T., Wellen, C., Arhonditsis, G., and Boyd, D. 2014. Evaluation of stormwater and snowmelt inputs, land use and seasonality on nutrient 
dynamics in the watersheds of Hamilton Harbour, Ontario, Canada. J. Great Lakes Res. 40: 964-979. doi:10.1016/j.jglr.2014.09.017.

Long, T., Wellen, C., Arhonditsis, G., Boyd, D., Mohamed, M., and O’Connor, K. 2015. Estimation of tributary total phosphorus loads to Hamilton Harbour, Ontario, Canada, using a series of regression equations. J. Great Lakes Res. 41: 780-793. doi:10.1016/j.jglr.2015.04.001.

Lott, D.A., and Stewart, M.T. 2016. Base flow separation: A comparison of analytical and mass balance methods. J. Hydrol. 535: 525-533. doi:10.1016/j. jhydrol.2016.01.063.

Lovett, G.M., Goodale, C.L., Ollinger, S.V., Fuss, C.B., Ouimette, A.P., and Likens, G.E. 2018. Nutrient retention during ecosystem succession: a revised conceptual model. Front. Ecol. Environ. 16: 532-538. doi:10.1002/ fee.1949.

Lu, C. 2019. Assessment of sediment transport functions with the modified SWAT-Twn model for a Taiwanese small mountainous watershed. Water, 11: 1749. doi:10.3390/w11091749.

Lun, F., Liu, J., Ciais, P., Nesme, T., Chang, J., Wang, R., et al. 2018. Global and regional phosphorus budgets in agricultural systems and their implications for phosphorus-use efficiency. Earth Syst. Sci. Data, 10: 1-18. doi:10.5194/essd-10-1-2018.

Maccoux, M.J., Dove, A., Backus, S.M., and Dolan, D.M. 2016. Total and soluble reactive phosphorus loadings to Lake Erie. J. Great Lakes Res. 42: 1151-1165. doi:10.1016/j.jglr.2016.08.005.

MacDonald, J.D.D., Kiniry, J.R.R., Putz, G., and Prepas, E.E.E. 2008. A multispecies, process based vegetation simulation module to simulate successional forest regrowth after forest disturbance in daily time step hydrological transport models. J. Environ. Eng. Sci. 7: 127-143. doi:10.1139/S08-008.

Macrae, M.L., English, M.C., Schiff, S.L., and Stone, M. 2007. Intra-annual variability in the contribution of tile drains to basin discharge and phosphorus export in a first-order agricultural catchment. Agric. Water Manage. 92: 171-182. doi:10.1016/j.agwat.2007.05.015.

Maniquiz, M.C., Choi, J.-Y., Lee, S.-Y., Cho, H.-J., and Kim, L.-H. 2010a. Appropriate methods in determining the event mean concentration and pollutant removal efficiency of a best management practice. Environ. Eng. Res. 15: 215-223. doi:10.4491/eer.2010.15.4.215.

Maniquiz, M.C., Lee, S., and Kim, L.-H. 2010b. Multiple linear regression models of urban runoff pollutant load and event mean concentration considering rainfall variables. J. Environ. Sci. 22: 946-952. doi:10.1016/ S1001-0742(09)60203-5.

Manning, R. 1891. On the flow of water in open channels and pipes. Trans. Inst. Civil Eng. Ireland, 20: 161-207.

Marchau, V.A.W.J., Walker, W.E., Bloemen, P.J.T.M., and Popper, S.W. 2019. Decision making under deep uncertainty: from theory to practice. Springer. doi:10.1007/978-3-030-05252-2_1.

Marshall, E., and Randhir, T.O. 2008. Spatial modeling of land cover change and watershed response using Markovian cellular automata and simulation. Water Resour. Res. 44: W04423. doi:10.1029/2006WR005514.

McDonald, C.P., and Urban, N.R. 2010. Using a model selection criterion to identify appropriate complexity in aquatic biogeochemical models. Ecol. Modell. 221: 428-432. doi:10.1016/j.ecolmodel.2009.10.021.

McDonnell, J.J. 1990. A rationale for old water discharge through macropores in a steep, humid catchment. Water Resour. Res. 26: 2821-2832. doi:10.1029/WR026i011p02821.

McIntire, E.J.B., and Fajardo, A. 2014. Facilitation as a ubiquitous driver of biodiversity. New Phytol. 201: 403-416. doi:10.1111/nph.12478. PMID:24102266.

McMahon, G., Alexander, R.B., and Qian, S. 2003. Support of total maximum daily load programs using spatially referenced regression models. J. Water Resour. Plann. Manage. 129: 315-329. doi:10.1061/(ASCE)0733-9496(2003)129:4 (315).

Meals, D.W., Dressing, S.A., and Davenport, T.E. 2010. Lag time in water quality response to best management practices: a review. J. Environ. Qual. 39: 85-96. doi:10.2134/jeq2009.0108. PMID:20048296.

Menzel, R.G. 1980. Enrichment ratios for water quality modeling. In CREAMS: a field scale model for chemicals, runoff, and erosion from agricultural management systems.

Merriman, K.R., Daggupati, P., Srinivasan, R., Toussant, C., Russell, A.M., and Hayhurst, B. 2018. Assessing the impact of site-specific BMPs using a spatially explicit, field-scale SWAT model with edge-of-field and tile hydrology and water-quality data in the Eagle Creek watershed, Ohio. Water, 10(10): 1299. doi:10.3390/w10101299.

Metson, G.S., Lin, J., Harrison, J.A., and Compton, J.E. 2017. Linking terrestrial phosphorus inputs to riverine export across the United States. Water Res. 124: 177-191. doi:10.1016/j.watres.2017.07.037. PMID:28756220.

Meybeck, M., and Moatar, F. 2012. Daily variability of river concentrations and fluxes: Indicators based on the segmentation of the rating curve. Hydrol. Process. 26: 1188-1207. doi:10.1002/hyp.8211.

Michalak, A.M. 2016. Study role of climate change in extreme threats to water quality. Nature, 535: 349-350. doi:10.1038/535349a. PMID:27443725.

Miller, J.A. 1984. Basic concepts of kinematic-wave models. U.S. Geological Survey, USA.

Mishra, S.K., and Singh, V.P. 2003. SCS-CN Method. In Soil conservation service curve number (SCS-CN) methodology. Springer, Berlin. pp. 84-146.

Moatar, F., and Meybeck, M. 2005. Compared performances of different algorithms for estimating annual nutrient loads discharged by the eutrophic River Loire. Hydrol. Process. 19: 429-444. doi:10.1002/hyp.5541.
Moatar, F., Abbott, B.W., Minaudo, C., Curie, F., and Pinay, G. 2017. Elemental properties, hydrology, and biology interact to shape concentrationdischarge curves for carbon, nutrients, sediment, and major ions. Water Resour. Res. 53: 1270-1287. doi:10.1002/2016WR019635.

Mohamed, M.N., Wellen, C., Parsons, C.T., Taylor, W.D., Arhonditsis, G., Chomicki, K.M., et al. 2019. Understanding and managing the re-eutrophication of Lake Erie: Knowledge gaps and research priorities. Freshw. Sci. 38: 675-691. doi:10.1086/705915.

Montgomery, D.R., and Buffington, J.M. 1998. Channel processes, classification, and response. River Ecol. Manage. 112: 1250-1263.

Moore, J. 2016. Literature review: Tile drainage and phosphorus losses from agricultural land. Available from http://www.lcbp.org/wp-content/uploads/2017/ 01/83_TileDrainage_LitReview.pdf.

Morgan, R.P.C., Quinton, J.N., Smith, R.E., Govers, G., Poesen, J.W.A., Auerswald, K., et al. 1999. Reply to discussion on 'The European Soil Erosion Model (EUROSEM): a dynamic approach for predicting sediment transport from fields and small catchments. Earth Surf. Process Landforms, 24: 567-568. doi:10.1002/(SICI)1096-9837(199906)24:6<567::AID-ESP990>3.0.CO;2-F.

Moriasi, D.N., Duriancik, L.F., Sadler, E.J., Tsegaye, T., Steiner, J.L., Locke, M.A., et al. 2020. Quantifying the impacts of the Conservation Effects Assessment Project watershed assessments: The first fifteen years. J. Soil Water Conserv. 75(3): 57A-574. A. doi:10.2489/jswc.75.3.57A.

Mudge, S.M. 2007. Multivariate statistical methods in environmental forensics. Environ. Forensics, 8: 155-163. doi:10.1080/15275920601180693.

Muenich, R.L., Kalcic, M., and Scavia, D. 2016. Evaluating the impact of legacy $P$ and agricultural conservation practices on nutrient loads from the Maumee River Watershed. Environ. Sci. Technol. 50: 8146-8154. doi:10.1021/ acs.est.6b01421. PMID:27322563.

Muñoz-Carpena, R., Parsons, J.E., and Gilliam, J.W. 1999. Modeling hydrology and sediment transport in vegetative filter strips. J. Hydrol. 214 (1-4): 111-129. doi:10.1016/S0022-1694(98)00272-8.

Myers, D.N., Metzker, K.D., and Davis, S. 2000. Status and trends in suspended-sediment discharges, soil erosion, and conservation tillage in the Maumee River basin-Ohio, Michigan, and Indiana. US Department of the Interior, US Geological Survey.

Nash, D., and Hannah, M. 2011. Using Monte-Carlo simulations and Bayesian Networks to quantify and demonstrate the impact of fertilizer best management practices. Environ. Model. Softw. 26: 1079-1088. doi:10.1016/j. envsoft.2011.03.009.

Neitsch, S.S.L., Arnold, J.G.J., Kiniry, J.J.R., and Williams, J.R.J. 2011. Soil and water assessment tool theoretical documentation version 2009. Texas Water Resources Institute. doi:10.1016/j.scitotenv.2015.11.063.

Nossent, J., and Bauwens, W. 2012. Multi-variable sensitivity and identifiability analysis for a complex environmental model in view of integrated water quantity and water quality modeling. Water Sci. Technol. 65: 539549. doi:10.2166/wst.2012.884. PMID:22258687.

Obenour, D.R., Gronewold, A.D., Stow, C.A., and Scavia, D. 2014. Using a Bayesian hierarchical model to improve Lake Erie cyanobacteria bloom forecasts. Water Resour. Res. 50: 7847-7860. doi:10.1002/2014WR015616.

Ockenden, M.C., Hollaway, M.J., Beven, K.J., Collins, A.L., Evans, R., Falloon, P.D. et al. 2017. Major agricultural changes required to mitigate phosphorus losses under climate change. Nat. Commun. 8: 161. doi:10.1038/s41467-017-00232-0. PMID:28757602.

O’Halloran, L.R., Borer, E.T., Seabloom, E.W., MacDougall, A.S., Cleland, E.E., McCulley, R.L., et al. 2013. Regional contingencies in the relationship between aboveground biomass and litter in the world's grasslands. PLoS ONE, 8: e54988. doi:10.1371/journal.pone.0054988. PMID:23405103.

Onstad, C.A., and Foster, G.R. 1975. Erosion modeling on a watershed. Trans. Am. Soc. Civil Eng. 18: 288-292.

Ontario Ministry of the Environment and Climate Change (OMECC). 2017. Canada-Ontario Lake Erie Action Plan. Available from https://www.canada. ca/content/dam/eccc/documents/pdf/great-lakes-protection/dap/action_plan.pdf.

Osman, K.T. 2013. Soils: Principles, properties and management. Springer, Netherlands, Dordrecht, New York. doi:10.1007/978-94-007-5663-2.

Palecki, M.A., Changnon, S.A., and Kunkel, K.E. 2001. The nature and impacts of the July 1999 heat wave in the midwestern United States: Learning from the lessons of 1995. Bull. Am. Meteorol. Soc. 82: 1353-1367. doi:10.1175/1520-0477(2001)082<1353:TNAIOT > 2.3.CO;2.

Parlange, J.-Y., Hogarth, W.L., and Haverkamp, R. 1987. Comments on "Goodness of fit for eight water infiltration models”. Soil Sci. Soc. Am. J. 51: 1088-1088. doi:10.2136/sssaj1987.03615995005100040051x.

Paudel, R., and Jawitz, J.W. 2012. Does increased model complexity improve description of phosphorus dynamics in a large treatment wetland? Ecol. Eng. 42: 283-294. doi:10.1016/j.ecoleng.2012.02.014.

Pearce, A.J. 1976. Geomorphic and hydrologic consequences of vegetation destruction, Sudbury, Ontario. Can. J. Earth Sci. 13(10): 1358-1373. doi:10.1139/ e76-141.

Pease, L.M., Oduor, P., and Padmanabhan, G. 2010. Estimating sediment, nitrogen, and phosphorous loads from the Pipestem Creek watershed, North Dakota, using AnnAGNPS. Comput. Geosci. 36: 282-291. doi:10.1016/j. cageo.2009.07.004.

Pettersson, A., Arheimer, B., and Johansson, B. 2001. NitrogeN-concentrations simulated with HBV-N: new response function and calibration strategy. Nord. Hydrol. 32: 227-248. doi:10.2166/nh.2001.0014. 
Philip, J.R. 1957. The theory of infiltration. Soil Sci. 83: 345-358. doi:10.1097| 00010694-195705000-00002.

Polasky, S., Carpenter, S.R., Folke, C., and Keeler, B. 2011. Decision-making under great uncertainty: Environmental management in an era of global change. Trends Ecol. Evol. 26: 398-404. doi:10.1016/j.tree.2011.04.007. PMID:21616553.

Qi, J., Li, S., Li, Q., Xing, Z., Bourque, C.P.-A., and Meng, F.-R. 2016. A new soil-temperature module for SWAT application in regions with seasonal snow cover. J. Hydrol. 538: 863-877. doi:10.1016/j.jhydrol.2016.05.003.

Qi, J., Li, S., Jamieson, R., Hebb, D., Xing, Z., and Meng, F.R. 2017. Modifying SWAT with an energy balance module to simulate snowmelt for maritime regions. Environ. Model. Softw. 93: 146-160. doi:10.1016/j.envsoft.2017.03.007.

Qi, Z., Kang, G., Shen, M., Wang, Y., and Chu, C. 2019. The improvement in GWLF model simulation performance in watershed hydrology by changing the transport framework. Water Resour. Manage. 33: 923-937. doi:10.1007/ s11269-018-2149-4.

Qian, S.S., Reckhow, K.H., Zhai, J., and McMahon, G. 2005. Nonlinear regression modeling of nutrient loads in streams: A Bayesian approach. Water Resour. Res. 41: 1-10. doi:10.1029/2005WR003986.

Radcliffe, D.E., Freer, J., and Schoumans, O. 2009. Diffuse phosphorus models in the United States and Europe: their usages, scales, and uncertainties. J. Environ. Qual. 38: 1956-1967. doi:10.2134/jeq2008.0060. PMID:19704139.

Radcliffe, D.E., Reid, D.K., Blombäck, K., Bolster, C.H., Collick, A.S., Easton, Z.M., et al. 2015. Applicability of models to predict phosphorus losses in drained fields: A review. J. Environ. Qual. 44: 614-628. doi:10.2134/jeq2014.05.0220. PMID:26023980.

Raftery, A.E., Gneiting, T., Balabdaoui, F., and Polakowski, M. 2005. Using Bayesian model averaging to calibrate forecast ensembles. Monit. Weather Rev. 133: 1155-1174. doi:10.1175/MWR2906.1.

Ramesh, T., Bolan, N.S., Kirkham, M.B., Wijesekara, H., Kanchikerimath, M., Srinivasa Rao, C., et al. 2019. Soil organic carbon dynamics: Impact of land use changes and management practices: a review. Adv. Agron. 156: 1-107. doi:10.1016/bs.agron.2019.02.001.

Ramin, M., Labencki, T., Boyd, D., Trolle, D., and Arhonditsis, G.B. 2012. A Bayesian synthesis of predictions from different models for setting water quality criteria. Ecol. Modell. 242: 127-145. doi:10.1016/j.ecolmodel.2012.05.023.

Rankinen, K., Granlund, K., Futter, M.N., Butterfield, D., Wade, A.J., Skeffington, R., et al. 2013. Controls on inorganic nitrogen leaching from Finnish catchments assessed using a sensitivity and uncertainty analysis of the INCA-N model. Boreal Environ. Res. 18(5): 373-386.

Rathjens, H., and Oppelt, N. 2012. SWATgrid: an interface for setting up SWAT in a gridbased discretization scheme. Comput. Geosci. 45: 161-167. doi:10.1016/j.cageo.2011.11.004.

Reckhow, K.H., Beaulac, M.N., and Simpson, J.T. 1980. Modeling phosphorus loading response under uncertain. A manual and compilation of export coefficients. Water Resour. Res. 30: 214. EPA-440/5-80-011.

Reddy, K.R., Kadlec, R.H., Flaig, E., and Gale, P.M. 1999. Phosphorus retention in streams and wetlands: a review. Crit. Rev. Environ. Sci. Technol. 29: 83-146. doi:10.1080/10643389991259182.

Reddy, V.R., Cunha, D.G.F., and Kurian, M. 2018. A Water-Energy-Food nexus perspective on the challenge of eutrophication. Water, 10: 101. doi:10.3390/w10020101.

Refsgaard, J.C., and Hansen, J.R. 2010. A good-looking catchment can turn into a modeller's nightmare. Hydrol. Sci. J. 55(6): 899-912. doi:10.1080/ 02626667.2010.505571.

Refsgaard, J.C., and Storm, B. 1995. Mike she. In Computer models of watershed hydrology. Edited by V.P. Singh. Water Resources Publ., Highlands Ranch, Colo. pp. 809-846.

Reid, D.K. 2011. A modified Ontario P index as a tool for on-farm phosphorus management. Can. J. Soil Sci. 91(3): 455-466. doi:10.4141/cjss09088.

Reid, K., Schneider, K., and McConkey, B. 2018. Components of phosphorus loss from agricultural landscapes, and how to incorporate them into risk assessment tools. Front. Earth Sci. 6: 135. doi:10.3389/feart.2018.00135.

Renard, K.G. 1991. The Revised Universal Soil Loss Equation. In Soil erosion research methods. Routledge. pp. 105-126. doi:10.1201/9780203739358-5

Renard, K.G., Foster, G., Weesies, G., McCool, D., and Yoder, D. 1997. Predicting soil erosion by water: a guide to conservation planning with the Revised Universal Soil Loss Equation (RUSLE). Agric. Handb. No. 703. Available from https://www.ars.usda.gov/arsuserfiles/64080530/rusle/ah_703.pdf.

Richards, L.A. 1931. Capillary conduction of liquids through porous mediums. Physics, 1: 318-333. doi:10.1063/1.1745010.

Richards, R.P., Baker, D.B., Crumrine, J.P., Kramer, J.W., Ewing, D.E., and Merryfield, B.J. 2008. Thirty-Year Trends in Suspended Sediment in Seven Lake Erie Tributaries. J. Environ. Qual. 37: 1894-1908. doi:10.2134/jeq2007.0590. PMID:18689751.

Richards, R.P., Baker, D.B., Crumrine, J.P., and Stearns, A.M. 2010. Unusually large loads in 2007 from the Maumee and Sandusky Rivers, tributaries to Lake Erie. J. Soil Water Conserv. 65: 450-462. doi:10.2489/jswc.65.6.450.

Ritchie, J.T. 1972. Model for predicting evaporation from a row crop with incomplete cover. Water Resour. Res. 8: 1204-1213. doi:10.1029/WR008i005p01204.

Rittenburg, R.A., Squires, A.L., Boll, J., Brooks, E.S., Easton, Z.M., and Steenhuis, T.S. 2015. Agricultural BMP effectiveness and dominant hydrological flow paths: concepts and a review. J. Am. Water Resour. Assoc. 51(2): 305-329. doi:10.1111/1752-1688.12293.
Robertson, D.M., and Saad, D.A. 2011. Nutrient inputs to the Laurentian Great Lakes by source and watershed estimated using SPARROW watershed models. J. Am. Water Resour. Assoc. 47: 1011-1033. doi:10.1111/j.17521688.2011.00574.x. PMID:22457580.

Robertson, D.M., Schwarz, G.E., Saad, D.A., and Alexander, R.B. 2009. Incorporating uncertainty Into the ranking of SPARROW model nutrient yields from Mississippi/Atchafalaya river basin watersheds. J. Am. Water Resour. Assoc. 45: 534-549. doi:10.1111/j.1752-1688.2009.00310.x. PMID:22457567.

Robertson, D.M., Saad, D.A., Benoy, G.A., Vouk, I., Schwarz, G.E., and Laitta, M.T. 2019. Phosphorus and nitrogen transport in the binational Great Lakes Basin estimated using SPARROW watershed models. J. Am. Water Resour. Assoc. doi:10.1111/1752-1688.12792.

Robeson, S.M. 2002. Increasing growing-season length in Illinois during the 20th Century. Clim. Change. 52: 219-238. doi:10.1023/A:1013088011223.

Ross, J.Z., and Omelon, S. 2018. Canada: Playing catch-up on phosphorus policy. FACETS, 3(1): 642-664. doi:10.1139/facets-2017-0105.

Rossman, L.A. 2017. Storm Water Management Model reference manual. Volume II - Hydraulics.

Rossman, L.A., and Huber, W.C. 2016a. Storm Water Management Model reference manual. Volume I - Hydrology [revised]. [EPA/600/R-15/162A.] U.S. Environ. Prot. Agency I, 231.

Rossman, L.A., and Huber, W.C. 2016b. Storm Water Management Model reference manual. Volume III - water quality. USEPA, Cincinnati, Ohio.

Roulston, M.S., and Smith, L.A. 2003. Combining dynamical and statistical ensembles. Tellus Ser. A Dyn. Meteorol. Oceanogr. 55: 16-30. doi:10.3402/ tellusa.v55i1.12082.

Rucinski, D.K., DePinto, J.V., Scavia, D., and Beletsky, D. 2014. Modeling Lake Erie's hypoxia response to nutrient loads and physical variability. J. Great Lakes Res. 40: 151-161. doi:10.1016/j.jglr.2014.02.003.

Ryberg, K.R. 2017. Structural equation model of total phosphorus loads in the Red River of the North Basin, USA and Canada. J. Environ. Qual. 46: 1072-1080. doi:10.2134/jeq2017.04.0131. PMID:28991977.

Sadeghi, S.H.R., Gholami, L., Khaledi, D.A., and Saeidi, P. 2014. A review of the application of the MUSLE model worldwide. Hydrol. Sci. J. 59: 365375. doi:10.1080/02626667.2013.866239.

Saint-Venant, B. 1871. Théorie du mouvement nonpermanent des eaux, avec application aux crues des rivières et à l'introduction des marées dans leur lit. C.R. Comptes Rendus des Séances de l'Académie des Sciences, Paris.

Santhi, C., Kannan, N., White, M., Di Luzio, M., Arnold, J.G., Wang, X., and Williams, J.R. 2014. An integrated modeling approach for estimating the water quality benefits of conservation practices at the river basin scale. J. Environ. Qual. 43: 177-198. doi:10.2134/jeq2011.0460. PMID:25602551.

Santillana, M., and Dawson, C. 2010. A numerical approach to study the properties of solutions of the diffusive wave approximation of the shallow water equations. Comput. Geosci. 14: 31-53. doi:10.1007/s10596-0099131-4.

Sattari, S.Z., Bouwman, A.F., Giller, K.E., and Van Ittersum, M.K. 2012. Residual soil phosphorus as the missing piece in the global phosphorus crisis puzzle. Proc. Natl. Acad. Sci. U.S.A. 109: 6348-6353. doi:10.1073/pnas.1113675109. PMID:22431593.

Scavia, D., David Allan, J., Arend, K.K., Bartell, S., Beletsky, D., Bosch, N.S., et al. 2014. Assessing and addressing the re-eutrophication of Lake Erie: Central basin hypoxia. J. Great Lakes Res. 40: 226-246. doi:10.1016/j. jglr.2014.02.004

Scavia, D., Kalcic, M., Muenich, R.L., Aloysius, N., Arnold, J., Boles, C., et al. 2016. Informing Lake Erie agriculture nutrient management via scenario evaluation. Technical report. Available from http:/graham.umich.edu/ media/pubs/InformingLakeErieAgricultureNutrientManagementviaScenario Evaluation.pdf.

Scavia, D., Kalcic, M., Muenich, R.L., Read, J., Aloysius, N., Bertani, I., et al. 2017. Multiple models guide strategies for agricultural nutrient reductions. Front. Ecol. Environ. 15: 126-132. doi:10.1002/fee.1472.

Schneiderman, E.M., Steenhuis, T.S., Thongs, D.J., Easton, Z.M., Zion, M.S., Neal, A.L., et al. 2007. Incorporating variable source area hydrology into a curve-number-based watershed model. Hydrol. Process. 21(25): 34203430. doi:10.1002/hyp.6556.

Scholz, R.W., Ulrich, A.E., Eilittä, M., and Roy, A. 2013. Sustainable use of phosphorus: A finite resource. Sci. Total Environ. 461-462: 799-803. doi:10.1016/j.scitotenv.2013.05.043. PMID:23769630.

Schoumans, O.F., Silgram, M., Walvoort, D.J.J., Groenendijk, P., Bouraoui, F., Andersen, H.E., et al. 2009. Evaluation of the difference of eight model applications to assess diffuse annual nutrient losses from agricultural land. J. Environ. Monit. 11: 540. doi:10.1039/b823240g. PMID:19280033.

Scown, M.W., McManus, M.G., Carson, J.H., and Nietch, C.T. 2017. Improving predictive models of in-stream phosphorus concentration based on nationally-available spatial data coverages. J. Am. Water Resour. Assoc. 53: 944-960. doi:10.1111/1752-1688.12543. PMID:30034212.

Seiller, G., Anctil, F., and Perrin, C. 2012. Multimodel evaluation of twenty lumped hydrological models under contrasted climate conditions. Hydrol. Earth Syst. Sci. 16(4): 1171-1189. doi:10.5194/hess-16-1171-2012.

Seitzinger, S.P., Harrison, J.A., Dumont, E., Beusen, A.H.W., and Bouwman, A.F. 2005. Sources and delivery of carbon, nitrogen, and phosphorus to the coastal zone: An overview of Global Nutrient Export from Watersheds (NEWS) 
models and their application. Global Biogeochem. Cycles, 19. doi:10.1029/ 2005 GB002606.

Seitzinger, S.P., Harrison, J.A., Böhlke, J.K., Bouwman, A.F., Lowrance, R., Peterson, B., et al. 2006. Denitrification across landscapes and waterscapes: A synthesis. Ecol. Appl. 16: 2064-2090. doi:10.1890/1051-0761(2006) 016[2064:DALAWA]2.0.CO;2. PMID:17205890.

Senthilkumar, K., Nesme, T., Mollier, A., and Pellerin, S. 2012. Regional-scale phosphorus flows and budgets within France: The importance of agricultural production systems. Nutr. Cycl. Agroecosyst. 92: 145-159. doi:10.1007/s10705011-9478-5.

Seo, M., Yen, H., Kim, M.K., and Jeong, J. 2014. Transferability of SWAT models between SWAT2009 and SWAT2012. J. Environ. Qual. 43: 869-880. doi:10.2134/jeq2013.11.0450. PMID:25602816.

Shaffer, M.J., Halvorson, A.D., Pierce, F.J., Follett, R.F., Keeney, D.R., Cruse, R.M., et al. 1991. Nitrate Leaching and Economic Analysis Package (NLEAP): model description and application. In Managing Nitrogen for Groundwater Quality and Farm Profitability: Proceedings of a Symposium. Soil Science Society of America. pp. 285-322. doi:10.2136/1991.managingnitrogen.c13.

Sharifi, A., Yen, H., Boomer, K.M.B., Kalin, L., Li, X., and Weller, D.E. 2017. Using multiple watershed models to assess the water quality impacts of alternate land development scenarios for a small community. Catena, 150: 87-99. doi:10.1016/j.catena.2016.11.009.

Sharpley, A., Jarvie, H.P., Buda, A., May, L., Spears, B., and Kleinman, P. 2013a. Phosphorus legacy: overcoming the effects of past management practices to mitigate future water quality impairment. J. Environ. Qual. 42: 1308-1326. doi:10.2134/jeq2013.03.0098. PMID:24216410.

Sharpley, A., Bolster, C., Conover, C., Dayton, E., Davis, J., Easton, Z., et al. 2013b. Technical guidance for assessing phosphorus indices. Southern Cooperative Series Bulletin No. 417 SERA-IEG 17. Available from https:// sera17dotorg.files.wordpress.com/2015/02/assessing-p-indices-sera17-1.pdf.

Sharpley, A.N., and Williams, J.R. 1990. EPIC-Erosion/Productivity Impact Calculator: 1. Model documentation, Technical Bulletin. U.S. Department of Agriculture.

Shrestha, M.K., Recknagel, F., Frizenschaf, J., and Meyer, W. 2016. Assessing SWAT models based on single and multi-site calibration for the simulation of flow and nutrient loads in the semi-arid Onkaparinga catchment in South Australia. Agric. Water Manage. 175: 61-71. doi:10.1016/j.agwat.2016.02.009.

Simons, D.B., Li, R.M., and Stevens, M.A. 1975. Developments of models for predicting water and sediment routing and yield from storms on small watershed. U.S. Department of Agriculture Forest Service, Rocky Mountain Forest and Range Experiment Station, Civil Engineering Department, Engineering Research Center, Colorado State University, Fort Collins. Final Report CER74-75DBS-RML-MAS24.

Singh, G., and Bhattarai, R. 2019. Evaluating effects of conservation practices using nonpoint source pollution models-a review. J. Spat. Hydrol. 15(1): 1.

Sinsabaugh, R.L., Lauber, C.L., Weintraub, M.N., Ahmed, B., Allison, S.D., Crenshaw, C., et al. 2008. Stoichiometry of soil enzyme activity at global scale. Ecol. Lett. 11(11): 1252-1264. doi:10.1111/j.1461-0248.2008.01245.x. PMID: 18823393.

Sipert, S., and Cohim, E.B. 2019. A phosphorus flow analysis of Brazil. Environ. Eng. Sci. 37(2): 148-163. doi:10.1089/ees.2019.0264.

Sitterson, J., Knightes, C., Parmar, R., Wolfe, K., Avant, B., and Muche, M. 2017. An overview of rainfall-runoff model types. Technical report EPA/ 600/R-14/152|. Available from https://cfpub.epa.gov/si/si_public_record_report. cfm?dirEntryld=339328\&Lab=NERL

Sivakumar, B., and Berndtsson, R. 2010. Advances in data-based approaches for hydrologic modeling and forecasting. World Scientific.

Sloan, P.G., and Moore, I.D. 1984. Modeling subsurface stormflow on steeply sloping forested watersheds. Water Resour. Res. 20: 1815-1822. doi:10.1029/ WR020i012p01815.

Sloan, P.G., Moore, I.D., Coltharp, G.B., and Eigel, J.D. 1983. Modeling surface and subsurface stormflow on steeply-sloping forested watersheds. Research Report No. 142. Available from https://uknowledge.uky.edu/ kwrri_reports/61/.

Smith, D.R., King, K.W., Johnson, L., Francesconi, W., Richards, P., Baker, D., and Sharpley, A.N. 2015. Surface runoff and tile drainage transport of phosphorus in the Midwestern United States. J. Environ. Qual. 44: 495502. doi:10.2134/jeq2014.04.0176. PMID:26023968.

Smith, R.A., Schwarz, G.E., and Alexander, R.B. 1997. Regional interpretation of water-quality monitoring data. Water Resour. Res. 33: 2781-2798. doi:10.1029/97WR02171.

Smith, T., Hayes, K., Marshall, L., McGlynn, B., and Jencso, K. 2016. Diagnostic calibration and cross-catchment transferability of a simple process-consistent hydrologic model. Hydrol. Process. 30(26): 5027-5038. doi:10.1002/hyp.10955.

Steenhuis, T.S., Winchell, M., Rossing, J., Zollweg, J.A., and Walter, M.F. 1995. SCS runoff equation revisited for variable-source runoff areas. J. Irrig. Drain. Eng. 121(3): 234-238. doi:10.1061/(ASCE)0733-9437(1995)121:3(234).

Steenhuis, T.S., Schneiderman, E.M., Mukundan, R., Hoang, L., Moges, M., and Owens, E.M. 2019. Revisiting SWAT as a saturation-excess runoff model. Water, 11(7): 1427. doi:10.3390/w11071427.

Stone, R.P. 2015. OMAFRA Fact Sheet: Universal Soil Loss Equation (USLE). Available from http://www.omafra.gov.on.ca/english/engineer/facts/12-051. htm.

Stow, C.A., Cha, Y., Johnson, L.T., Confesor, R., and Richards, R.P. 2015. Longterm and seasonal trend decomposition of Maumee River nutrient inputs to Western Lake Erie. Environ. Sci. Technol. 49: 3392-3400. doi:10.1021/ es5062648. PMID:25679045.

Stow, C.A., Glassner-Shwayder, K., Lee, D., Wang, L., Arhonditsis, G., DePinto, J.V., and Twiss, M.R. 2020. Lake Erie phosphorus targets: An imperative for active adaptive management. J. Great Lakes Res. 46(3): 672676. doi:10.1016/j.jglr.2020.02.005.

Strömqvist, J., Arheimer, B., Dahné, J., Donnelly, C., and Lindström, G. 2012. Water and nutrient predictions in ungauged basins: set-up and evaluation of a model at the national scale. Hydrol. Sci. J. 57: 229-247. doi:10.1080/02626667.2011.637497.

Stumpf, R.P., Wynne, T.T., Baker, D.B., and Fahnenstiel, G.L. 2012. Interannual variability of cyanobacterial blooms in Lake Erie. PLoS ONE, 7: e42444. doi:10.1371/journal.pone.0042444. PMID:22870327.

Sutton, M.A., Bleeker, A., Howard, C.M., Erisman, J.W., Abrol, Y.P., Bekunda, M., et al. 2013. Our nutrient world: The challenge to produce more food \& energy with less pollution. Centre for Ecology \& Hydrology. Available from https:/| nora.nerc.ac.uk/id/eprint/500700/1/N500700BK.pdf.

Swedish Meteorological and Hydrological Institute (SMHI). 2019. HYPE model description. Online technical documentation. Available from https://hypeweb. smhi.se/wp-content/uploads/2019/09/hype_model_description.pdf.

Talbot, M., McGuire, O., Olivier, C., and Fleming, R. 2016. Parameterization and application of agricultural best management practices in a rural Ontario watershed using PCSWMM. J. Water Manage. Model. [Online.] doi:10.14796/JWMM.C400.

Tang, H., Zhao, H., Li, Z., Yuan, S., Li, Q., Ji, F., and Xiao, Y. 2017. Phosphorus sorption to suspended sediment in freshwater. Proc. Inst. Civ. Eng. Water Manage. 170: 231-242. doi:10.1680/jwama.15.00056.

Tayfur, G., Kavvas, M.L., Govindaraju, R.S., and Storm, D.E. 1993. Applicability of St. Venant equations for two-dimensional overland flows over rough infiltrating surfaces. J. Hydraul. 119: 51-63. doi:10.1061/(ASCE)07339429(1993)119:1(51).

Tesoriero, A.J., Duff, J.H., Wolock, D.M., Spahr, N.E., and Almendinger, J.E. 2009. Identifying pathways and processes affecting nitrate and orthophosphate inputs to streams in agricultural watersheds. J. Environ. Qual. 38: 1892-1900. doi:10.2134/jeq2008.0484. PMID:19643755.

Theurer, F.D., and Clarke, C.D. 1991. Wash load component for sediment yield modeling. In Proceedings of the Fifth Federal Interagency Sedimentation Conference. pp. 18-21.

Thirup, C., Graham, D.N., and Refsgaard, J.C. 2014. DAISY - MIKE SHE coupling using OpenMI. NiCA Technical Note. Available from www.nitrat.dk.

Tiessen, H., Stewart, J.W.B., and Hunt, H.W. 1984. Concepts of soil organic matter transformations in relation to organo-mineral particle size fractions. Plant Soil , 76: 287-295. doi:10.1007/BF02205587.

Tilahun, S.A.T., Mukundan, R., Demisse, B.A., Engda, T.A., Guzman, C.D., Tarakegn, B.C., et al. 2013. A saturation-excess erosion model. Trans. Am. Soc. Agric. Biol. Eng. (ASABE), 56: 681-695. doi:10.13031/2013.42675.

Tisseuil, C., Wade, A.J., Tudesque, L., and Lek, S. 2008. Modeling the stream water nitrate dynamics in a 60,000-km 2 European catchment, the Garonne, Southwest France. J. Environ. Qual. 37: 2155-2169. doi:10.2134/jeq2007.0507. PMID:18948469.

Tzabiras, J., Vasiliades, L., Sidiropoulos, P., Loukas, A., and Mylopoulos, N. 2016. Evaluation of water resources management strategies to overturn climate change impacts on Lake Karla watershed. Water Resour. Manage. 30: 5819-5844. doi:10.1007/s11269-016-1536-y.

U.S. Department of Agriculture, NRCS (USDA-NRCS). 2004. National Engineering Handbook, Part 630, Chapter 11: Snowmelt. In Part 630 Hydrology National Engineering Handbook. United States Department of Agriculture, Natural Resources Conservation Service.

U.S. Department of Agriculture, NRCS (USDA-NRCS). 2016. Effects of conservation practice adoption on cultivated cropland acres in Western Lake Erie basin, 2003-06 and 2012. Conserv. Eff. Assess. Proj. Spec. Study Report. Washington, DC USDA Nat. Resour. Conserv. Serv. 120 pp.

U.S. Department of Agriculture, NRCS (USDA-NRCS). 2017. Effects of conservation practices on phosphorus loss from farm fields: a national assessment based on the 2003-06 CEAP survey and APEX modeling databases.

U.S. Department of Agriculture, Soil Conservation Service (USDA-SCS). 1985. Hydrology, National Engineering Handbook, Supplement A, Section 4, Chapter 10, U.S. Department of Agriculture, Soil Conservation Service, Washington, D.C.

U.S. Geological Survey. 2019. Mineral commodity summaries. U.S. Geological Survey. doi:10.3133/70202434

US Environmental Protection Agency (US EPA). 1983. Results of the nationwide urban runoff program. Vol. 1. Final report. Available from https:/ www3.epa.gov/npdes/pubs/sw_nurp_vol_1_finalreport.pdf.

US Environmental Protection Agency (US EPA). 2000. Estimating hydrology and hydraulic parameters for HSPF. BASINS Technical Note 6. Available from https://www.epa.gov/sites/production/files/2015-08/documents/2000_ 08_14_basins_tecnote6.pdf

Vadas, P.A., and White, M.J. 2010. Validating soil phosphorus routines in the SWAT model. Trans. Am. Soc. Agric. Biol. Eng. (ASABE), 53: 1469-1476. doi:10.13031/2013.34897.

Vadas, P.A., Joern, B.C., and Moore, P.A. 2012. Simulating soil phosphorus dynamics for a phosphorus loss quantification tool. J. Environ. Qual. 41: 1750-1757. doi:10.2134/jeq2012.0003. PMID:23128732. 
Vadas, P.A., Bolster, C.H., and Good, L.W. 2013. Critical evaluation of models used to study agricultural phosphorus and water quality. Soil Use Manage. 29: 36-44. doi:10.1111/j.1475-2743.2012.00431.x.

Valipour, R., León, L.F., Depew, D., Dove, A., and Rao, Y.R. 2016. High-resolution modeling for development of nearshore ecosystem objectives in eastern Lake Erie. J. Great Lakes Res. 42: 1241-1251. doi:10.1016/j.jglr.2016.08.011.

van Bochove, E., Thériault, G., and Denault, J.-T. 2010. Indicator of risk of water contamination by phosphorus (IROWC-P): A handbook for presenting the IROWC_P algorithms. Research Branch, Agriculture and AgriFood Canada, Quebec. Contrib. AAFC/AAC. 92pp.

van Bochove, E., Thériault, G., Denault, J.-T.T., Dechmi, F., Allaire, S.E., and Rousseau, A.N. 2012. Risk of phosphorus desorption from Canadian agricultural land: 25-year temporal trend. J. Environ. Qual. 41: 1402-1412. doi:10.2134/jeq2011.0307. PMID:23099931.

van der Plas, F. 2019. Biodiversity and ecosystem functioning in naturally assembled communities. Biol. Rev. 94(4): 1220-1245. doi:10.1111/brv.12499.

van Dijk, K.C., Lesschen, J.P., and Oenema, O. 2016. Phosphorus flows and balances of the European Union Member States. Sci. Total Environ. 542: 1078-1093. doi:10.1016/j.scitotenv.2015.08.048. PMID:26421756.

van Griensven, A., and Meixner, T. 2006. Methods to quantify and identify the sources of uncertainty for river basin water quality models. Water Sci. Technol. 53: 51-59. doi:10.2166/wst.2006.007. PMID:16532735.

Van Meter, K.J., and Basu, N.B. 2015. Catchment legacies and time lags: A parsimonious watershed model to predict the effects of legacy storage on nitrogen export. PLoS ONE, 10: e0125971. doi:10.1371/journal.pone.0125971. PMID:25985290.

Vaze, J., and Chiew, F.H.S. 2003. Study of pollutant wash-off from small impervious experimental plots. Water Resour. Res. [In press.] doi:10.1029/ 2002WR001786.

Velázquez, J.A., Schmid, J., Ricard, S., Muerth, M.J., Gauvin St-Denis, B., Minville, M., et al. 2013. An ensemble approach to assess hydrological models' contribution to uncertainties in the analysis of climate change impact on water resources. Hydrol. Earth Syst. Sci. 17: 565-578. doi:10.5194/ hess-17-565-2013.

Verma, S., Bhattarai, R., Bosch, N.S., Cooke, R.C., Kalita, P.K., and Markus, M. 2015. Climate change impacts on flow, sediment and nutrient export in a Great Lakes watershed using SWAT. Clean Soil Air Water, 43: 1464-1474. doi:10.1002/clen.201400724.

Vervloet, L.S.C., Binning, P.J., Børgesen, C.D., and Højberg, A.L. 2018. Delay in catchment nitrogen load to streams following restrictions on fertilizer application. Sci. Total Environ. 627: 1154-1166. doi:10.1016/j.scitotenv.2018.01.255. PMID:30857080.

Vested, H.J., Justesen, P., and Ekebjærg, L. 1992. Advection-dispersion modelling in three dimensions. Appl. Math. Model. 16: 506-519. doi:10.1016/0307-904X(92) 90001-J.

Vidon, P., and Cuadra, P.E. 2010. Impact of precipitation characteristics on soil hydrology in tile-drained landscapes. Hydrol. Process. 24: 1821-1833. doi:10.1002/hyp.7627.

Wade, A.J., Durand, P., Beaujouan, V., Wessel, W.W., Raat, K.J., Whitehead, P.G., et al. 2002a. A nitrogen model for European catchments: INCA, new model structure and equations. Hydrol. Earth Syst. Sci. 6: 559-582. doi:10.5194/hess-6559-2002.

Wade, A.J., Whitehead, P.G., and Butterfield, D. 2002b. The Integrated Catchments model of Phosphorus dynamics (INCA-P), a new approach for multiple source assessment in heterogeneous river systems: model structure and equations. Hydrol. Earth Syst. Sci. 6: 583-606. doi:10.5194/hess-6-5832002.

Wallace, C.W., Flanagan, D.C., and Engel, B.A. 2017. Quantifying the effects of future climate conditions on runoff, sediment, and chemical losses at different watershed sizes. Trans. Am. Soc. Agric. Biol. Eng. (ASABE), 60: 915-929. doi:10.13031/trans.12094

Wang, L. 2015. Climate change impacts on the soil erosion and nutrient losses in the Great Lakes region. Open Access Dissertations. 1459. https:// docs.lib.purdue.edu/open_access_dissertations/1459.

Wang, X., Kannan, N., Santhi, C., Potter, S.R., Williams, J.R., and Arnold, J.G. 2011. Integrating APEX output for cultivated cropland with SWAT simulation for regional modeling. Trans. Am. Soc. Agric. Biol. Eng. (ASABE), 54(4): 12811298.

Wang, Y.T., Zhang, T.Q., O'halloran, I.P., Tan, C.S., and Hu, Q.C. 2016. Predicting environmental soil phosphorus limits for dissolved reactive phosphorus loss. Soil Use Manage. 32: 60-68. doi:10.1111/sum.12238.

Wang, Z., Zhang, T.Q., Tan, C.S., Wang, X., Taylor, R.A.J., Qi, Z.M., and Yang, J.W. 2019. Modeling the impacts of manure on phosphorus loss in surface runoff and subsurface drainage. J. Environ. Qual. 48(1): 39-46. doi:10.2134/jeq2018.06.0240.

Watson, S.B., Miller, C., Arhonditsis, G., Boyer, G.L., Carmichael, W., Charlton, M.N., et al. 2016. The re-eutrophication of Lake Erie: Harmful algal blooms and hypoxia. Harmful Algae, 56: 44-66. doi:10.1016/j.hal.2016.04.010. PMID:28073496.

Weiler, M., McDonnell, J.J., Tromp-van Meerveld, I., and Uchida, T. 2006. Subsurface stormflow. In Encyclopedia of hydrological sciences. Edited by M.G. Anderson and J.J. McDonnell. Wiley. doi:10.1002/0470848944.hsa119.

Wellen, C., Arhonditsis, G.B., Labencki, T., and Boyd, D. 2012. A Bayesian methodological framework for accommodating interannual variability of nutrient loading with the SPARROW model. Water Resour. Res. 48: 1-22. doi:10.1029/2012WR011821.
Wellen, C., Arhonditsis, G.B., Labencki, T., and Boyd, D. 2014a. Application of the SPARROW model in watersheds with limited information: a Bayesian assessment of the model uncertainty and the value of additional monitoring. Hydrol. Process. 28: 1260-1283. doi:10.1002/hyp.9614.

Wellen, C., Arhonditsis, G.B., Long, T., and Boyd, D. 2014b. Accommodating environmental thresholds and extreme events in hydrological models: A Bayesian approach. J. Great Lakes Res. 40: 102-116. doi:10.1016/j.jglr.2014. 04.002 .

Wellen, C., Kamran-Disfani, A.-R., and Arhonditsis, G.B. 2015. Evaluation of the current state of distributed watershed nutrient water quality modeling. Environ. Sci. Technol. 49: 3278-3290. doi:10.1021/es5049557. PMID:25691078.

Whitaker, S. 1986. Flow in porous media I: A theoretical derivation of Darcy's law. Transp. Porous Med. 1: 3-25. doi:10.1007/BF01036523.

Wilks, D.S. 2002. Realizations of daily weather in forecast seasonal climate. J. Hydrometeorol. 3: 195-207. doi:10.1175/1525-7541(2002)003<0195:RODWIF $>2.0$. $\mathrm{CO} ; 2$

Williams, J.R. 1975a. Sediment yield prediction with universal equation using runoff energy factor. U.S. Department of Agriculture, Agricultural Research Service. ARS-S-40.

Williams, J.R. 1975b. HYMO flood routing. J. Hydrol. 26: 17-27. doi:10.1016/ 0022-1694(75)90122-5.

Williams, J.R., and Hann, R.W. 1972. HYMO, A problem-oriented computer language for building hydrologic models. Water Resour. Res. 8: 79-86. doi:10.1029/WR008i001p00079.

Williams, J.R., Renard, K.G., and Dyke, P.T. 1983. EPIC: A new method for assessing erosion's effect on soil productivity. J. Soil Water Conserv. 38: 381-383.

Williams, J.R., Izaurralde, R.C., Williams, C., and Steglich, E.M. 2015. Agricultural Policy/Environmental eXtender Model - Theoretical Documentation v.0806. AgriLife Research Texas A\&M System. Available from http://agrilife. org/epicapex/files/2017/03/THE-APEX0806-theoretical-documentation-Oct-2015.pdf.

Williams, M.R., King, K.W., LaBarge, G.A., Confesor, R.B., Jr., and Fausey, N.R. 2017. Edge-of-field evaluation of the Ohio Phosphorus Risk Index. J. Environ. Qual. 46: 1306-1313. doi:10.2134/jeq2016.05.0198.

Wilson, C.O. 2015. Land use/land cover water quality nexus: quantifying anthropogenic influences on surface water quality. Environ. Monit. Assess. 187: 424. doi:10.1007/s10661-015-4666-4. PMID:26065891.

Wilson, K.A., Howell, E.T., and Jackson, D.A. 2006. Replacement of zebra mussels by quagga mussels in the Canadian nearshore of Lake Ontario: The importance of substrate, round goby abundance, and upwelling frequency. J. Great Lakes Res. 32: 11-28. doi:10.3394/0380-1330(2006)32[11: ROZMBQ]2.0.CO;2.

Windolf, J., Thodsen, H., Troldborg, L., Larsen, S.E., Bøgestrand, J., Ovesen, N.B., and Kronvang, B. 2011. A distributed modelling system for simulation of monthly runoff and nitrogen sources, loads and sinks for ungauged catchments in Denmark. J. Environ. Monit. 13: 2645. doi:10.1039/c1em10139k. PMID:21842096.

Winter, J.G., and Duthie, H.C. 2000. Export coefficient modeling to assess phosphorus loading in an urban watershed. J. Am. Water Resour. Assoc. 36: 1053-1061. doi:10.1111/j.1752-1688.2000.tb05709.x.

Wischmeier, W., and Smith, D. 1978. Predicting rainfall erosion losses: a guide to conservation planning, U.S. Department of Agriculture, Handbook No. 537. doi:10.1029/TR039i002p00285.

Woodward, D.E., Hawkins, R.H., Jiang, R., Hjelmfelt, A.T., Jr., Van Mullem, J.A., and Quan, Q.D. 2003. Run-off curve number method: examination of the initial abstraction ratio. In World Water \& Environmental Resources Congress. American Society of Civil Engineers, Reston, Va. pp. 1-10. doi:10.1061/40685(2003)308.

Woznicki, S.A., and Pouyan Nejadhashemi, A. 2014. Assessing uncertainty in best management practice effectiveness under future climate scenarios. Hydrol. Process. 28: 2550-2566. doi:10.1002/hyp.9804.

Wu, R.-S., and Lin, I.-W. 2015. Modification of generalized watershed loading functions (GWLF) for daily flow simulation. Paddy Water Environ. 13: 269-279. doi:10.1007/s10333-014-0438-y.

Yang, W., Jiu, Q., and Wu, J. 2018. The 3D incompressible Boussinesq equations with fractional partial dissipation. Commun. Math. Sci. 16(3): 617633. doi:10.4310/CMS.2018.v16.n3.a2.

Young, R.A., Onstad, C.A., Bosch, D.D., and Anderson, W.P. 1989. AGNPS: A nonpoint-source pollution model for evaluating agricultural watersheds. J. Soil Water Conserv. 44(2): 168-173.

Yusoff, I.M., Ujang, M.U., and Rahman, A.A. 2009. 3D dynamic simulation and visualization for GIS-based infiltration-excess overland flow modelling. In 3D geo-information sciences. Springer, Berlin, Heidelberg. pp. 413-430.

Zafar, M., Tiecher, T., de Castro Lima, J.A.M., Schaefer, G.L., Santanna, M.A., and dos Santos, D.R. 2016. Phosphorus seasonal sorption-desorption kinetics in suspended sediment in response to land use and management in the Guaporé catchment, Southern Brazil. Environ. Monit. Assess. 188: 643. doi:10.1007/s10661-016-5650-3. PMID:27796828.

Zehe, E., and Sivapalan, M. 2009. Threshold behaviour in hydrological systems as (human) geo-ecosystems: Manifestations, controls, implications. Hydrol. Earth Syst. Sci. 13: 1273-1297. doi:10.5194/hess-13-1273-2009.

Zehe, E., Maurer, T., Ihringer, J., and Plate, E. 2001. Modeling water flow and mass transport in a loess catchment. Phys. Chem. Earth Part B Hydrol. Oceans Atmos. 26: 487-507. doi:10.1016/S1464-1909(01)00041-7.

Zhang, T., Wang, Y., Tan, C.S., and Welacky, T. 2020. An 11-year agronomic, economic, and phosphorus loss potential evaluation of legacy phosphorus utilization 
in a clay loam soil of the Lake Erie Basin. Front. Earth Sci. 8: 115. doi:10.3389/ feart.2020.00115.

Zhang, X., Srinivasan, R., Arnold, J., Izaurralde, R.C., and Bosch, D. 2011. Simultaneous calibration of surface flow and baseflow simulations: a revisit of the SWAT model calibration framework. Hydrol. Process. 25: 2313-2320. doi:10.1002/hyp.8058.

Zhang, X.C.J., and Wang, Z.L. 2017. Interrill soil erosion processes on steep slopes. J. Hydrol. 548: 652-664. doi:10.1016/j.jhydrol.2017.03.046.

Zhao, F., Veldkamp, T.I.E., Frieler, K., Schewe, J., Ostberg, S., Willner, S., et al. 2017. The critical role of the routing scheme in simulating peak river discharge in global hydrological models. Environ. Res. Lett. 12: 075003. doi:10.1088/1748-9326/aa7250.
Zhou, B., Xu, Y., Vogt, R.D., Lu, X., Li, X., Deng, X., et al. 2016. Effects of land use change on phosphorus levels in surface waters-a case study of a watershed strongly influenced by agriculture. Water Air Soil Pollut. 227: 160. doi:10.1007/s11270-016-2855-6.

Zhou, Y., Obenour, D.R., Scavia, D., Johengen, T.H., and Michalak, A.M. 2013. Spatial and temporal trends in Lake Erie hypoxia, 1987-2007. Environ. Sci. Technol. 47: 899-905. doi:10.1021/es303401b. PMID:23237424.

Zobrist, J., and Reichert, P. 2006. Bayesian estimation of export coefficients from diffuse and point sources in Swiss watersheds. J. Hydrol. 329: 207223. doi:10.1016/j.jhydrol.2006.02.014. 